\title{
Marine Natural Product for Pesticide Candidate: Pulmonarin Alkaloids as Novel
}

\section{Antiviral and Anti-Phytopathogenic-Fungus Agents}

Mingjun Zhang ${ }^{\dagger}$, Xin Ding ${ }^{\dagger}$, Jin Kang ${ }^{\dagger}$, Yongyue $\mathrm{Gao}^{\dagger}$, Ziwen Wang ${ }^{\dagger, *}$, Qingmin Wang*,*

${ }^{\dagger}$ Tianjin Key Laboratory of Structure and Performance for Functional Molecules, College of Chemistry, Tianjin Normal University, Tianjin 300387, China;

ॠState Key Laboratory of Elemento-Organic Chemistry, Research Institute of Elemento-Organic Chemistry, College of Chemistry, Collaborative Innovation Center of Chemical Science and Engineering (Tianjin), Nankai University, Tianjin 300071, China;

Ziwen Wang, Tel: 0086-22-23766531; Fax:0086-22-23766531; e-mail: hxxywzw@tjnu.edu.cn;

Prof. Qingmin Wang, Tel.: 0086-22-23503952; Fax:0086-22-23503952; e-mail: wangqm@nankai.edu.cn. 


\section{Contents}

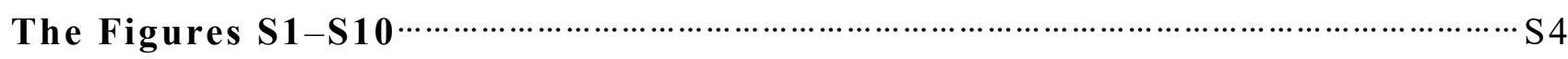

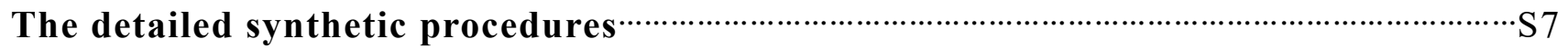

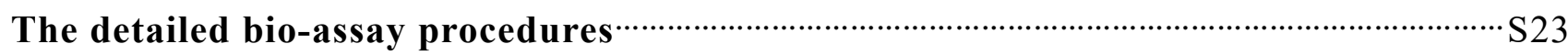

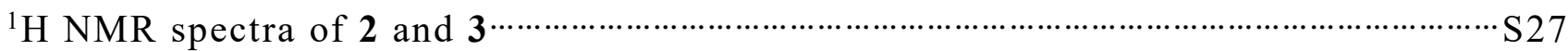

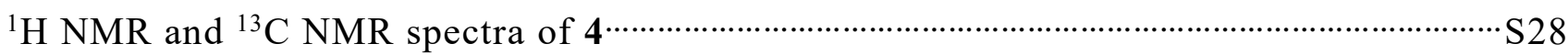

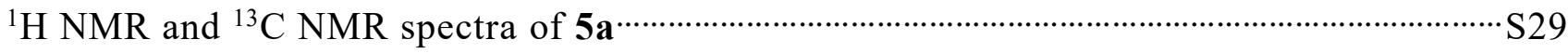

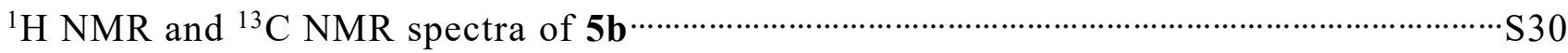

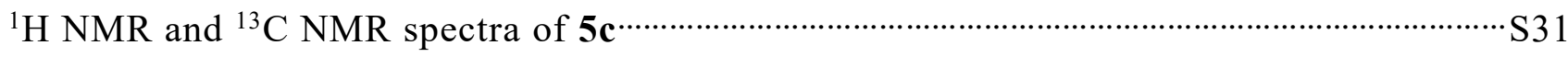

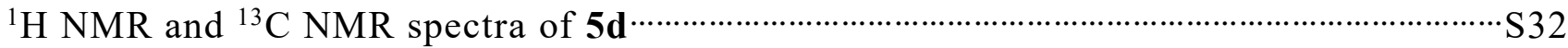

${ }^{1} \mathrm{H}$ NMR and ${ }^{13} \mathrm{C}$ NMR spectra of 5e

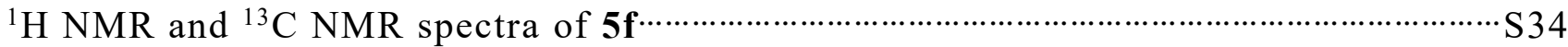

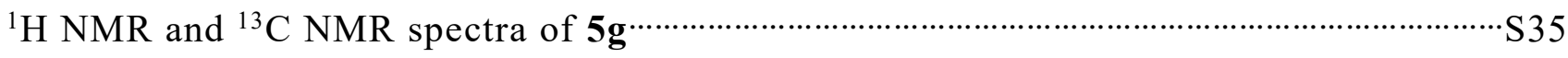

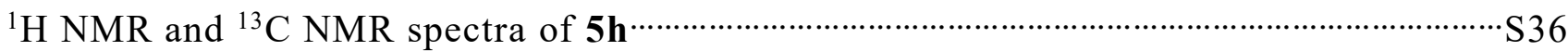

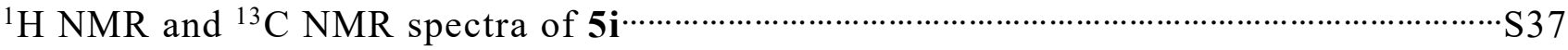

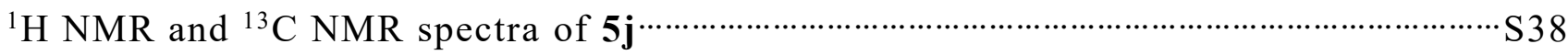

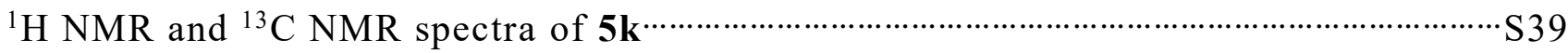

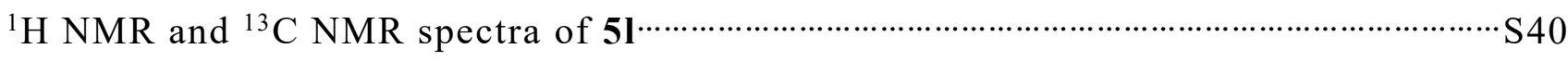

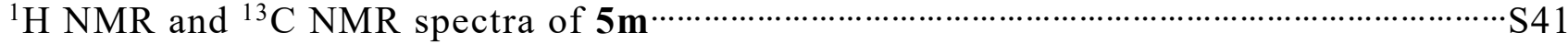

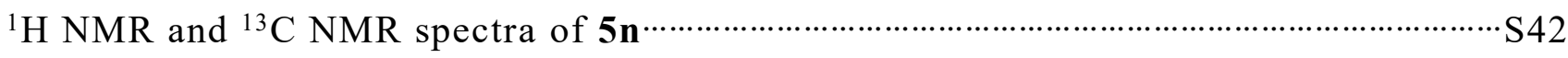

${ }^{1} \mathrm{H}$ NMR and ${ }^{13} \mathrm{C}$ NMR spectra of 50

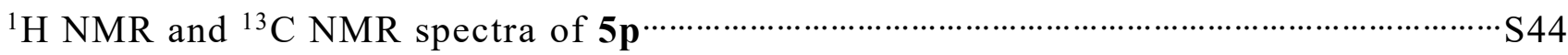

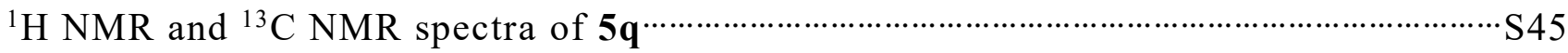

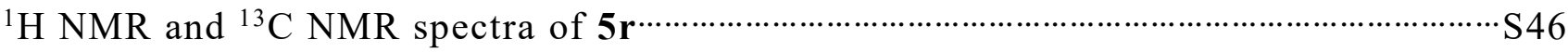

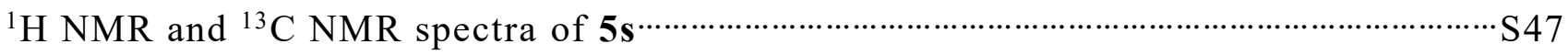

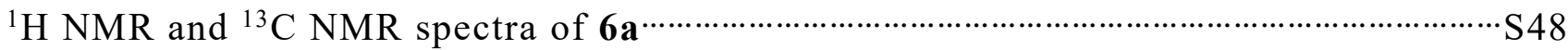

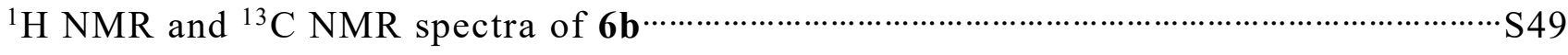

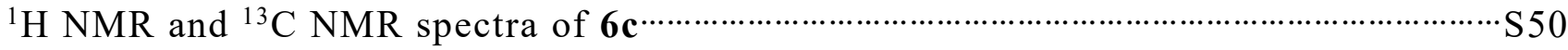

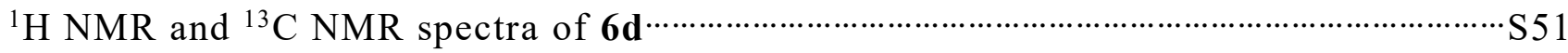


${ }^{1} \mathrm{H}$ NMR and ${ }^{13} \mathrm{C}$ NMR spectra of $6 \mathrm{e}$

${ }^{1} \mathrm{H}$ NMR and ${ }^{13} \mathrm{C}$ NMR spectra of $\mathbf{6} \mathbf{f}$

${ }^{1} \mathrm{H}$ NMR and ${ }^{13} \mathrm{C}$ NMR spectra of $\mathbf{6 g}$

${ }^{1} \mathrm{H}$ NMR and ${ }^{13} \mathrm{C}$ NMR spectra of $\mathbf{6 h}$

${ }^{1} \mathrm{H}$ NMR and ${ }^{13} \mathrm{C}$ NMR spectra of $\mathbf{6} \mathbf{i}$

${ }^{1} \mathrm{H}$ NMR and ${ }^{13} \mathrm{C}$ NMR spectra of $\mathbf{6} \mathbf{j}$

${ }^{1} \mathrm{H}$ NMR and ${ }^{13} \mathrm{C}$ NMR spectra of $6 \mathbf{k}$

${ }^{1} \mathrm{H}$ NMR and ${ }^{13} \mathrm{C}$ NMR spectra of $\mathbf{6 l}$

${ }^{1} \mathrm{H}$ NMR and ${ }^{13} \mathrm{C}$ NMR spectra of $6 \mathbf{m}$

${ }^{1} \mathrm{H}$ NMR and ${ }^{13} \mathrm{C}$ NMR spectra of $\mathbf{6 n}$

${ }^{1} \mathrm{H}$ NMR and ${ }^{13} \mathrm{C}$ NMR spectra of $\mathbf{6 0}$ S62

${ }^{1} \mathrm{H}$ NMR and ${ }^{13} \mathrm{C}$ NMR spectra of $6 \mathbf{p}$ S63

${ }^{1} \mathrm{H}$ NMR and ${ }^{13} \mathrm{C}$ NMR spectra of $\mathbf{6 q}$ S64

${ }^{1} \mathrm{H}$ NMR and ${ }^{13} \mathrm{C}$ NMR spectra of $\mathbf{6 r}$ S65

${ }^{1} \mathrm{H}$ NMR and ${ }^{13} \mathrm{C}$ NMR spectra of $\mathbf{6 s}$ S66

${ }^{1} \mathrm{H}$ NMR and ${ }^{13} \mathrm{C}$ NMR spectra of $6 \mathbf{t}$ S67

${ }^{1} \mathrm{H}$ NMR and ${ }^{13} \mathrm{C}$ NMR spectra of $6 \mathbf{u}$ S68

${ }^{1}$ H NMR spectra of 8 and 9

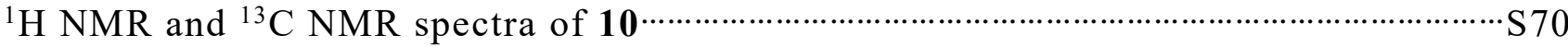

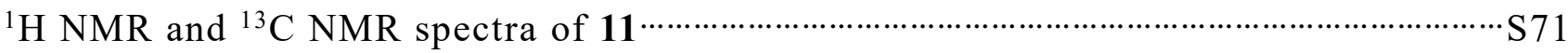

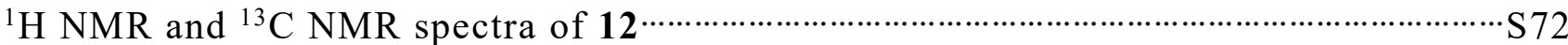

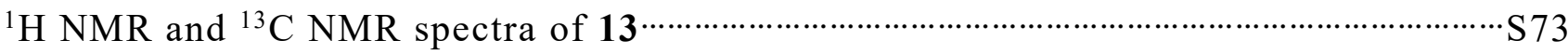

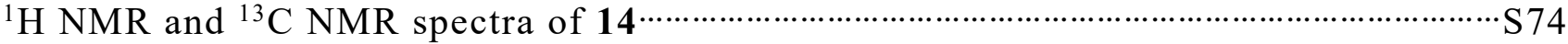

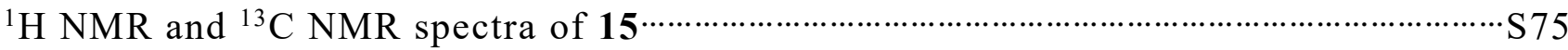

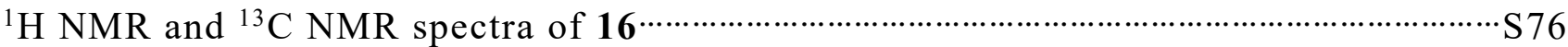

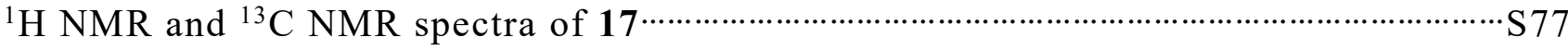

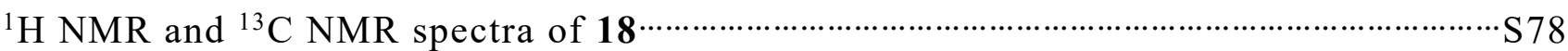


Figure S1. A Method for Preparation of Pulmonarin A (Cl).<smiles>COc1c(Br)cc(C(=O)O)cc1Br</smiles>

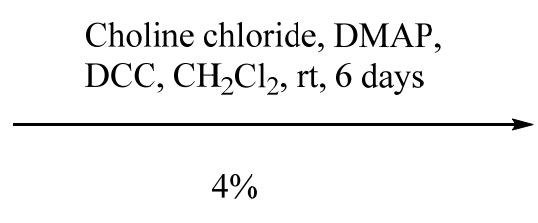<smiles>COc1c(Br)cc(C(=O)OCC[N+](C)(C)Cl)cc1Br</smiles>

Pulmonarin A (Cl)

Figure S2. A Method for Preparation of Pulmonarin B (I).<smiles>COc1ccc(CC(=O)O)cc1</smiles><smiles>COc1c(Br)cc(CC(=O)NCCCCC[N+](C)(C)C)cc1Br</smiles>

Pulmonarin B (I)

Figure S3. An Other Method for Preparation of Pulmonarin B (I).
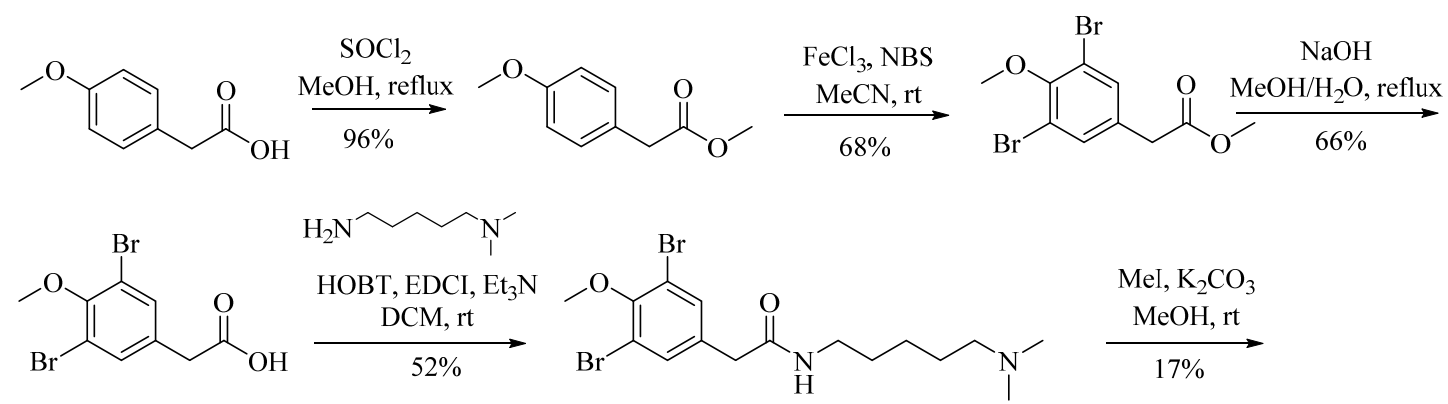<smiles>COc1c(Br)cc(CC(=O)NCCCCC[N+](C)(C)[I-])cc1Br</smiles>

Pulmonarin B (I) 
Figure S4. Synthesis of Compound $6 \mathbf{6}$.

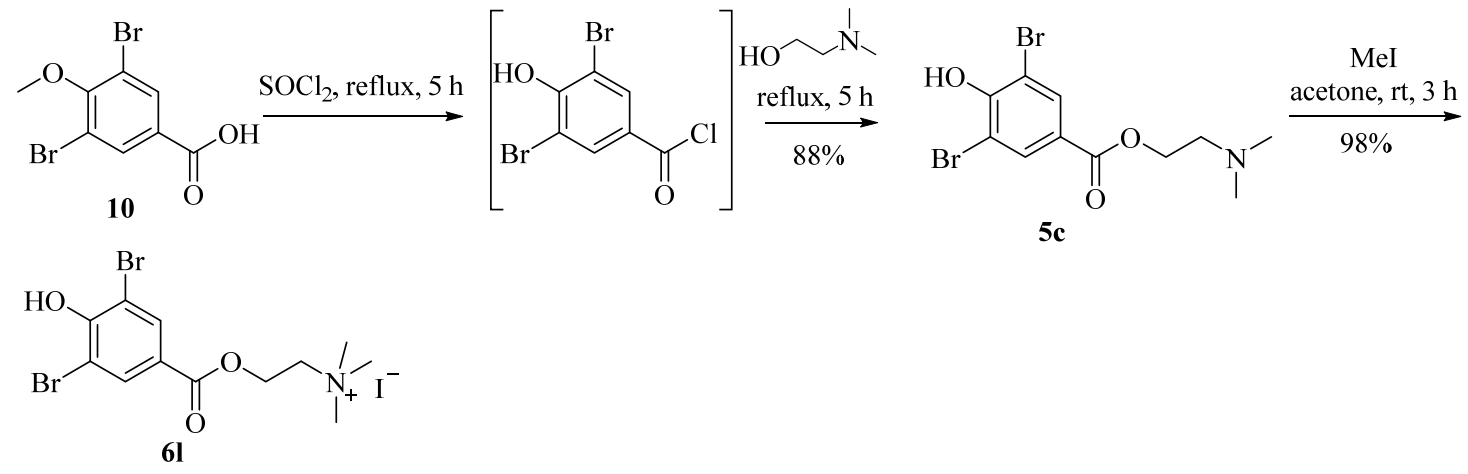

Figure S5. Synthesis of Compounds $\mathbf{6 m - 6}$.
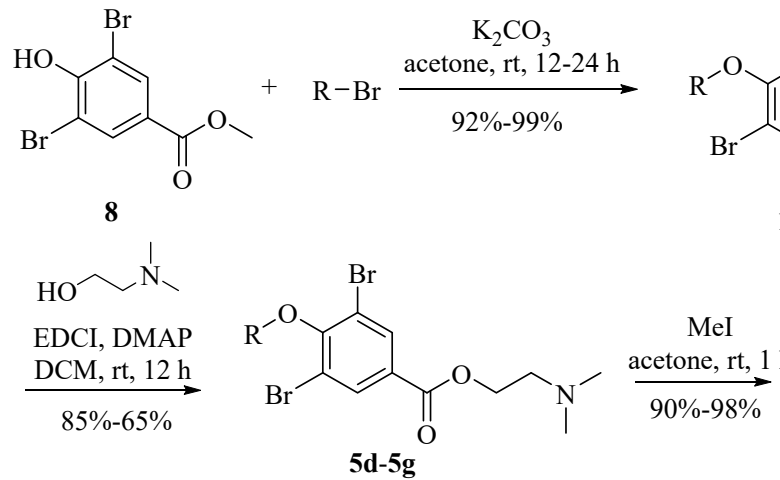

$R=$

5d

$\mathrm{R}=$

$\widehat{2} 5 \mathrm{e}$

$\mathrm{R}=$

$\mathrm{R}=$

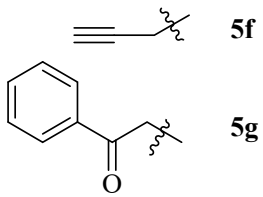<smiles>[R]Oc1c(Br)cc(C(=O)OC)cc1Br</smiles>

11-14

15-18<smiles>[R]Oc1c(Br)cc(C(=O)OCC[N+](C)(C)[AlH2])cc1Br</smiles>

$6 m$

6n

60

$6 \mathbf{p}$

Figure S6. Synthesis of Compounds $\mathbf{6 q}-\mathbf{6 r}$.

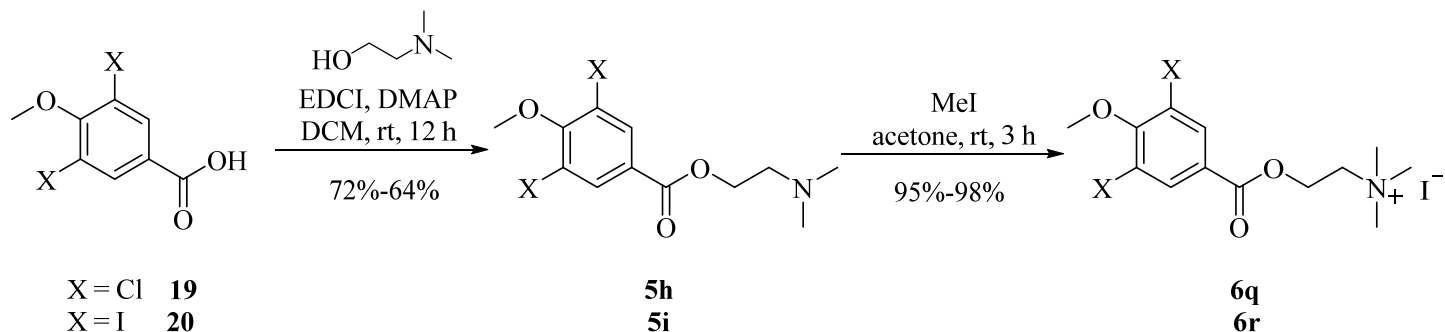


Figure S7. Synthesis of Compound $\mathbf{6 s .}$<smiles>COc1c(Br)cc(C(=O)O)cc1Br</smiles>

Figure S8. Synthesis of Compounds 5l-5r and $\mathbf{6 t}$.

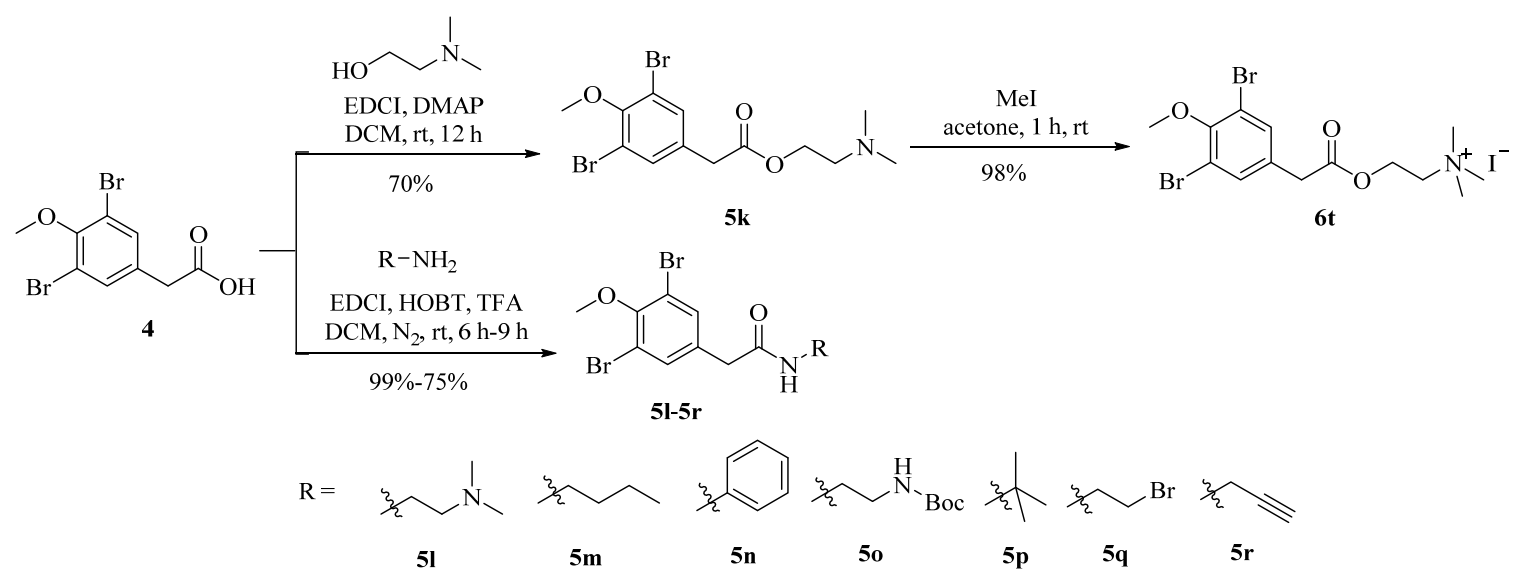

Figure S9. Synthesis of Compound $\mathbf{6 u}$.<smiles>COc1c(Br)cc(CC(=O)NCCN(C)C)cc1Br</smiles>

$5 \mathbf{l}$<smiles>COc1c(Br)cc(CC(=O)NCC[N+](C)(C)[I-])cc1Br</smiles>

6u

Figure S10. Synthesis of Compound $\mathbf{5 s}$.<smiles>COc1c(Br)cc(CC(=O)NCCNC(=O)OC(C)(C)C)cc1Br</smiles>

50

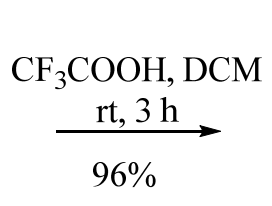<smiles>COc1c(Br)cc(CC(=O)NCCN)cc1Br</smiles>

5s 


\section{The detailed synthetic procedures.}

Chemicals. The reagents were purchased from commercial sources and were used as received. All anhydrous solvents were dried and purified by standard techniques prior to use.

Instruments. The melting points of the compounds were tested on an X-4 binocular microscope (Beijing Tech Instruments Company). NMR spectra were obtained with a Bruker AV 400 spectrometer with either $\mathrm{CDCl}_{3}$ or $\mathrm{DMSO}_{-} d_{6}$ as the solvent. High-resolution mass spectra were obtained with an FT-ICR mass spectrometer (Ionspec, 7.0 T). The in vitro TMV rod assembly inhibition and 20S coat protein (CP) disk assembly inhibition were tested via transmission electron microscopy (Tecnai G2 F20).

Preparation of Methyl 2-(4-methoxyphenyl)acetate (2). To the solution of acid 1 (2.0 g, 11.2 mmol $)$ in methanol $(10 \mathrm{~mL})$ was added dropwise $\mathrm{SOCl}_{2}(0.5 \mathrm{~mL})$. The reaction solution was stirred at $70{ }^{\circ} \mathrm{C}$ for $4 \mathrm{~h}$, concentrated in vacuo. The residue was taken into $\mathrm{H}_{2} \mathrm{O}(50 \mathrm{~mL})$, extracted with ethyl acetate $(20 \mathrm{~mL} \times 3)$. The combined organic phase was dried over anhydrous $\mathrm{Na}_{2} \mathrm{SO}_{4}$, filtered, and concentrated to give compound $2(2.08 \mathrm{~g}, 95 \%)$ as a colorless oil. ${ }^{1} \mathrm{H}$ NMR $\left(400 \mathrm{MHz}, \mathrm{CDCl}_{3}\right) \delta$ $7.23(\mathrm{~d}, J=8.6 \mathrm{~Hz}, 2 \mathrm{H}, \mathrm{Ar}-\mathrm{H}), 6.89$ (d, $J=8.6 \mathrm{~Hz}, 2 \mathrm{H}, \mathrm{Ar}-\mathrm{H}), 3.82\left(\mathrm{~s}, 3 \mathrm{H}, \mathrm{OCH}_{3}\right), 3.72(\mathrm{~s}, 3 \mathrm{H}$, $\left.\mathrm{OCH}_{3}\right), 3.60\left(\mathrm{~s}, 2 \mathrm{H}, \mathrm{COCH}_{2}\right) .{ }^{13} \mathrm{C} \mathrm{NMR}\left(100 \mathrm{MHz}, \mathrm{CDCl}_{3}\right) \delta 172.4,169.5,158.7,155.4,130.3$, $126.1,114.0,55.3,52.0,40.3$.

Preparation of Methyl 2-(3,5-dibromo-4-methoxyphenyl)acetate (3). To the stirred solution of compound $2(1.2 \mathrm{~g}, 6.2 \mathrm{mmol})$ in acetonitrile $(5 \mathrm{~mL})$ was added $\mathrm{FeCl}_{3}(1.1 \mathrm{~g}, 6.2 \mathrm{mmol})$ at $0{ }^{\circ} \mathrm{C}$. The reaction mixture was stirred at $0{ }^{\circ} \mathrm{C}$ for $15 \mathrm{~min}$, then added $\mathrm{N}$-bromosuccinimide (NBS, $2.2 \mathrm{~g}, 12.4$ mmol). The mixture was stirred at room temperature for $5 \mathrm{~h}$, quenched by addition of $\mathrm{H}_{2} \mathrm{O}(50 \mathrm{~mL})$ and extracted with ethyl acetate $(20 \mathrm{~mL} \times 3)$. The combined organic phase was dried over anhydrous 
$\mathrm{Na}_{2} \mathrm{SO}_{4}$, filtered, and concentrated. The residue was purified by flash chromatography on a silica gel using petroleum ether and ethyl acetate $(15: 1, \mathrm{v} / \mathrm{v})$ as the eluent to give $3(1.68 \mathrm{~g}, 75 \%)$ as a yellow oil. ${ }^{1} \mathrm{H}$ NMR (400 MHz, $\left.\mathrm{CDCl}_{3}\right) \delta 7.43$ (s, 2H, Ar-H), 3.87 (s, 3H, $\left.\mathrm{OCH}_{3}\right), 3.72\left(\mathrm{~s}, 3 \mathrm{H}, \mathrm{OCH}_{3}\right), 3.54$ (s, $\left.2 \mathrm{H}, \mathrm{COCH}_{2}\right) .{ }^{13} \mathrm{C} \mathrm{NMR}\left(100 \mathrm{MHz}, \mathrm{CDCl}_{3}\right) \delta 171.0,153.3,133.5,132.4,118.1,60.6,52.4,39.6$.

Preparation of 2-(3,5-Dibromo-4-methoxyphenyl)acetic Acid (4). To the stirred solution of compound $3(0.34 \mathrm{~g}, 1 \mathrm{mmol})$ in tetrahydrofuran $(7 \mathrm{~mL})$ and $\mathrm{H}_{2} \mathrm{O}(3 \mathrm{~mL})$ was added $\mathrm{NaOH}(0.08 \mathrm{~g}$, $2 \mathrm{mmol}$ ). The solution was stirred at room temperature for $4 \mathrm{~h}$, then adjust the $\mathrm{pH}$ value to $1-2$ with $3 \mathrm{M}$ sulfuric acid, filtrated to give compound 4 (0.31 g, 95\%). White solid, mp $125-128{ }^{\circ} \mathrm{C} ;{ }^{1} \mathrm{H}$ NMR (400 MHz, DMSO-d $) \delta 7.57$ (s, 2H, Ar-H), 3.79 (s, 3H, $\left.\mathrm{OCH}_{3}\right), 3.60\left(\mathrm{~s}, 2 \mathrm{H}, \mathrm{COCH}_{2}\right) .{ }^{13} \mathrm{C}$ NMR (100 MHz, DMSO- $\left.d_{6}\right) \delta 172.6,152.5,135.3,134.3,117.4,60.8$.

\section{Preparation of 2-(3,5-Dibromo-4-methoxyphenyl)- $N$-(5-(dimethylamino)pentyl)acetamide (5a).}

To the stirred solution of compound $4(0.5 \mathrm{~g}, 1.56 \mathrm{mmol})$ in dichloromethane $(5 \mathrm{~mL})$ was added $N^{1}, N^{1}$-dimethylpentane-1,5-diamine g, 1.72 mmol), 1-(3-dimethylaminopropyl)-3-ethylcarbodiimide hydrochloride (EDCI, $0.45 \mathrm{~g}, 2.34 \mathrm{mmol}$ ), 1-hydroxybenzotriazole (HOBT, $0.11 \mathrm{~g}, 0.78 \mathrm{mmol})$ and $\mathrm{Et}_{3} \mathrm{~N}(0.48 \mathrm{~g}, 4.68 \mathrm{mmol})$. The mixture was stirred at room temperature for $6 \mathrm{~h}$ under $\mathrm{N}_{2}$ atmosphere, then concentrated. The residue was taken into $\mathrm{H}_{2} \mathrm{O}(20 \mathrm{~mL})$, extracted with ethyl acetate $(10 \mathrm{~mL} \times 3)$. The combined organic phase was dried over anhydrous $\mathrm{Na}_{2} \mathrm{SO}_{4}$, filtered, and concentrated to give compound $\mathbf{5 a}(0.6 \mathrm{~g}, 89 \%)$ as a colorless oil. ${ }^{1} \mathrm{H}$ NMR (400 MHz, $\left.\mathrm{CDCl}_{3}\right) \delta 7.45(\mathrm{~s}, 2 \mathrm{H}, \mathrm{Ar}-\mathrm{H}), 5.89(\mathrm{~s}, 1 \mathrm{H}, \mathrm{NH}), 3.89$ (s, 3H, $\left.\mathrm{OCH}_{3}\right), 3.44$ (s, $\left.2 \mathrm{H}, \mathrm{COCH}_{2}\right), 3.25$ (t, $\left.J=6.1 \mathrm{~Hz}, 2 \mathrm{H}, \mathrm{CONH}-\mathrm{CH}_{2}\right), 2.27$ (t, $\left.J=7.3 \mathrm{~Hz}, 2 \mathrm{H}, \mathrm{N}-\mathrm{CH}_{2}\right), 2.22(\mathrm{~s}, 6 \mathrm{H}$, $\left.\mathrm{N}-\mathrm{CH}_{3}\right), 1.53-1.46\left(\mathrm{~m}, 4 \mathrm{H}, \mathrm{CH}_{2}\right), 1.34-1.29\left(\mathrm{~m}, 2 \mathrm{H}, \mathrm{CH}_{2}\right) .{ }^{13} \mathrm{C} \mathrm{NMR}\left(100 \mathrm{MHz}, \mathrm{CDCl}_{3}\right) \delta 169.6$, 153.2, 133.4, 118.3, 60.6, 59.4, 45.4, 42.1, 39.8, 29.2, 27.1, 24.6. HRMS (ESI) calcd for 
$\mathrm{C}_{16} \mathrm{H}_{25} \mathrm{Br}_{2} \mathrm{~N}_{2} \mathrm{O}_{2}(\mathrm{M}+\mathrm{H})^{+}$435.0277, found 435.0271.

Preparation of Pulmonarin B (I, 6a). To the solution of compound 5a $(0.20 \mathrm{~g}, 0.46 \mathrm{mmol})$ in acetone $(5 \mathrm{~mL})$ was added $\mathrm{CH}_{3} \mathrm{I}(0.10 \mathrm{~g}, 0.69 \mathrm{mmol})$. The solution was stirred at room temperature for $1 \mathrm{~h}$, concentrated to give $6 \mathbf{a}(0.19 \mathrm{~g}, 98 \%)$ as a colorless oil. ${ }^{1} \mathrm{H}$ NMR (400 MHz, DMSO- $\left.d_{6}\right) \delta$ $8.14(\mathrm{~s}, 1 \mathrm{H}, \mathrm{NH}), 7.53(\mathrm{~s}, 2 \mathrm{H}, \mathrm{Ar}-\mathrm{H}), 3.76\left(\mathrm{~s}, 3 \mathrm{H}, \mathrm{OCH}_{3}\right), 3.38\left(\mathrm{~s}, 2 \mathrm{H}, \mathrm{COCH}_{2}\right), 3.27(\mathrm{t}, J=6.1 \mathrm{~Hz}$, 2H, CONH-CH 2$), 3.06$ (t, $\left.J=7.8 \mathrm{~Hz}, 2 \mathrm{H}, \mathrm{N}-\mathrm{CH}_{2}\right), 3.06\left(\mathrm{~s}, 9 \mathrm{H}, \mathrm{N}-\mathrm{CH}_{3}\right), 1.69-1.66\left(\mathrm{~m}, 2 \mathrm{H}, \mathrm{CH}_{2}\right)$, $1.47-1.45\left(\mathrm{~m}, 2 \mathrm{H}, \mathrm{CH}_{2}\right), 1.33-1.23\left(\mathrm{~m}, 2 \mathrm{H}, \mathrm{CH}_{2}\right) .{ }^{13} \mathrm{C} \mathrm{NMR}\left(100 \mathrm{MHz}, \mathrm{DMSO}-d_{6}\right) \delta 169.6,152.3$, $136.4,133.7,117.5,65.7,60.9,52.7,41.0,38.8,29.0,23.7,22.2$. HRMS (ESI) calcd for $\mathrm{C}_{17} \mathrm{H}_{27} \mathrm{Br}_{2} \mathrm{~N}_{2} \mathrm{O}_{2}\left(\mathrm{M}-\mathrm{I}^{-}\right)^{+} 449.0434$, found 449.0437 .

Preparation of Methyl 3,5-dibromo-4-hydroxybenzoate (8). To the solution of acid 7 (1.0 g, 3.28 $\mathrm{mmol})$ in methanol $(20 \mathrm{~mL})$ was added concentrated sulfuric acid $(0.07 \mathrm{~g}, 0.64 \mathrm{mmol})$ at $0{ }^{\circ} \mathrm{C}$. The solution was stirred at $80{ }^{\circ} \mathrm{C}$ for $16 \mathrm{~h}$, concentrated to remove methanol. The residue was taken into $\mathrm{H}_{2} \mathrm{O}(50 \mathrm{~mL})$, extracted with ethyl acetate $(20 \mathrm{~mL} \times 3)$. The combined organic phase was dried over anhydrous $\mathrm{Na}_{2} \mathrm{SO}_{4}$, filtered, and concentrated to give compound $\mathbf{8}(1.04 \mathrm{~g}, 98 \%)$ as a white solid, mp 119-122 ${ }^{\circ} \mathrm{C} .{ }^{1} \mathrm{H}$ NMR (400 MHz, $\left.\mathrm{CDCl}_{3}\right) \delta 8.15$ (s, 2H, Ar-H), $6.38(\mathrm{~s}, 1 \mathrm{H}, \mathrm{OH}), 3.91(\mathrm{~s}, 3 \mathrm{H}$, $\left.\mathrm{OCH}_{3}\right) .{ }^{13} \mathrm{C} \mathrm{NMR}\left(100 \mathrm{MHz}, \mathrm{CDCl}_{3}\right) \delta 164.5,153.2,133.7,124.7,109.7,52.6$.

Preparation of Methyl 3,5-dibromo-4-methoxybenzoate (9). The mixture of compound 8 (1.0 g, $3.1 \mathrm{mmol})$ and $\mathrm{K}_{2} \mathrm{CO}_{3}$ in acetone $(30 \mathrm{~mL})$ was stirred at room temperature for $10 \mathrm{~min}$, and added $\mathrm{CH}_{3} \mathrm{I}(0.53 \mathrm{~g}, 3.7 \mathrm{mmol})$, then further stirred at room temperature for $12 \mathrm{~h}$ and concentrated. The residue was taken into $\mathrm{H}_{2} \mathrm{O}(50 \mathrm{~mL})$, extracted with ethyl acetate $(20 \mathrm{~mL} \times 3)$. The combined organic phase was dried over anhydrous $\mathrm{Na}_{2} \mathrm{SO}_{4}$, filtered, and concentrated to give compound 9 (1.01 g, 97\%) as a white solid, mp 88-90 ${ }^{\circ} \mathrm{C} .{ }^{1} \mathrm{H}$ NMR (400 MHz, $\left.\mathrm{CDCl}_{3}\right) \delta 8.19(\mathrm{~s}, 2 \mathrm{H}, \mathrm{Ar}-\mathrm{H}), 3.94$ 
$\left(\mathrm{s}, 3 \mathrm{H}, \mathrm{OCH}_{3}\right), 3.92\left(\mathrm{~s}, 3 \mathrm{H}, \mathrm{OCH}_{3}\right) .{ }^{13} \mathrm{C} \mathrm{NMR}\left(100 \mathrm{MHz}, \mathrm{CDCl}_{3}\right) \delta 164.4,157.9,134.1,128.3,118.2$, $60.8,52.7$.

Preparation of 3,5-Dibromo-4-methoxybenzoic Acid (10). The similar procedure for the preparation of 4 was used. White solid, yield 95\%; mp 181-183 ${ }^{\circ} \mathrm{C} ;{ }^{1} \mathrm{H}$ NMR (400 MHz, DMSO- $d_{6}$ ) $\delta 13.53(\mathrm{~s}, 1 \mathrm{H}, \mathrm{COOH}), 8.10(\mathrm{~s}, 2 \mathrm{H}, \mathrm{Ar}-\mathrm{H}), 3.86\left(\mathrm{~s}, 3 \mathrm{H}, \mathrm{OCH}_{3}\right) .{ }^{13} \mathrm{C} \mathrm{NMR}\left(100 \mathrm{MHz}, \mathrm{DMSO}-d_{6}\right) \delta$ $165.0,157.5,134.1,130.1,118.2,61.1$.

Preparation of 2-(Dimethylamino)ethyl 3,5-dibromo-4-methoxybenzoate (5b). To the stirred solution of compound $\mathbf{1 0}(0.10 \mathrm{~g}, 0.32 \mathrm{mmol})$ in dichloromethane $(10 \mathrm{~mL})$ was added 2-(dimethylamino)ethan-1-ol $\quad(0.057 \mathrm{~g}, \quad 0.64 \mathrm{mmol}), \quad$ EDCI $\quad(0.12 \mathrm{~g}, \quad 0.64 \mathrm{mmol})$, and 4-dimethylaminopyridine (DMAP, $0.004 \mathrm{~g}, 0.032 \mathrm{mmol}$ ). The mixture was stirred at room temperature for $12 \mathrm{~h}$, then quenched with $\mathrm{H}_{2} \mathrm{O}(20 \mathrm{~mL})$, extracted with ethyl acetate $(10 \mathrm{~mL} \times 3)$. The combined organic phase was dried over anhydrous $\mathrm{Na}_{2} \mathrm{SO}_{4}$, filtered, and concentrated. The residue was purified by flash chromatography on a silica gel using dichloromethane and methanol $(100: 1, \mathrm{v} / \mathrm{v})$ as the eluent to give compound $\mathbf{5 b}(0.06 \mathrm{~g}, 75 \%)$ as a colorless oil. ${ }^{1} \mathrm{H}$ NMR (400 MHz, $\left.\mathrm{CDCl}_{3}\right) \delta 8.20(\mathrm{~s}, 2 \mathrm{H}, \mathrm{Ar}-\mathrm{H}), 4.43\left(\mathrm{t}, J=5.8 \mathrm{~Hz}, 2 \mathrm{H}, \mathrm{OCH}_{2}\right), 3.95\left(\mathrm{~s}, 3 \mathrm{H}, \mathrm{OCH}_{3}\right), 2.72(\mathrm{t}, J=5.8 \mathrm{~Hz}$, 2H, N-CH 2$), 2.34\left(\mathrm{~s}, 6 \mathrm{H}, \mathrm{N}-\mathrm{CH}_{3}\right) .{ }^{13} \mathrm{C} \mathrm{NMR}\left(100 \mathrm{MHz}, \mathrm{CDCl}_{3}\right) \delta 163.9,158.0,134.1,128.4,118.2$, 63.5, 60.8, 57.8, 45.8. HRMS (ESI) calcd for $\mathrm{C}_{12} \mathrm{H}_{16} \mathrm{Br}_{2} \mathrm{NO}_{3}(\mathrm{M}+\mathrm{H})^{+}$379.9491, found 379.9493.

Preparation of Pulmonarin A (I, 6b). The similar procedure for the preparation of 6 a was used. White solid, yield 95\%; mp $180-182{ }^{\circ} \mathrm{C} ;{ }^{1} \mathrm{H}$ NMR (400 MHz, DMSO- $\left.d_{6}\right) \delta 8.19(\mathrm{~s}, 2 \mathrm{H}, \mathrm{Ar}-\mathrm{H}), 4.71$ (t, $\left.J=5.8 \mathrm{~Hz}, 2 \mathrm{H}, \mathrm{OCH}_{2}\right), 3.88\left(\mathrm{~s}, 3 \mathrm{H}, \mathrm{OCH}_{3}\right), 3.82\left(\mathrm{t}, J=5.8 \mathrm{~Hz}, 2 \mathrm{H}, \mathrm{N}-\mathrm{CH}_{2}\right), 3.18\left(\mathrm{~s}, 9 \mathrm{H}, \mathrm{N}-\mathrm{CH}_{3}\right)$. ${ }^{13} \mathrm{C}$ NMR (100 MHz, DMSO- $\left.d_{6}\right) \delta 163.0,158.2,134.1,128.4,118.6,64.2,61.2,59.9,53.3$. HRMS (ESI) calcd for $\mathrm{C}_{13} \mathrm{H}_{18} \mathrm{Br}_{2} \mathrm{NO}_{3}\left(\mathrm{M}-\mathrm{I}^{-}\right)^{+}$393.9648, found 393.9653. 
General Procedures for the Preparation of Compounds 6c-6k. To a solution of compound 5b $(1.0 \mathrm{mmol})$ in $\mathrm{CHCl}_{3}(5 \mathrm{~mL})$ was added corresponding bromides $(1.2 \mathrm{mmol})$. The solution was stirred at $70{ }^{\circ} \mathrm{C}$ for $5 \mathrm{~h}$, then concentrated. The residue was recrystallized in acetone and petroleum ether to give compounds $\mathbf{6 c}-\mathbf{6 k}$.

$N$-Benzyl-2-((3,5-dibromo-4-methoxybenzoyl)oxy)- $N, N$-dimethylethan-1-aminium Bromide (6c). White solid, yield 95\%; mp $166-168{ }^{\circ} \mathrm{C} ;{ }^{1} \mathrm{H}$ NMR (400 MHz, DMSO-d $) \delta 8.21(\mathrm{~s}, 2 \mathrm{H}, \mathrm{Ar}-\mathrm{H})$, $7.61(\mathrm{~d}, J=7.5 \mathrm{~Hz}, 2 \mathrm{H}, \mathrm{Ar}-\mathrm{H}), 7.57-7.53(\mathrm{~m}, 3 \mathrm{H}, \mathrm{Ar}-\mathrm{H}), 4.80\left(\mathrm{t}, J=4.0 \mathrm{~Hz}, 2 \mathrm{H}, \mathrm{OCH}_{2}\right), 4.71(\mathrm{~s}$, $\left.2 \mathrm{H}, \mathrm{CH}_{2}\right), 3.88\left(\mathrm{~s}, 3 \mathrm{H}, \mathrm{OCH}_{3}\right), 3.88\left(\mathrm{t}, J=4.0 \mathrm{~Hz}, 2 \mathrm{H}, \mathrm{N}-\mathrm{CH}_{2}\right), 3.10\left(\mathrm{~s}, 6 \mathrm{H}, \mathrm{N}-\mathrm{CH}_{3}\right) .{ }^{13} \mathrm{C} \mathrm{NMR}(100$ MHz, DMSO- $\left.d_{6}\right) \delta 163.1,158.1,134.1,133.6,130.8,129.4,128.5,128.4,118.6,67.5,67.4,61.2$, 59.8, 49.9. HRMS (ESI) calcd for $\mathrm{C}_{19} \mathrm{H}_{22} \mathrm{Br}_{2} \mathrm{NO}_{3}\left(\mathrm{M}-\mathrm{Br}^{-}\right)^{+} 469.9961$, found 469.9966 .

2-((3,5-Dibromo-4-methoxybenzoyl)oxy)- $N, N$-dimethyl-N-(4-(trifluoromethyl)benzyl)ethan-1-a minium Bromide (6d). White solid, yield 90\%; mp 157-159 ${ }^{\circ} \mathrm{C} ;{ }^{1} \mathrm{H}$ NMR (400 MHz, DMSO-d $) \delta$ $8.21(\mathrm{~s}, 2 \mathrm{H}, \mathrm{Ar}-\mathrm{H}), 7.93$ (d, J=8.1 Hz, 2H, Ar-H), 7.84 (d, J=8.1 Hz, 2H, Ar-H), $4.81\left(\mathrm{~s}, 2 \mathrm{H}, \mathrm{CH}_{2}\right)$, $4.78\left(\mathrm{t}, J=4.0 \mathrm{~Hz}, 2 \mathrm{H}, \mathrm{OCH}_{2}\right), 3.88\left(\mathrm{t}, J=4.0 \mathrm{~Hz}, 2 \mathrm{H}, \mathrm{N}-\mathrm{CH}_{2}\right), 3.88\left(\mathrm{~s}, 3 \mathrm{H}, \mathrm{OCH}_{3}\right), 3.12(\mathrm{~s}, 6 \mathrm{H}$, $\left.\mathrm{N}-\mathrm{CH}_{3}\right) .{ }^{13} \mathrm{C}$ NMR $\left(100 \mathrm{MHz}, \mathrm{DMSO}-d_{6}\right) \delta 172.8,163.1,158.2,134.6,134.1,133.0,131.2,128.4$, 126.3, 118.6, 66.4, 63.2, 61.2, 59.7, 50.1. HRMS (ESI) calcd for $\mathrm{C}_{20} \mathrm{H}_{21} \mathrm{Br}_{2} \mathrm{~F}_{3} \mathrm{NO}_{3}\left(\mathrm{M}-\mathrm{Br}^{-}\right)^{+}$537.9835, found 437.9839 .

$N$-(4-(tert-Butyl)benzyl)-2-((3,5-dibromo-4-methoxybenzoyl)oxy)- $N, N$-dimethylethan-1-aminiu m Bromide (6e). White solid, yield 88\%; mp 133-135 ${ }^{\circ} \mathrm{C} ;{ }^{1} \mathrm{H}$ NMR (400 MHz, DMSO- $\left.d_{6}\right) \delta 8.21(\mathrm{~s}$, 2H, Ar-H), 7.57 (d, $J=8.4 \mathrm{~Hz}, 2 \mathrm{H}, \mathrm{Ar}-\mathrm{H}), 7.53$ (d, $J=8.4 \mathrm{~Hz}, 2 \mathrm{H}, \mathrm{Ar}-\mathrm{H}), 4.80$ (t, $J=4.0 \mathrm{~Hz}, 2 \mathrm{H}$, $\left.\mathrm{OCH}_{2}\right), 4.65\left(\mathrm{~s}, 2 \mathrm{H}, \mathrm{Ar}-\mathrm{CH}_{2}\right), 3.89\left(\mathrm{~s}, 3 \mathrm{H}, \mathrm{OCH}_{3}\right), 3.85$ (t, $\left.J=4.0 \mathrm{~Hz}, 2 \mathrm{H}, \mathrm{N}-\mathrm{CH}_{2}\right), 3.09$ (s, 6H, $\left.\mathrm{N}-\mathrm{CH}_{3}\right), 1.32\left(\mathrm{~s}, 9 \mathrm{H}, \mathrm{CH}_{3}\right) .{ }^{13} \mathrm{C} \mathrm{NMR}\left(100 \mathrm{MHz}, \mathrm{DMSO}-d_{6}\right) \delta 162.6,157.7,152.9,133.6,132.9$, 
$128.0,125.8,125.0,118.0,66.9,62.1,60.7,59.3,49.4,34.5,30.9$. HRMS (ESI) calcd for $\mathrm{C}_{23} \mathrm{H}_{30} \mathrm{Br}_{2} \mathrm{NO}_{3}\left(\mathrm{M}-\mathrm{Br}^{-}\right)^{+}$526.0587, found 526.0593.

\section{$N$-(Cyanomethyl)-2-((3,5-dibromo-4-methoxybenzoyl)oxy)- $N, N$-dimethylethan-1-aminium}

Bromide (6f). White solid, yield 95\%; mp 184-186 ${ }^{\circ} \mathrm{C}$; ${ }^{1} \mathrm{H}$ NMR (400 MHz, DMSO- $\left.d_{6}\right) \delta 8.24$ (s, 2H, Ar-H), $5.06\left(\mathrm{~s}, 2 \mathrm{H}, \mathrm{CN}-\mathrm{CH}_{2}\right), 4.75\left(\mathrm{t}, J=4.0 \mathrm{~Hz}, 2 \mathrm{H}, \mathrm{OCH}_{2}\right), 4.06\left(\mathrm{t}, J=4.0 \mathrm{~Hz}, 2 \mathrm{H}, \mathrm{N}-\mathrm{CH}_{2}\right)$, $3.89\left(\mathrm{~s}, 3 \mathrm{H}, \mathrm{OCH}_{3}\right), 3.38\left(\mathrm{~s}, 6 \mathrm{H}, \mathrm{N}-\mathrm{CH}_{3}\right) .{ }^{13} \mathrm{C} \mathrm{NMR}\left(100 \mathrm{MHz}, \mathrm{DMSO}-d_{6}\right) \delta 162.5,157.7,133.7$, 127.8, 118.0, 112.3, 63.5, 60.7, 59.2, 51.9, 51.7. HRMS (ESI) calcd for $\mathrm{C}_{14} \mathrm{H}_{17} \mathrm{Br}_{2} \mathrm{~N}_{2} \mathrm{O}_{3}\left(\mathrm{M}-\mathrm{Br}^{-}\right)^{+}$ 418.9600, found 418.9603 .

$N$-(2-((3,5-Dibromo-4-methoxybenzoyl)oxy)ethyl)-2-ethoxy- $N, N$-dimethyl-2-oxoethan-1-aminiu m Bromide (6g). White solid, yield 95\%; mp $166-168{ }^{\circ} \mathrm{C} ;{ }^{1} \mathrm{H}$ NMR $\left(400 \mathrm{MHz}, \mathrm{DMSO}-d_{6}\right) \delta 8.16(\mathrm{~s}$, 2H, Ar-H), $4.74\left(\mathrm{t}, J=7.1 \mathrm{~Hz}, 2 \mathrm{H}, \mathrm{OCH}_{2}\right), 4.67\left(\mathrm{~s}, 2 \mathrm{H}, \mathrm{COCH}_{2}\right), 4.11\left(\mathrm{q}, J=6.0 \mathrm{~Hz}, 2 \mathrm{H}, \mathrm{CH}_{3}-\mathrm{CH}_{2}\right)$, $4.11\left(\mathrm{t}, J=7.1 \mathrm{~Hz}, 2 \mathrm{H}, \mathrm{N}-\mathrm{CH}_{2}\right), 3.88\left(\mathrm{~s}, 3 \mathrm{H}, \mathrm{OCH}_{3}\right), 3.36\left(\mathrm{~s}, 6 \mathrm{H}, \mathrm{N}-\mathrm{CH}_{3}\right), 1.18(\mathrm{t}, J=6.0 \mathrm{~Hz}, 3 \mathrm{H}$, $\left.\mathrm{OCH}_{2}-\mathrm{CH}_{3}\right) .{ }^{13} \mathrm{C} \mathrm{NMR}\left(100 \mathrm{MHz}, \mathrm{DMSO}-d_{6}\right) \delta 164.9,162.5,157.7,133.5,127.8,118.1,62.4,62.0$, 60.9, 60.7, 59.4, 52.0, 13.7. HRMS (ESI) calcd for $\mathrm{C}_{16} \mathrm{H}_{22} \mathrm{Br}_{2} \mathrm{NO}_{5}\left(\mathrm{M}-\mathrm{Br}^{-}\right)^{+}$465.9859, found 465.9857.

2-Amino- $N$-(2-((3,5-dibromo-4-methoxybenzoyl)oxy)ethyl)- $N, N$-dimethyl-2-oxoethan-1-aminiu m Bromide (6h). White solid, yield 95\%; mp $159-162{ }^{\circ} \mathrm{C} ;{ }^{1} \mathrm{H}$ NMR (400 MHz, DMSO- $\left.d_{6}\right) \delta 8.17$ (s, 2H, Ar-H), $8.01\left(\mathrm{~s}, 1 \mathrm{H}, \mathrm{NH}_{2}\right), 7.68\left(\mathrm{~s}, 1 \mathrm{H}, \mathrm{NH}_{2}\right), 4.74\left(\mathrm{t}, J=4.0 \mathrm{~Hz}, 2 \mathrm{H}, \mathrm{OCH}_{2}\right), 4.26(\mathrm{~s}, 2 \mathrm{H}$, $\left.\mathrm{COCH}_{2}\right), 4.10\left(\mathrm{t}, J=4.0 \mathrm{~Hz}, 2 \mathrm{H}, \mathrm{N}-\mathrm{CH}_{2}\right), 3.88\left(\mathrm{~s}, 3 \mathrm{H}, \mathrm{OCH}_{3}\right), 3.33\left(\mathrm{~s}, 6 \mathrm{H}, \mathrm{N}-\mathrm{CH}_{3}\right) .{ }^{13} \mathrm{C} \mathrm{NMR}(100$ MHz, DMSO-d $d_{6} \delta 165.4,162.6,157.6,133.6,127.8,118.0,62.3,61.9,60.7,59.3,51.7 . \mathrm{HRMS}$ (ESI) calcd for $\mathrm{C}_{14} \mathrm{H}_{19} \mathrm{Br}_{2} \mathrm{~N}_{2} \mathrm{O}_{4}\left(\mathrm{M}-\mathrm{Br}^{-}\right)^{+} 436.9706$, found 436.9709 .

$N$-(2-((3,5-Dibromo-4-methoxybenzoyl)oxy)ethyl)- $N, N$-dimethylprop-2-en-1-aminium Bromide 
(6i). White solid, yield 90\%; mp 79-82 ${ }^{\circ} \mathrm{C} ;{ }^{1} \mathrm{H}$ NMR (400 MHz, DMSO-d $d_{6} \delta 8.19$ (s, 2H, Ar-H), $6.19-6.01\left(\mathrm{~m}, 1 \mathrm{H}, \mathrm{CH}_{2}-\mathrm{CH}\right), 5.67\left(\mathrm{~d}, J=11.6 \mathrm{~Hz}, 2 \mathrm{H},=\mathrm{CH}_{2}\right), 4.73\left(\mathrm{q}, J=8.0 \mathrm{~Hz}, 2 \mathrm{H}, \mathrm{CH}-\mathrm{CH}_{2}\right)$, $4.15\left(\mathrm{t}, J=6.4 \mathrm{~Hz}, 2 \mathrm{H}, \mathrm{OCH}_{2}\right), 3.88\left(\mathrm{~s}, 3 \mathrm{H}, \mathrm{OCH}_{3}\right), 3.83\left(\mathrm{t}, J=6.4 \mathrm{~Hz}, 2 \mathrm{H}, \mathrm{N}-\mathrm{CH}_{2}\right), 3.14(\mathrm{~s}, 6 \mathrm{H}$, $\left.\mathrm{N}-\mathrm{CH}_{3}\right) .{ }^{13} \mathrm{C}$ NMR $\left(100 \mathrm{MHz}, \mathrm{DMSO}-d_{6}\right) \delta 162.5,157.6,133.6,127.9,127.8,125.9,118.0,66.0$, 61.6, 60.7, 59.2, 50.1. HRMS (ESI) calcd for $\mathrm{C}_{15} \mathrm{H}_{20} \mathrm{Br}_{2} \mathrm{NO}_{3}\left(\mathrm{M}-\mathrm{Br}^{-}\right)^{+}$419.9804, found 419.9808 .

$N$-(2-((3,5-Dibromo-4-methoxybenzoyl)oxy)ethyl)- $N, N$-dimethylprop-2-yn-1-aminium Bromide (6j). White solid, yield 89\%; mp 164-166 ${ }^{\circ} \mathrm{C} ;{ }^{1} \mathrm{H}$ NMR (400 MHz, DMSO-d 6 ) $\delta 8.22$ (s, 2H, Ar-H), $4.73\left(\mathrm{t}, J=4.0 \mathrm{~Hz}, 2 \mathrm{H}, \mathrm{OCH}_{2}\right), 4.59\left(\mathrm{~d}, J=2.0 \mathrm{~Hz}, 2 \mathrm{H}, \mathrm{C}-\mathrm{CH}_{2}\right), 4.14(\mathrm{~s}, 1 \mathrm{H}, \mathrm{CH}), 3.94(\mathrm{t}, J=4.0$ $\left.\mathrm{Hz}, 2 \mathrm{H}, \mathrm{N}-\mathrm{CH}_{2}\right), 3.89\left(\mathrm{~s}, 3 \mathrm{H}, \mathrm{OCH}_{3}\right), 3.26\left(\mathrm{~s}, 6 \mathrm{H}, \mathrm{N}-\mathrm{CH}_{3}\right) .{ }^{13} \mathrm{C} \mathrm{NMR}\left(100 \mathrm{MHz}, \mathrm{DMSO}-d_{6}\right) \delta 162.5$, 157.6, 133.6, 127.9, 118.0, 83.3, 72.5, 61.7, 60.7, 59.2, 54.0, 50.5. HRMS (ESI) calcd for $\mathrm{C}_{15} \mathrm{H}_{18} \mathrm{Br}_{2} \mathrm{NO}_{3}\left(\mathrm{M}-\mathrm{Br}^{-}\right)^{+}$417.9648, found 417.9647.

$N$-(2-((3,5-Dibromo-4-methoxybenzoyl)oxy)ethyl)- $N, N$-dimethyl-2-oxo-2-phenylethan-1-aminiu m Bromide (6k). White solid, yield 95\%; mp $182-185{ }^{\circ} \mathrm{C} ;{ }^{1} \mathrm{H}$ NMR (400 MHz, DMSO- $\left.d_{6}\right) \delta 7.95$ (s, 2H, Ar-H), $7.88(\mathrm{~d}, J=7.6 \mathrm{~Hz}, 2 \mathrm{H}, \mathrm{Ar}-\mathrm{H}), 7.71-7.63(\mathrm{~m}, 1 \mathrm{H}, \mathrm{Ar}-\mathrm{H}), 7.54-7.50(\mathrm{~m}, 2 \mathrm{H}, \mathrm{Ar}-\mathrm{H})$, $5.53\left(\mathrm{~s}, 2 \mathrm{H}, \mathrm{COCH}_{2}\right), 4.78\left(\mathrm{t}, J=4.0 \mathrm{~Hz}, 2 \mathrm{H}, \mathrm{OCH}_{2}\right), 4.19\left(\mathrm{t}, J=4.0 \mathrm{~Hz}, 2 \mathrm{H}, \mathrm{N}-\mathrm{CH}_{2}\right), 3.83(\mathrm{~s}, 3 \mathrm{H}$, $\left.\mathrm{OCH}_{3}\right), 3.44\left(\mathrm{~s}, 6 \mathrm{H}, \mathrm{N}-\mathrm{CH}_{3}\right) .{ }^{13} \mathrm{C} \mathrm{NMR}\left(100 \mathrm{MHz}, \mathrm{DMSO}-d_{6}\right) \delta 191.4,162.6,157.4,134.7,134.0$, 133.3, 128.9, 127.7, 127.5, 117.8, 65.3, 62.3, 60.6, 59.6, 52.5. HRMS (ESI) calcd for $\mathrm{C}_{20} \mathrm{H}_{22} \mathrm{Br}_{2} \mathrm{NO}_{4}$ $\left(\mathrm{M}-\mathrm{Br}^{-}\right)^{+}$497.9910, found 497.9911.

Preparation of 2-(Dimethylamino)ethyl 3,5-Dibromo-4-hydroxybenzoate (5c). The mixture of acid $10(1.0 \mathrm{~g}, 3.25 \mathrm{mmol})$ in $\mathrm{SOCl}_{2}(5 \mathrm{~mL})$ was stirred at $70{ }^{\circ} \mathrm{C}$ for $5 \mathrm{~h}$, concentrated to remove $\mathrm{SOCl}_{2}$. The residue was taken into 2-(dimethylamino)ethan-1-ol $(10 \mathrm{~mL})$ and stirred at $140{ }^{\circ} \mathrm{C}$ for 5 h, then concentrated. The residue was taken into $\mathrm{H}_{2} \mathrm{O}(50 \mathrm{~mL})$, extracted with ethyl acetate $(20 \mathrm{~mL} \times$ 
3). The combined organic phase was dried over anhydrous $\mathrm{Na}_{2} \mathrm{SO}_{4}$, filtered, and concentrated. The residue was purified by flash chromatography on a silica gel using dichloromethane and methanol $(30: 1, \mathrm{v} / \mathrm{v})$ as the eluent to give compound $\mathbf{5 c}(1.05 \mathrm{~g}, 88 \%)$ as a white solid, $\mathrm{mp} 183-185{ }^{\circ} \mathrm{C} .{ }^{1} \mathrm{H}$ NMR (400 MHz, DMSO-d $) \delta 7.77(\mathrm{~s}, 2 \mathrm{H}, \mathrm{Ar}-\mathrm{H}), 4.41\left(\mathrm{t}, J=6.0 \mathrm{~Hz}, 2 \mathrm{H}, \mathrm{OCH}_{2}\right), 3.37(\mathrm{t}, J=6.0$ $\left.H z, 2 \mathrm{H}, \mathrm{N}-\mathrm{CH}_{2}\right), 2.81\left(\mathrm{~s}, 6 \mathrm{H}, \mathrm{N}-\mathrm{CH}_{3}\right) .{ }^{13} \mathrm{C} \mathrm{NMR}\left(100 \mathrm{MHz}, \mathrm{DMSO}-d_{6}\right) \delta 165.0,164.6,133.3,114.3$, 110.3, 58.7, 56.2, 43.6. HRMS (ESI) calcd for $\mathrm{C}_{11} \mathrm{H}_{14} \mathrm{Br}_{2} \mathrm{NO}_{3}(\mathrm{M}+\mathrm{H})^{+}$365.9335, found 365.9338.

Preparation of 2-((3,5-Dibromo-4-hydroxybenzoyl)oxy)- $N, N, N$-trimethylethan-1-aminium Iodide (I, 61). The similar procedure for the preparation of $\mathbf{6 a}$ was used. White solid, yield 98\%; mp $185-187{ }^{\circ} \mathrm{C} ;{ }^{1} \mathrm{H}$ NMR (400 MHz, DMSO- $\left.d_{6}\right) \delta 8.04(\mathrm{~s}, 2 \mathrm{H}, \mathrm{Ar}-\mathrm{H}), 4.65\left(\mathrm{t}, J=6.0 \mathrm{~Hz}, 2 \mathrm{H}, \mathrm{OCH}_{2}\right)$, $3.81\left(\mathrm{t}, J=6.0 \mathrm{~Hz}, 2 \mathrm{H}, \mathrm{N}-\mathrm{CH}_{2}\right), 3.19\left(\mathrm{~s}, 9 \mathrm{H}, \mathrm{N}-\mathrm{CH}_{3}\right) .{ }^{13} \mathrm{C} \mathrm{NMR}\left(100 \mathrm{MHz}, \mathrm{DMSO}-d_{6}\right) \delta 163.6$, 134.0, 133.7, 112.5, 64.3, 63.3, 59.2, 53.3, 43.1, 40.6. HRMS (ESI) calcd for $\mathrm{C}_{12} \mathrm{H}_{16} \mathrm{Br}_{2} \mathrm{NO}_{3}\left(\mathrm{M}-\mathrm{I}^{-}\right)^{+}$ 379.9491, found 379.9498 .

General Procedures for the Preparation of Compounds 11-14. The similar procedure for the preparation of 9 was used.

Methyl 4-(benzyloxy)-3,5-dibromobenzoate (11). White solid, yield 95\%; mp 116-118 ${ }^{\circ} \mathrm{C} ;{ }^{1} \mathrm{H}$ NMR (400 MHz, $\left.\mathrm{CDCl}_{3}\right) \delta 8.24(\mathrm{~s}, 2 \mathrm{H}, \mathrm{Ar}-\mathrm{H}), 7.62(\mathrm{~d}, J=6.5 \mathrm{~Hz}, 2 \mathrm{H}, \mathrm{Ar}-\mathrm{H}), 7.47-7.39(\mathrm{~m}, 3 \mathrm{H}$, Ar-H), $5.11\left(\mathrm{~s}, 2 \mathrm{H}, \mathrm{OCH}_{2}\right), 3.95\left(\mathrm{~s}, 3 \mathrm{H}, \mathrm{OCH}_{3}\right) .{ }^{13} \mathrm{C} \mathrm{NMR}\left(100 \mathrm{MHz}, \mathrm{CDCl}_{3}\right) \delta 164.4,156.6,135.7$ $134.2,128.7,128.6,128.6,128.5,118.7,74.9,52.7$.

Methyl 4-(Allyloxy)-3,5-dibromobenzoate (12). White solid, yield 92\%; mp 83-86 ${ }^{\circ} \mathrm{C}$; ${ }^{1} \mathrm{H}$ NMR $\left(400 \mathrm{MHz}, \mathrm{CDCl}_{3}\right) \delta 8.21(\mathrm{~s}, 2 \mathrm{H}, \mathrm{Ar}-\mathrm{H}), 6.24-6.14\left(\mathrm{~m}, 1 \mathrm{H}, \mathrm{CH}_{2}-\mathrm{CH}\right), 5.49$ (dd, $J=10.4,1.2 \mathrm{~Hz}$, $\left.1 \mathrm{H},=\mathrm{CH}_{2}\right), 5.34\left(\mathrm{dd}, J=10.4,1.2 \mathrm{~Hz}, 1 \mathrm{H},=\mathrm{CH}_{2}\right), 4.63\left(\mathrm{~d}, J=4.8 \mathrm{~Hz}, 1.1 \mathrm{~Hz}, 2 \mathrm{H}, \mathrm{CH}-\mathrm{CH}_{2}\right), 3.94(\mathrm{~s}$, $\left.3 \mathrm{H}, \mathrm{OCH}_{3}\right) .{ }^{13} \mathrm{C} \mathrm{NMR}\left(100 \mathrm{MHz}, \mathrm{CDCl}_{3}\right) \delta 164.4,156.9,134.1,132.5,128.2,119.3,118.69,74.3$, 
52.7.

Methyl 3,5-Dibromo-4-(prop-2-yn-1-yloxy)benzoate (13). White solid, yield 98\%; mp 106-108 ${ }^{\circ} \mathrm{C} ;{ }^{1} \mathrm{H}$ NMR (400 MHz, DMSO-d $) \delta 8.13(\mathrm{~s}, 2 \mathrm{H}, \mathrm{Ar}-\mathrm{H}), 4.87\left(\mathrm{~d}, J=1.5 \mathrm{~Hz}, 2 \mathrm{H}, \mathrm{C}-\mathrm{CH}_{2}\right)$, $3.87\left(\mathrm{~s}, 3 \mathrm{H}, \mathrm{OCH}_{3}\right), 3.70(\mathrm{~s}, 1 \mathrm{H}, \mathrm{CH}) .{ }^{13} \mathrm{C} \mathrm{NMR}\left(100 \mathrm{MHz}, \mathrm{DMSO}-d_{6}\right) \delta 163.5,155.1,133.3,128.7$, $118.5,79.9,77.7,60.6,52.8$.

Methyl 3,5-dibromo-4-(2-oxo-2-phenylethoxy)benzoate (14). White solid, yield 92\%; mp 117-119 ${ }^{\circ} \mathrm{C} ;{ }^{1} \mathrm{H}$ NMR $\left(400 \mathrm{MHz}, \mathrm{CDCl}_{3}\right) \delta 8.24$ (s, 2H, Ar-H), 8.03 (d, J=7.3 Hz, 2H, Ar-H), 7.67 - $7.64(\mathrm{~m}, 1 \mathrm{H}, \mathrm{Ar}-\mathrm{H}), 7.55-7.52(\mathrm{~m}, 2 \mathrm{H}, \mathrm{Ar}-\mathrm{H}), 5.36\left(\mathrm{~s}, 2 \mathrm{H}, \mathrm{OCH}_{2}\right), 3.96\left(\mathrm{~s}, 3 \mathrm{H}, \mathrm{OCH}_{3}\right) .{ }^{13} \mathrm{C} \mathrm{NMR}$ $\left(100 \mathrm{MHz}, \mathrm{CDCl}_{3}\right) \delta 192.20,164.20,156.30,134.2,134.0,128.9,128.1,118.1,74.4,52.8$.

General Procedures for the Preparation of Compounds 15-18. The similar procedure for the preparation of 4 was used.

4-(Benzyloxy)-3,5-dibromobenzoic Acid (15). White solid, yield 95\%; mp 202-204 ${ }^{\circ} \mathrm{C}$; ${ }^{1} \mathrm{H}$ NMR $\left(400 \mathrm{MHz}, \mathrm{DMSO}-d_{6}\right) \delta 13.58(\mathrm{~s}, 1 \mathrm{H}, \mathrm{COOH}), 8.15(\mathrm{~s}, 2 \mathrm{H}, \mathrm{Ar}-\mathrm{H}), 7.59$ (d, $\left.J=6.6 \mathrm{~Hz}, 2 \mathrm{H}, \mathrm{Ar}-\mathrm{H}\right)$, $7.48-7.40(\mathrm{~m}, 3 \mathrm{H}, \mathrm{Ar}-\mathrm{H}), 5.06\left(\mathrm{~s}, 2 \mathrm{H}, \mathrm{OCH}_{2}\right) .{ }^{13} \mathrm{C} \mathrm{NMR}\left(100 \mathrm{MHz}, \mathrm{DMSO}-d_{6}\right) \delta 164.5,155.6$, $135.7,133.64,133.5,129.7,128.5,128.4,118.2,74.5$.

4-(Allyloxy)-3,5-dibromobenzoic Acid (16). White solid, yield 92\%; mp 160-162 ${ }^{\circ} \mathrm{C} ;{ }^{1} \mathrm{H}$ NMR (400 MHz, DMSO-d $\left.d_{6}\right) \delta 13.55(\mathrm{~s}, 1 \mathrm{H}, \mathrm{COOH}), 8.10(\mathrm{~s}, 2 \mathrm{H}, \mathrm{Ar}-\mathrm{H}), 6.18-6.09\left(\mathrm{~m}, 1 \mathrm{H}, \mathrm{CH}_{2}-\mathrm{CH}\right)$, $5.46\left(\mathrm{dd}, J=10.2,1.1 \mathrm{~Hz}, 1 \mathrm{H},=\mathrm{CH}_{2}\right), 5.32\left(\mathrm{dd}, J=10.2 \mathrm{~Hz} 1.1 \mathrm{~Hz}, 1 \mathrm{H},=\mathrm{CH}_{2}\right), 4.59(\mathrm{~d}, J=5.6 \mathrm{~Hz}$, $\left.2 \mathrm{H}, \mathrm{CH}-\mathrm{CH}_{2}\right) .{ }^{13} \mathrm{C}$ NMR $\left(100 \mathrm{MHz}, \mathrm{DMSO}-d_{6}\right) \delta 165.0,156.4,134.0,133.3,130.0,119.4,118.6$, 74.5.

3,5-Dibromo-4-(prop-2-yn-1-yloxy)benzoic Acid (17). White solid, yield 93\%; mp 201-203 ${ }^{\circ} \mathrm{C} ;{ }^{1} \mathrm{H}$ NMR (400 MHz, DMSO-d $)_{6} \delta 13.60(\mathrm{~s}, 1 \mathrm{H}, \mathrm{COOH}), 8.11(\mathrm{~s}, 2 \mathrm{H}, \mathrm{Ar}-\mathrm{H}), 4.86(\mathrm{~d}, J=2.1 \mathrm{~Hz}, 2 \mathrm{H}$, 
$\left.\mathrm{C}-\mathrm{CH}_{2}\right), 3.71(\mathrm{~s}, 1 \mathrm{H}, \mathrm{CH}) .{ }^{13} \mathrm{C} \mathrm{NMR}\left(100 \mathrm{MHz}, \mathrm{DMSO}-d_{6}\right) \delta 165.0,155.3,134.0,130.5,118.9,80.3$, $78.3,61.0$.

3,5-Dibromo-4-(2-oxo-2-phenylethoxy)benzoic Acid (18). White solid, yield 90\%; mp 188-190 ${ }^{\circ} \mathrm{C}$; ${ }^{1} \mathrm{H}$ NMR (400 MHz, DMSO- $\left.d_{6}\right) \delta 13.60$ (s, $\left.1 \mathrm{H}, \mathrm{COOH}\right), 8.13$ (s, 2H, Ar-H), 8.01 (d, $J=8.3 \mathrm{~Hz}, 2 \mathrm{H}$, Ar-H), $7.72-7.67$ (m, 1H, Ar-H), $7.57-7.55$ (m, 2H, Ar-H), 5.50 (s, 2H, OCH $).{ }^{13} \mathrm{C}$ NMR (100 MHz, DMSO-d $) \delta 192.9,165.0,156.2,134.5,134.3,134.1,130.3,129.4,128.4,118.2,75.1$.

General Procedures for the Preparation of Compounds 5d-5i, 5k. The similar procedure for the preparation of $\mathbf{5 b}$ was used.

2-(Dimethylamino)ethyl 4-(Benzyloxy)-3,5-dibromobenzoate (5d). Colorless oil, yield 65\%; ${ }^{1} \mathrm{H}$ NMR (400 MHz, $\left.\mathrm{CDCl}_{3}\right) \delta 8.22(\mathrm{~s}, 2 \mathrm{H}, \mathrm{Ar}-\mathrm{H}), 7.60(\mathrm{~s}, 2 \mathrm{H}, \mathrm{Ar}-\mathrm{H}), 7.45-7.41(\mathrm{~m}, 3 \mathrm{H}, \mathrm{Ar}-\mathrm{H}), 5.08(\mathrm{~s}$, $\left.2 \mathrm{H}, \mathrm{OCH}_{2}\right), 4.43\left(\mathrm{t}, J=5.8 \mathrm{~Hz}, 2 \mathrm{H}, \mathrm{COOCH}_{2}\right), 2.72\left(\mathrm{t}, J=5.8 \mathrm{~Hz}, 2 \mathrm{H}, \mathrm{N}-\mathrm{CH}_{2}\right), 2.33\left(\mathrm{~s}, 6 \mathrm{H}, \mathrm{N}-\mathrm{CH}_{3}\right)$. ${ }^{13} \mathrm{C}$ NMR $\left(100 \mathrm{MHz}, \mathrm{CDCl}_{3}\right) \delta 174.5,134.2,128.6,118.7,116.4,114.2,74.9,63.6,57.8,45.8$. HRMS (ESI) calcd for $\mathrm{C}_{18} \mathrm{H}_{20} \mathrm{Br}_{2} \mathrm{NO}_{3}(\mathrm{M}+\mathrm{H})^{+}$455.9804, found 455.9801 .

2-(Dimethylamino)ethyl 4-(Allyloxy)-3,5-dibromobenzoate (5e). Colorless oil, yield 85\%; ${ }^{1} \mathrm{H}$ NMR (400 MHz, $\left.\mathrm{CDCl}_{3}\right) \delta 8.19(\mathrm{~s}, 2 \mathrm{H}, \mathrm{Ar}-\mathrm{H}), 6.22-6.12(\mathrm{~m}, 1 \mathrm{H}, \mathrm{CH}), 5.47$ (dd, $J=17.1 \mathrm{~Hz} 1.1$ $\left.\mathrm{Hz}, 1 \mathrm{H},=\mathrm{CH}_{2}\right), 5.32\left(\mathrm{dd}, J=17.1 \mathrm{~Hz} 1.1 \mathrm{~Hz}, 1 \mathrm{H},=\mathrm{CH}_{2}\right), 4.60\left(\mathrm{~d}, J=5.6 \mathrm{~Hz}, 2 \mathrm{H}, \mathrm{CH}-\mathrm{CH}_{2}\right), 4.42(\mathrm{t}$, $\left.J=5.4 \mathrm{~Hz}, 2 \mathrm{H}, \mathrm{OCH}_{2}\right), 2.70\left(\mathrm{t}, J=5.4 \mathrm{~Hz}, 2 \mathrm{H}, \mathrm{N}-\mathrm{CH}_{2}\right), 2.33\left(\mathrm{~s}, 6 \mathrm{H}, \mathrm{N}-\mathrm{CH}_{3}\right) .{ }^{13} \mathrm{C} \mathrm{NMR}(100 \mathrm{MHz}$, $\left.\mathrm{CDCl}_{3}\right) \delta 163.9,156.9,134.1,132.5,128.31,119.3,118.6,74.3,63.5,57.8,45.8$. HRMS (ESI) calcd for $\mathrm{C}_{14} \mathrm{H}_{18} \mathrm{Br}_{2} \mathrm{NO}_{3}(\mathrm{M}+\mathrm{H})^{+}$405.9648, found 405.9644 .

2-(Dimethylamino)ethyl 3,5-Dibromo-4-(prop-2-yn-1-yloxy)benzoate (5f). Colorless oil, yield $76 \% ;{ }^{1} \mathrm{H}$ NMR $\left(400 \mathrm{MHz}, \mathrm{CDCl}_{3}\right) \delta 8.21(\mathrm{~s}, 2 \mathrm{H}, \mathrm{Ar}-\mathrm{H}), 4.86\left(\mathrm{~d}, J=2.4 \mathrm{~Hz}, 2 \mathrm{H}, \mathrm{C}-\mathrm{CH}_{2}\right), 4.44(\mathrm{t}, J=$ $\left.5.8 \mathrm{~Hz}, 2 \mathrm{H}, \mathrm{OCH}_{2}\right), 2.72\left(\mathrm{t}, J=5.8 \mathrm{~Hz}, 2 \mathrm{H}, \mathrm{N}-\mathrm{CH}_{2}\right), 2.59(\mathrm{t}, J=2.4 \mathrm{~Hz}, 1 \mathrm{H}, \mathrm{CH}), 2.35(\mathrm{~s}, 6 \mathrm{H}$, 
$\left.\mathrm{N}-\mathrm{CH}_{3}\right) .{ }^{13} \mathrm{C} \mathrm{NMR}\left(100 \mathrm{MHz}, \mathrm{CDCl}_{3}\right) \delta 163.8,155.7,134.1,128.9,118.7,76.8,63.6,60.6,57.8$, 45.8. HRMS (ESI) calcd for $\mathrm{C}_{14} \mathrm{H}_{16} \mathrm{Br}_{2} \mathrm{NO}_{3}(\mathrm{M}+\mathrm{H})^{+}$403.9491, found 403.9497 .

2-(Dimethylamino)ethyl 3,5-Dibromo-4-(2-0xo-2-phenylethoxy)benzoate (5g). White solid, yield 78\%; mp 73-75 ${ }^{\circ} \mathrm{C} ;{ }^{1} \mathrm{H}$ NMR (400 MHz, $\left.\mathrm{CDCl}_{3}\right) \delta 8.21(\mathrm{~s}, 2 \mathrm{H}, \mathrm{Ar}-\mathrm{H}), 8.00(\mathrm{~d}, J=7.7 \mathrm{~Hz}, 2 \mathrm{H}$, Ar-H), $7.64-7.60(\mathrm{~m}, 1 \mathrm{H}, \mathrm{Ar}-\mathrm{H}), 7.52-7.48(\mathrm{~m}, 2 \mathrm{H}, \mathrm{Ar}-\mathrm{H}), 5.33$ (s, 2H, $\left.\mathrm{OCH}_{2}\right), 4.43$ (t, $J=5.4 \mathrm{~Hz}$, $\left.2 \mathrm{H}, \mathrm{COOCH}_{2}\right), 2.71\left(\mathrm{t}, J=5.4 \mathrm{~Hz}, 2 \mathrm{H}, \mathrm{N}-\mathrm{CH}_{2}\right), 2.33\left(\mathrm{~s}, 6 \mathrm{H}, \mathrm{N}-\mathrm{CH}_{3}\right) .{ }^{13} \mathrm{C} \mathrm{NMR}\left(100 \mathrm{MHz}, \mathrm{CDCl}_{3}\right) \delta$ $192.2,163.7,156.3,134.3,134.2,134.0,129.0,128.9,128.1,118.1,74.4,63.6,57.7,45.8$. HRMS (ESI) calcd for $\mathrm{C}_{19} \mathrm{H}_{20} \mathrm{Br}_{2} \mathrm{NO}_{4}(\mathrm{M}+\mathrm{H})^{+} 483.9754$, found 483.9758 .

2-(Dimethylamino)ethyl 3,5-Dichloro-4-methoxybenzoate (5h). Colorless oil, yield 72\%; ${ }^{1} \mathrm{H}$ NMR (400 MHz, $\left.\mathrm{CDCl}_{3}\right) \delta 8.00(\mathrm{~s}, 2 \mathrm{H}, \mathrm{Ar}-\mathrm{H}), 4.44\left(\mathrm{t}, J=5.4 \mathrm{~Hz}, 2 \mathrm{H}, \mathrm{OCH}_{2}\right), 3.98\left(\mathrm{~s}, 3 \mathrm{H}, \mathrm{OCH}_{3}\right)$, $2.72\left(\mathrm{t}, J=5.4 \mathrm{~Hz}, 2 \mathrm{H}, \mathrm{N}-\mathrm{CH}_{2}\right), 2.35\left(\mathrm{~s}, 6 \mathrm{H}, \mathrm{N}-\mathrm{CH}_{3}\right) .{ }^{13} \mathrm{C} \mathrm{NMR}\left(100 \mathrm{MHz}, \mathrm{CDCl}_{3}\right) \delta 174.2,130.3$, 129.6, 113.2, 63.6, 60.9, 57.8, 45.8. HRMS (ESI) calcd for $\mathrm{C}_{12} \mathrm{H}_{16} \mathrm{Cl}_{2} \mathrm{NO}_{3}(\mathrm{M}+\mathrm{H})^{+} 292.0502$, found 292.0507.

2-(Dimethylamino)ethyl 3,5-Diiodo-4-methoxybenzoate (5i). Colorless oil, yield 64\%; ${ }^{1} \mathrm{H}$ NMR $\left(400 \mathrm{MHz}, \mathrm{CDCl}_{3}\right) \delta 8.44(\mathrm{~s}, 2 \mathrm{H}, \mathrm{Ar}-\mathrm{H}), 4.43\left(\mathrm{t}, J=5.8 \mathrm{~Hz}, 2 \mathrm{H}, \mathrm{OCH}_{2}\right), 3.91\left(\mathrm{~s}, 3 \mathrm{H}, \mathrm{OCH}_{3}\right), 2.72(\mathrm{t}$, $\left.J=5.8 \mathrm{~Hz}, 2 \mathrm{H}, \mathrm{N}-\mathrm{CH}_{2}\right), 2.35\left(\mathrm{~s}, 6 \mathrm{H}, \mathrm{N}-\mathrm{CH}_{3}\right) .{ }^{13} \mathrm{C} \mathrm{NMR}\left(100 \mathrm{MHz}, \mathrm{CDCl}_{3}\right) \delta 163.4,162.6,141.3$, 129.4, 90.1, 63.5, 60.8, 57.8, 45.8. HRMS (ESI) calcd for $\mathrm{C}_{12} \mathrm{H}_{16} \mathrm{I}_{2} \mathrm{NO}_{3}(\mathrm{M}+\mathrm{H})^{+}$475.9214, found 475.9217.

2-(Dimethylamino)ethyl 2-(3,5-Dibromo-4-methoxyphenyl)acetate (5k). Colorless oil, yield 70\%; ${ }^{1} \mathrm{H}$ NMR (400 MHz, $\left.\mathrm{CDCl}_{3}\right) \delta 7.47$ (s, 2H, Ar-H), 4.26 (t, J=6.9 Hz, 2H, $\left.\mathrm{CO}_{2}-\mathrm{CH}_{2}\right), 3.90(\mathrm{~s}, 3 \mathrm{H}$, $\left.-\mathrm{CH}_{3}\right), 3.58\left(\mathrm{~s}, 2 \mathrm{H}, \mathrm{COCH}_{2}\right), 2.65\left(\mathrm{~s}, J=8.9 \mathrm{~Hz}, 2 \mathrm{H}, \mathrm{N}-\mathrm{CH}_{2}\right), 2.34\left(\mathrm{~s}, 6 \mathrm{H}, \mathrm{N}-\mathrm{CH}_{3}\right) .{ }^{13} \mathrm{C} \mathrm{NMR}(100$ $\left.\mathrm{MHz}, \mathrm{CDCl}_{3}\right) \delta 135.3,133.6,132.4,118.1,117.8,77.35,77.0,76.7,62.5,60.6,57.4,45.3,39.7$. 
HRMS (ESI) calcd for $\mathrm{C}_{13} \mathrm{H}_{18} \mathrm{Br}_{2} \mathrm{NO}_{3}(\mathrm{M}+\mathrm{H})^{+}$393.9648, found 393.9647.

General Procedures for the Preparation of Compounds $\mathbf{6 m - 6 u}$. The similar procedure for the preparation of $6 \mathbf{a}$ was used.

2-((4-(Benzyloxy)-3,5-dibromobenzoyl)oxy)- $N, N, N$-trimethylethan-1-aminium Iodide (6m). White solid, yield 95\%; mp 191-193 ${ }^{\circ} \mathrm{C} ;{ }^{1} \mathrm{H}$ NMR (400 MHz, DMSO-d $) \delta 8.23$ (s, 2H, Ar-H), 7.58 $(\mathrm{d}, J=6.8 \mathrm{~Hz}, 2 \mathrm{H}, \mathrm{Ar}-\mathrm{H}), 7.48-7.39(\mathrm{~m}, 3 \mathrm{H}, \mathrm{Ar}-\mathrm{H}), 5.08\left(\mathrm{~s}, 2 \mathrm{H}, \mathrm{OCH}_{2}\right), 4.73(\mathrm{t}, J=5.8 \mathrm{~Hz}, 2 \mathrm{H}$, $\left.\mathrm{COOCH}_{2}\right), 3.84\left(\mathrm{t}, J=5.8 \mathrm{~Hz}, 2 \mathrm{H}, \mathrm{N}-\mathrm{CH}_{2}\right), 3.21\left(\mathrm{~s}, 9 \mathrm{H}, \mathrm{N}-\mathrm{CH}_{3}\right) .{ }^{13} \mathrm{C} \mathrm{NMR}\left(100 \mathrm{MHz}, \mathrm{DMSO}-d_{6}\right) \delta$ $163.1,156.8,136.0,134.1,129.1,129.0,129.0,128.6,119.0,75.1,64.2,59.9,53.4$. HRMS (ESI) calcd for $\mathrm{C}_{19} \mathrm{H}_{22} \mathrm{Br}_{2} \mathrm{NO}_{3}\left(\mathrm{M}-\mathrm{I}^{-}\right)^{+}$469.9961, found 469.9965 .

2-((4-(Allyloxy)-3,5-dibromobenzoyl)oxy)- $N, N, N$-trimethylethan-1-aminium Iodide (6n). White solid, yield 98\%; mp $170-172{ }^{\circ} \mathrm{C} ;{ }^{1} \mathrm{H}$ NMR (400 MHz, DMSO- $\left.d_{6}\right) \delta 8.19$ (s, 2H, Ar-H), $6.16-6.13$ $(\mathrm{m}, 1 \mathrm{H}, \mathrm{CH}), 5.46\left(\mathrm{dd}, J=17.2,1.4 \mathrm{~Hz}, 1 \mathrm{H},=\mathrm{CH}_{2}\right), 5.32\left(\mathrm{dd}, J=17.2,0.9 \mathrm{~Hz}, 1 \mathrm{H},=\mathrm{CH}_{2}\right), 4.71(\mathrm{t}, J$ $\left.=5.4 \mathrm{~Hz}, 2 \mathrm{H}, \mathrm{COOCH}_{2}\right), 4.61\left(\mathrm{~d}, J=5.7 \mathrm{~Hz}, 2 \mathrm{H}, \mathrm{CH}-\mathrm{CH}_{2}\right), 3.84\left(\mathrm{t}, J=5.4 \mathrm{~Hz}, 2 \mathrm{H}, \mathrm{N}-\mathrm{CH}_{2}\right), 3.19(\mathrm{~s}$, 9H, N-CH 3$).{ }^{13} \mathrm{C}$ NMR (100 MHz, DMSO- $\left.d_{6}\right) \delta 163.0,157.0,134.0,133.1,128.4,119.7,118.9,74.6$, 64.2, 59.9, 53.3. HRMS (ESI) calcd for $\mathrm{C}_{15} \mathrm{H}_{20} \mathrm{Br}_{2} \mathrm{NO}_{3}\left(\mathrm{M}-\mathrm{I}^{-}\right)^{+} 419.9804$, found 419.9807 .

2-((3,5-Dibromo-4-(prop-2-yn-1-yloxy)benzoyl)oxy)- $N, N, N$-trimethylethan-1-aminium Iodide (6o). White solid, yield 98\%; mp $180-182{ }^{\circ} \mathrm{C} ;{ }^{1} \mathrm{H}$ NMR (400 MHz, DMSO- $\left.d_{6}\right) \delta 8.19$ (s, 2H, Ar-H), $4.90\left(\mathrm{~d}, J=2.4 \mathrm{~Hz}, 2 \mathrm{H}, \mathrm{C}-\mathrm{CH}_{2}\right), 4.71\left(\mathrm{t}, J=5.8 \mathrm{~Hz}, 2 \mathrm{H}, \mathrm{OCH}_{2}\right), 3.84\left(\mathrm{t}, J=5.8 \mathrm{~Hz}, 2 \mathrm{H}, \mathrm{N}-\mathrm{CH}_{2}\right)$, $3.71(\mathrm{t}, J=2.4 \mathrm{~Hz}, 1 \mathrm{H}, \mathrm{CH}), 3.20\left(\mathrm{~s}, 9 \mathrm{H}, \mathrm{N}-\mathrm{CH}_{3}\right) .{ }^{13} \mathrm{C} \mathrm{NMR}\left(100 \mathrm{MHz}, \mathrm{DMSO}-d_{6}\right) \delta 163.0,155.9$, 134.0, 128.8, 119.2, 80.4, 78.1, 64.2, 61.1, 60.0, 53.4. HRMS (ESI) calcd for $\mathrm{C}_{15} \mathrm{H}_{18} \mathrm{Br}_{2} \mathrm{NO}_{3}\left(\mathrm{M}-\mathrm{I}^{-}\right)^{+}$ 417.9648, found 417.9645.

2-((3,5-Dibromo-4-(2-oxo-2-phenylethoxy)benzoyl)oxy)- $N, N, N$-trimethylethan-1-aminium 
Iodide (6p). White solid, yield 97\%; mp 179-182 ${ }^{\circ} \mathrm{C} ;{ }^{1} \mathrm{H}$ NMR (400 MHz, DMSO- $\left.d_{6}\right) \delta 8.22(\mathrm{~s}, 2 \mathrm{H}$, Ar-H), $8.02(\mathrm{~d}, J=6.9 \mathrm{~Hz}, 2 \mathrm{H}, \mathrm{Ar}-\mathrm{H}), 7.71-7.65$ (m, 1H, Ar-H), $7.62-7.57$ (m, 2H, Ar-H), 5.55 (s, $\left.2 \mathrm{H}, \mathrm{COCH}_{2}\right), 4.75\left(\mathrm{t}, J=6.6 \mathrm{~Hz}, 2 \mathrm{H}, \mathrm{OCH}_{2}\right), 3.82\left(\mathrm{t}, J=6.6 \mathrm{~Hz}, 2 \mathrm{H}, \mathrm{N}-\mathrm{CH}_{2}\right), 3.21\left(\mathrm{~s}, 9 \mathrm{H}, \mathrm{N}-\mathrm{CH}_{3}\right)$. ${ }^{13} \mathrm{C}$ NMR (100 MHz, DMSO-d $\left.d_{6}\right) \delta 192.4,175.6,162.5,134.0,133.8,133.6,128.9,127.9,117.9$, 74.6, 63.7, 59.5, 52.9. HRMS (ESI) calcd for $\mathrm{C}_{20} \mathrm{H}_{22} \mathrm{Br}_{2} \mathrm{NO}_{4}\left(\mathrm{M}^{-} \mathrm{I}^{-}\right)^{+} 497.9910$, found 497.9918.

2-((3,5-Dichloro-4-methoxybenzoyl)oxy)- $N, N, N$-trimethylethan-1-aminium Iodide (6q). White solid, yield 95\%; mp 177-179 ${ }^{\circ} \mathrm{C} ;{ }^{1} \mathrm{H}$ NMR (400 MHz, DMSO- $\left.d_{6}\right) \delta 8.04(\mathrm{~s}, 2 \mathrm{H}, \mathrm{Ar}-\mathrm{H}), 4.73(\mathrm{t}, J=$ $\left.5.4 \mathrm{~Hz}, 2 \mathrm{H}, \mathrm{OCH}_{2}\right), 3.92\left(\mathrm{~s}, 3 \mathrm{H}, \mathrm{OCH}_{3}\right), 3.86\left(\mathrm{t}, J=5.4 \mathrm{~Hz}, 2 \mathrm{H}, \mathrm{N}-\mathrm{CH}_{2}\right), 3.22\left(\mathrm{~s}, 9 \mathrm{H}, \mathrm{N}-\mathrm{CH}_{3}\right) .{ }^{13} \mathrm{C}$ NMR (100 MHz, DMSO- $\left.d_{6}\right) \delta 162.7,155.7,130.0,128.9,126.9,63.7,61.0,59.4,52.9$. HRMS (ESI) calcd for $\mathrm{C}_{13} \mathrm{H}_{17} \mathrm{Cl}_{2} \mathrm{NO}_{3}\left(\mathrm{M}-\mathrm{I}^{-}\right)^{+}$305.0580, found 305.0583 .

2-((3,5-Diiodo-4-methoxybenzoyl)oxy)- $N, N, N$-trimethylethan-1-aminium Iodide (6r). White solid, yield 98\%; mp 180-182 ${ }^{\circ} \mathrm{C} ;{ }^{1} \mathrm{H}$ NMR (400 MHz, DMSO-d 6 ) $\delta 8.35$ (s, 2H, Ar-H), 4.69 (t, $J=$ $\left.5.8 \mathrm{~Hz}, 2 \mathrm{H}, \mathrm{OCH}_{2}\right), 3.82\left(\mathrm{t}, J=5.8 \mathrm{~Hz}, 2 \mathrm{H}, \mathrm{N}-\mathrm{CH}_{2}\right), 3.81\left(\mathrm{~s}, 3 \mathrm{H}, \mathrm{OCH}_{3}\right), 3.18\left(\mathrm{~s}, 9 \mathrm{H}, \mathrm{N}-\mathrm{CH}_{3}\right) .{ }^{13} \mathrm{C}$ NMR (100 MHz, DMSO-d $d_{6} \delta 163.2,162.8,140.8,129.1,92.7,64.2,61.0,59.7,53.3$. HRMS (ESI) calcd for $\mathrm{C}_{13} \mathrm{H}_{17} \mathrm{I}_{2} \mathrm{NO}_{3}\left(\mathrm{M}-\mathrm{I}^{-}\right)^{+}$488.9292, found 488.9291.

2-(3,5-Dibromo-4-methoxybenzamido)- $N, N, N$-trimethylethan-1-aminium Iodide (6s). White solid, yield 95\%; mp $175-177{ }^{\circ} \mathrm{C} ;{ }^{1} \mathrm{H}$ NMR (400 MHz, DMSO- $\left.d_{6}\right) \delta 8.96(\mathrm{t}, J=5.2 \mathrm{~Hz}, 1 \mathrm{H}, \mathrm{NH})$, $8.12(\mathrm{~s}, 2 \mathrm{H}, \mathrm{Ar}-\mathrm{H}), 3.85\left(\mathrm{~s}, 3 \mathrm{H}, \mathrm{OCH}_{3}\right), 3.69\left(\mathrm{t}, J=6.3 \mathrm{~Hz}, 2 \mathrm{H}, \mathrm{CONH}-\mathrm{CH}_{2}\right), 3.50$ (t, $J=6.3 \mathrm{~Hz}, 2 \mathrm{H}$, $\left.\mathrm{N}-\mathrm{CH}_{2}\right), 3.14\left(\mathrm{~s}, 9 \mathrm{H}, \mathrm{N}-\mathrm{CH}_{3}\right) .{ }^{13} \mathrm{C} \mathrm{NMR}\left(100 \mathrm{MHz}, \mathrm{DMSO}-d_{6}\right) \delta 163.5,156.0,132.1,131.8,117.7$, 63.6, 60.6, 52.6, 33.9. HRMS (ESI) calcd for $\mathrm{C}_{13} \mathrm{H}_{19} \mathrm{Br}_{2} \mathrm{~N}_{2} \mathrm{O}_{2}\left(\mathrm{M}-\mathrm{I}^{-}\right)^{+}$392.9808, found 392.9806.

2-(2-(3,5-Dibromo-4-methoxyphenyl)acetoxy)- $N, N, N$-trimethylethan-1-aminium Iodide (6t). White solid, yield 98\%; mp 171-173 ${ }^{\circ} \mathrm{C} ;{ }^{1} \mathrm{H}$ NMR (400 MHz, DMSO-d $) \delta 7.65$ (s, 2H, Ar-H), 4.48 
$\left(\mathrm{t}, J=6.9 \mathrm{~Hz}, 2 \mathrm{H}, \mathrm{CO}_{2}-\mathrm{CH}_{2}\right), 3.80\left(\mathrm{~s}, 3 \mathrm{H}, \mathrm{OCH}_{3}\right), 3.7\left(\mathrm{t}, J=7.9 \mathrm{~Hz}, 2 \mathrm{H}, \mathrm{N}-\mathrm{CH}_{2}\right), 3.68(\mathrm{~s}, 2 \mathrm{H}$, $\left.\mathrm{COCH}_{2}\right), 3.12\left(\mathrm{~s}, 9 \mathrm{H}, \mathrm{N}-\mathrm{CH}_{3}\right) .{ }^{13} \mathrm{C} \mathrm{NMR}\left(100 \mathrm{MHz}, \mathrm{DMSO}-d_{6}\right) \delta 169.9,152.3,134.0,133.5,117.0$, $63.6,60.4,58.5,52.9,40.2,39.9,39.7,39.5,39.3,39.1,38.9,38.2$. HRMS (ESI) calcd for $\mathrm{C}_{14} \mathrm{H}_{20} \mathrm{Br}_{2} \mathrm{NO}_{3}\left(\mathrm{M}-\mathrm{I}^{-}\right)^{+}$407.9804, found 407.9807.

2-(2-(3,5-Dibromo-4-methoxyphenyl)acetamido)- $N, N, N$-trimethylethan-1-aminium Iodide (6u). White solid, yield 98\%; mp $178-180{ }^{\circ} \mathrm{C} ;{ }^{1} \mathrm{H}$ NMR (400 MHz, DMSO- $\left.d_{6}\right) \delta 8.34$ (t, $J=5.2 \mathrm{~Hz}, 1 \mathrm{H}$, $\mathrm{NH}), 7.56(\mathrm{~s}, 2 \mathrm{H}, \mathrm{Ar}-\mathrm{H}), 3.78\left(\mathrm{~s}, 3 \mathrm{H}, \mathrm{OCH}_{3}\right), 3.48\left(\mathrm{~s}, 2 \mathrm{H}, \mathrm{COCH}_{2}\right), 3.37\left(\mathrm{t}, J=8.0 \mathrm{~Hz}, 2 \mathrm{H}, \mathrm{N}-\mathrm{CH}_{2}\right)$, $3.35\left(\mathrm{t}, J=8.0 \mathrm{~Hz}, 2 \mathrm{H}, \mathrm{N}-\mathrm{CH}_{2}\right), 3.10\left(\mathrm{~s}, 9 \mathrm{H}, \mathrm{N}-\mathrm{CH}_{3}\right) .{ }^{13} \mathrm{C} \mathrm{NMR}\left(100 \mathrm{MHz}, \mathrm{DMSO}-d_{6}\right) \delta 170.4$,

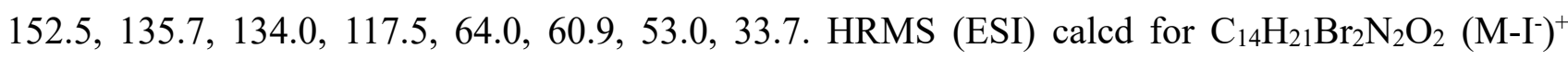
406.9964, found 406.9967.

General Procedures for the Preparation of Compounds 5j, 5l-5r. The similar procedure for the preparation of 5a was used.

3,5-Dibromo- $N$-(2-(dimethylamino)ethyl)-4-methoxybenzamide (5j). White solid, yield 83\%; mp 100-102 ${ }^{\circ} \mathrm{C} ;{ }^{1} \mathrm{H}$ NMR (400 MHz, $\left.\mathrm{CDCl}_{3}\right) \delta 7.95(\mathrm{~s}, 2 \mathrm{H}, \mathrm{Ar}-\mathrm{H}), 6.88(\mathrm{~s}, 1 \mathrm{H}, \mathrm{NH}), 3.92(\mathrm{~s}, 3 \mathrm{H}$, $\left.\mathrm{OCH}_{3}\right), 3.50\left(\mathrm{t}, J=5.4 \mathrm{~Hz}, 2 \mathrm{H}, \mathrm{CONH}-\mathrm{CH}_{2}\right), 2.52\left(\mathrm{t}, J=5.4 \mathrm{~Hz}, 2 \mathrm{H}, \mathrm{N}-\mathrm{CH}_{2}\right), 2.28\left(\mathrm{~s}, 6 \mathrm{H}, \mathrm{N}-\mathrm{CH}_{3}\right)$. ${ }^{13} \mathrm{C}$ NMR $\left(100 \mathrm{MHz}, \mathrm{CDCl}_{3}\right) \delta 164.2,156.6,132.9,131.6,118.3,57.6,45.2,37.4$. HRMS (ESI) calcd for $\mathrm{C}_{12} \mathrm{H}_{17} \mathrm{Br}_{2} \mathrm{~N}_{2} \mathrm{O}_{2}(\mathrm{M}+\mathrm{H})^{+}$378.9651, found 378.9655 .

2-(3,5-Dibromo-4-methoxyphenyl)- $N$-(2-(dimethylamino)ethyl)acetamide (51). White solid, yield 75\%; mp 86-88 ${ }^{\circ} \mathrm{C} ;{ }^{1} \mathrm{H}$ NMR (400 MHz, $\left.\mathrm{CDCl}_{3}\right) \delta 7.45$ (s, 2H, Ar-H), 6.49 (s, 1H, NH), $3.86(\mathrm{~s}, 3 \mathrm{H}$, $\left.\mathrm{OCH}_{3}\right), 3.44\left(\mathrm{~s}, 2 \mathrm{H}, \mathrm{COCH}_{2}\right), 3.35-3.31\left(\mathrm{~m}, 2 \mathrm{H}, \mathrm{CONH}-\mathrm{CH}_{2}\right), 2.47\left(\mathrm{t}, J=5.8 \mathrm{~Hz}, 2 \mathrm{H}, \mathrm{N}-\mathrm{CH}_{2}\right)$, $2.27\left(\mathrm{~s}, 6 \mathrm{H}, \mathrm{N}-\mathrm{CH}_{3}\right) .{ }^{13} \mathrm{C} \mathrm{NMR}\left(100 \mathrm{MHz}, \mathrm{CDCl}_{3}\right) \delta 170.1,153.1,133.9,133.4,118.1,60.6,57.7$, 45.0, 41.8, 36.9. HRMS (ESI) calcd for $\mathrm{C}_{13} \mathrm{H}_{19} \mathrm{Br}_{2} \mathrm{~N}_{2} \mathrm{O}_{2}(\mathrm{M}+\mathrm{H})^{+}$392.9808, found 392.9805 . 
N-Butyl-2-(3,5-dibromo-4-methoxyphenyl)acetamide (5m). White solid, yield 98\%; mp 90-92 ${ }^{\circ} \mathrm{C}$; ${ }^{1} \mathrm{H}$ NMR (400 MHz, $\left.\mathrm{CDCl}_{3}\right) \delta 7.44(\mathrm{~s}, 2 \mathrm{H}, \mathrm{Ar}-\mathrm{H}), 5.62(\mathrm{~s}, 1 \mathrm{H}, \mathrm{NH}), 3.89$ (s, 3H, $\left.\mathrm{OCH}_{3}\right), 3.44(\mathrm{~s}, 2 \mathrm{H}$, $\left.\mathrm{COCH}_{2}\right), 3.27-3.22\left(\mathrm{~m}, 2 \mathrm{H}, \mathrm{CONH}-\mathrm{CH}_{2}\right), 1.51-1.44\left(\mathrm{~m}, 2 \mathrm{H}, \mathrm{NHCH}_{2}-\mathrm{CH}_{2}\right), 1.35-1.30(\mathrm{~m}, 2 \mathrm{H}$, $\left.\mathrm{CH}_{3}-\mathrm{CH}_{2}\right), 0.93\left(\mathrm{~d}, J=7.3 \mathrm{~Hz}, 3 \mathrm{H}, \mathrm{CH}_{2}-\mathrm{CH}_{3}\right) .{ }^{13} \mathrm{C} \mathrm{NMR}\left(100 \mathrm{MHz}, \mathrm{CDCl}_{3}\right) \delta 169.5,153.3,133.7$, 133.4, 118.3, 60.7, 42.2, 39.6, 31.6, 20.1, 13.7. HRMS (ESI) calcd for $\mathrm{C}_{13} \mathrm{H}_{18} \mathrm{Br}_{2} \mathrm{NO}_{2}(\mathrm{M}+\mathrm{H})^{+}$ 377.9699, found 377.9704 .

2-(3,5-Dibromo-4-methoxyphenyl)- $N$-phenylacetamide (5n). White solid, yield 92\%; mp 166-168 ${ }^{\circ} \mathrm{C} ;{ }^{1} \mathrm{H}$ NMR $\left(400 \mathrm{MHz}, \mathrm{CDCl}_{3}\right) \delta 7.50$ (s, 2H, Ar-H), $7.48(\mathrm{~d}, J=8.3 \mathrm{~Hz}, 2 \mathrm{H}, \mathrm{Ar}-\mathrm{H}), 7.34$ - $7.29(\mathrm{~m}, 2 \mathrm{H}, \mathrm{Ar}-\mathrm{H}), 7.16-7.12(\mathrm{~m}, 1 \mathrm{H}, \mathrm{Ar}-\mathrm{H}), 3.89\left(\mathrm{~s}, 3 \mathrm{H}, \mathrm{OCH}_{3}\right), 3.61\left(\mathrm{~s}, 2 \mathrm{H}, \mathrm{COCH}_{2}\right) .{ }^{13} \mathrm{C}$ NMR (100 MHz, $\left.\mathrm{CDCl}_{3}\right) \delta 167.9,153.0,137.4,133.5,133.1,129.1,124.8,120.1,118.5,60.7,43.0$. HRMS (ESI) calcd for $\mathrm{C}_{15} \mathrm{H}_{14} \mathrm{Br}_{2} \mathrm{NO}_{2}(\mathrm{M}+\mathrm{H})^{+}$397.9386, found 397.9389.

tert-Butyl (2-(2-(3,5-dibromo-4-methoxyphenyl)acetamido)ethyl)carbamate (5o). White solid, yield 78\%; mp $127-129{ }^{\circ} \mathrm{C} ;{ }^{1} \mathrm{H}$ NMR (400 MHz, $\left.\mathrm{CDCl}_{3}\right) \delta 7.43(\mathrm{~s}, 2 \mathrm{H}, \mathrm{Ar}-\mathrm{H}), 6.54(\mathrm{~s}, 1 \mathrm{H}, \mathrm{CONH})$, $4.94(\mathrm{~s}, 1 \mathrm{H}, \mathrm{NH}), 3.87\left(\mathrm{~s}, 3 \mathrm{H}, \mathrm{OCH}_{3}\right), 3.42\left(\mathrm{~s}, 2 \mathrm{H}, \mathrm{COCH}_{2}\right), 3.35\left(\mathrm{t}, J=5.4 \mathrm{~Hz}, 2 \mathrm{H}, \mathrm{N}-\mathrm{CH}_{2}\right), 3.26(\mathrm{t}$, $\left.J=4.9 \mathrm{~Hz}, 2 \mathrm{H}, \mathrm{N}-\mathrm{CH}_{2}\right), 1.43\left(\mathrm{~s}, 9 \mathrm{H}, \mathrm{CH}_{3}\right) .{ }^{13} \mathrm{C} \mathrm{NMR}\left(100 \mathrm{MHz}, \mathrm{CDCl}_{3}\right) \delta 170.2,153.3,133.4$ 118.3, 80.0, 60.6, 42.1, 28.4. HRMS (ESI) calcd for $\mathrm{C}_{16} \mathrm{H}_{23} \mathrm{Br}_{2} \mathrm{~N}_{2} \mathrm{O}_{4}(\mathrm{M}+\mathrm{H})^{+}$465.0019, found 465.0011.

$N$-(tert-Butyl)-2-(3,5-dibromo-4-methoxyphenyl)acetamide (5p). White solid, yield 88\%; mp $121-122{ }^{\circ} \mathrm{C} ;{ }^{1} \mathrm{H}$ NMR (400 MHz, $\left.\mathrm{CDCl}_{3}\right) \delta 7.41(\mathrm{~s}, 2 \mathrm{H}, \mathrm{Ar}-\mathrm{H}), 5.40(\mathrm{~s}, 1 \mathrm{H}, \mathrm{NH}), 3.87(\mathrm{~s}, 3 \mathrm{H}$, $\left.\mathrm{OCH}_{3}\right), 3.35\left(\mathrm{~s}, 2 \mathrm{H}, \mathrm{COCH}_{2}\right), 1.34\left(\mathrm{~s}, 9 \mathrm{H}, \mathrm{CH}_{3}\right) .{ }^{13} \mathrm{C} \mathrm{NMR}\left(100 \mathrm{MHz}, \mathrm{CDCl}_{3}\right) \delta 168.8,153.1,134.0$, 133.4, 118.2 60.6, 51.7, 42.9, 28.8. HRMS (ESI) calcd for $\mathrm{C}_{13} \mathrm{H}_{18} \mathrm{Br}_{2} \mathrm{NO}_{2}(\mathrm{M}+\mathrm{H})^{+}$377.9699, found 377.9693. 
$N$-(2-Bromoethyl)-2-(3,5-dibromo-4-methoxyphenyl)acetamide (5q). Colorless oil, yield 65\%; ${ }^{1} \mathrm{H}$ NMR (400 MHz, $\left.\mathrm{CDCl}_{3}\right) \delta 7.47(\mathrm{~s}, 2 \mathrm{H}, \mathrm{Ar}-\mathrm{H}), 4.32-4.27\left(\mathrm{~m}, 2 \mathrm{H}, \mathrm{CONH}-\mathrm{CH}_{2}\right), 3.91$ (t, J = $1.2 \mathrm{~Hz}$, $\left.2 \mathrm{H}, \mathrm{CH}_{2} \mathrm{Br}\right), 3.89$ (s, 3H, $\left.\mathrm{OCH}_{3}\right), 3.54\left(\mathrm{~s}, 2 \mathrm{H}, \mathrm{COCH}_{2}\right) .{ }^{13} \mathrm{C} \mathrm{NMR}\left(100 \mathrm{MHz}, \mathrm{CDCl}_{3}\right) \delta 133.2,118.1$, 67.9, 62.0, 60.6, 54.5, 42.6, 42.0, 33.3. HRMS (ESI) calcd for $\mathrm{C}_{11} \mathrm{H}_{13} \mathrm{Br}_{3} \mathrm{NO}_{2}(\mathrm{M}+\mathrm{H})^{+}$427.8491, found 427.8495 .

2-(3,5-Dibromo-4-methoxyphenyl)- $N$-(prop-2-yn-1-yl)acetamide (5r). White solid, yield 95\%; mp $140-142{ }^{\circ} \mathrm{C} ;{ }^{1} \mathrm{H}$ NMR (400 MHz, $\left.\mathrm{CDCl}_{3}\right) \delta 7.46(\mathrm{~s}, 2 \mathrm{H}, \mathrm{Ar}-\mathrm{H}), 5.73(\mathrm{~s}, 1 \mathrm{H}, \mathrm{NH}), 4.08(\mathrm{dd}, J=$ 5.2, $\left.2.5 \mathrm{~Hz}, 2 \mathrm{H}, \mathrm{CONH}-\mathrm{CH}_{2}\right), 3.91\left(\mathrm{~s}, 3 \mathrm{H}, \mathrm{OCH}_{3}\right), 3.50\left(\mathrm{~s}, 2 \mathrm{H}, \mathrm{COCH}_{2}\right), 2.28(\mathrm{t}, J=2.5 \mathrm{~Hz}, 1 \mathrm{H}$, $\mathrm{CH}) .{ }^{13} \mathrm{C} \mathrm{NMR}\left(100 \mathrm{MHz}, \mathrm{CDCl}_{3}\right) \delta 169.2,133.5,132.9,118.5,79.1,72.0,60.7,42.5,41.8,29.5$. HRMS (ESI) calcd for $\mathrm{C}_{12} \mathrm{H}_{12} \mathrm{Br}_{2} \mathrm{NO}_{2}(\mathrm{M}+\mathrm{H})^{+}$359.9229, found 359.9233.

Preparation of $\mathrm{N}$-(2-Aminoethyl)-2-(3,5-dibromo-4-methoxyphenyl)acetamide (5s). Colorless oil, yield 96\%; ${ }^{1} \mathrm{H}$ NMR (400 MHz, $\left.\mathrm{CDCl}_{3}\right) \delta 7.45$ (s, 2H, Ar-H), $6.10(\mathrm{~s}, 1 \mathrm{H}, \mathrm{NH}), 3.88$ (s, 3H, $\left.\mathrm{OCH}_{3}\right), 3.46\left(\mathrm{~s}, 2 \mathrm{H}, \mathrm{COCH}_{2}\right), 3.30\left(\mathrm{t}, J=5.9 \mathrm{~Hz}, 2 \mathrm{H}, \mathrm{CONH}-\mathrm{CH}_{2}\right), 2.83(\mathrm{t}, J=5.8 \mathrm{~Hz}, 2 \mathrm{H}$, $\left.\mathrm{NH}_{2}-\mathrm{CH}_{2}\right) .{ }^{13} \mathrm{C} \mathrm{NMR}\left(100 \mathrm{MHz}, \mathrm{CDCl}_{3}\right) \delta 170.1,153.2,133.7,133.4,118.2,60.7,42.0,41.8,41.0$. HRMS (ESI) calcd for $\mathrm{C}_{11} \mathrm{H}_{15} \mathrm{Br}_{2} \mathrm{~N}_{2} \mathrm{O}_{2}(\mathrm{M}+\mathrm{H})^{+}$364.9495, found 364.9497. 


\section{Detailed bio-assay procedures}

Phytotoxic Activity. The growing 3-5 leaf stage tobaccos (Nicotiana tabacum var Xanthi nc) were selected. The compound solution $(100 \mu \mathrm{g} / \mathrm{mL}$ and $500 \mu \mathrm{g} / \mathrm{mL})$ was sprayed on the leaves and then tested the plant height and weight changes after $0,3,7$ and 10 days respectively. There are three replicates for each compound.

\section{Antiviral Biological Assay. ${ }^{1}$}

Purification of Tobacco Mosaic Virus.

Using Gooding's method ${ }^{2}$, the upper leaves of Nicotiana tabacum L. inoculated with TMV were selected and ground in phosphate buffer and then filtered through double-layer pledget. The filtrate was centrifuged at $10000 \mathrm{~g}$, treated with PEG twice, and centrifuged again. The whole experiment was processed at $4{ }^{\circ} \mathrm{C}$. Absorbance value was estimated at $260 \mathrm{~nm}$ by ultraviolet spectrophotometer.

$$
\text { Virus conch }=\left(A_{260} \times \text { dilution ratio }\right) E /_{1 \mathrm{~cm}}^{0.1 \%, 260 \mathrm{~nm}}
$$

Protective Effect of Compounds against TMV in Vivo.

The compound solution was smeared on growing Nicotiana. tabacum L. leaves (at least 3 leaves) of the same age. In another pot, the leaves were smeared with the solvent as a control. After $12 \mathrm{~h}$, the leaves were inoculated with TMV with the juice-leaf rubbing method and then washed with water. The total local lesion numbers appearing on the leaves 3-4 days after inoculation were recorded. ${ }^{3}$ There are three replicates for each compound.

Inactivation Effect of Compounds against TMV in Vivo.

To test viral inhibition, equal volumes of the virus and the compound solution were mixed together for $30 \mathrm{~min}$. The mixture was then inoculated into the growing $N$. tabacum L leaves of the same age, and another pot was inoculated with the mixture of solvent and the virus as the control. 
The local lesion numbers were recorded 3-4 days after inoculation. ${ }^{3}$ There are three replicates for each compound.

Curative Effect of Compounds against TMV in Vivo.

TMV (concentration of $6.0 \times 10^{-3} \mu \mathrm{g} / \mathrm{mL}$ ) was inoculated on the growing leaves of $N$. tabacum L. of the same age. Then, the leaves were washed with water and dried. The compound solution was smeared on the inoculated leaves, while inoculated leaves in another pot were smeared with the solvent as a control. The local lesion numbers were recorded 3-4 days after inoculation. ${ }^{3}$ There are three replicates for each compound. The in vitro and in vivo inhibition rates of the compound were then calculated according to the following formula ("av" means average, and controls were not treated with compound).

Inhibition rate $(\%)=[($ av local lesion no. of control - av local lesion no. of drug-treated $) /$ av local lesion no. of control] $\times 100 \%$

\section{Mode of Action Studies.}

In vitro TMV rod assembly inhibition : TMV purification was performed according to the instructions by Leberman. ${ }^{4}$ TMV RNA was purified by RNApure virus kit (CoWin Biosciences) and TMV capsid protein (TMV CP) was isolated using glacial acetic acid as described by Fraenkel-Conrat. ${ }^{5}$ Before assembly, 20S CP Disk was prepared by incubating $23.5 \mathrm{mg} / \mathrm{mL}$ TMV CP in $0.1 \mathrm{M}$ phosphate buffer ( $\mathrm{pH} 7.0$ ) at $20{ }^{\circ} \mathrm{C}$ for $12 \mathrm{~h}$. After incubation, in vitro TMV reconstitution reactions were performed by adding $7.5 \mu \mathrm{L}$ of phosphate buffer $(0.1 \mathrm{M}, \mathrm{pH} 7.0), 2 \mu \mathrm{L}$ of 20S Disk $(23.5 \mathrm{mg} / \mathrm{mL})$ and $0.5 \mu \mathrm{L}$ of TMV RNA $(2 \mu \mathrm{g} / \mu \mathrm{L})$. The assembly reaction mixture was incubated at $20{ }^{\circ} \mathrm{C}$ for $12 \mathrm{~h}$ and could be then transferred into the copper grid for transmission electron microscopy (TEM) assay. The assembly reaction mixture $(5 \mu \mathrm{L})$ was mixed with $5 \mu \mathrm{L} 0.1 \mathrm{M}$ 
phosphate buffer ( $\mathrm{pH}$ 7.0) and dropped onto the copper film waiting for 5 minutes. After the incubation, the droplet was removed by filter paper and negatively stained by $2 \%$ phosphotungstic acid ( $\mathrm{pH}$ 7.0) for three minutes. After removing the staining agent, the copper was placed at $37{ }^{\circ} \mathrm{C}$ for $2 \mathrm{~h}$ for drying. The morphology of the reconstituted TMV rods was imaged at $200 \mathrm{keV}$ on a CCD camera. For the inhibition tests with the compounds, in vitro TMV reconstitution inhibition reactions were performed by adding $7.4 \mu \mathrm{L}$ of phosphate buffer (0.1 M, pH 7.0), $2 \mu \mathrm{L}$ of $20 \mathrm{~S}$ Disk $(2 \mathrm{mg} / \mathrm{mL})$, $0.5 \mu \mathrm{L}$ of TMV RNA $(2 \mu \mathrm{g} / \mu \mathrm{L})$ and $0.1 \mu \mathrm{L}$ of DMSO or the compound $(10 \mu \mathrm{M})$. All treatments were repeated over time to validate the results.

In vitro 20S CP Disk assembly inhibition: For the inhibition tests with the compounds, TMV CP was first adjusted to $23.5 \mathrm{mg} / \mathrm{mL}$ with $0.1 \mathrm{M}$ phosphate buffer (pH 7.0). In vitro 20S CP Disk assembly reactions were performed by adding $4.9 \mu \mathrm{L}$ of phosphate buffer $(0.1 \mathrm{M}, \mathrm{pH} 7.0), 5 \mu \mathrm{L}$ TMV CP $(23.5 \mathrm{mg} / \mathrm{mL})$ and $0.1 \mu \mathrm{L}$ DMSO or the compound $(10 \mu \mathrm{M})$. The assembly reaction was incubated at $20{ }^{\circ} \mathrm{C}$ for $12 \mathrm{~h}$. The morphology of the 20S CP Disk was imaged via TEM at $200 \mathrm{keV}$ on a CCD camera. All treatments were repeated over time for confirmation.

\section{Detailed bioassay procedures for the fungicidal activities ${ }^{6}$}

In Vitro Antifungal Bioassay. The fungicidal activities of compounds were evaluated in mycelial growth tests conducted in artificial media against 14 plant pathogens at a rate of $50 \mu \mathrm{g} / \mathrm{mL}$. Each test compound was dissolved in a suitable amount of acetone and diluted with water containing $0.1 \%$ TW-80 to a concentration of $500 \mu \mathrm{g} / \mathrm{mL}$. To each petri dish was added $1 \mathrm{~mL}$ of the test solution and $9 \mathrm{~mL}$ of culture medium to make a $50 \mu \mathrm{g} / \mathrm{mL}$ concentration of the test compound, while in another petri dish was added $1 \mathrm{~mL}$ distilled water containing $0.1 \% \mathrm{TW}-80$ and $9 \mathrm{~mL}$ of culture medium as a blank control. A $4 \mathrm{~mm}$ diameter of hyphal growth was cut using a hole puncher on a growing fungal 
culture and the hyphae were moved to the petri dish containing the test compound. Each assay was performed three times. The dishes were stored in controlled environment cabinets $\left(24 \pm 1^{\circ} \mathrm{C}\right)$ for 4 days, after which the diameter of mycelial growth was measured and the percentage inhibition was calculated using the following equation: Percentage inhibition $(\%)=($ averaged diameter of mycelia in blank controls - averaged diameter of mycelia in medicated tablets) / (averaged diameter of mycelia in blank controls $-4 \mathrm{~mm}) \times 100$.

\section{Reference:}

(1) Wang, Z. W.; Wei, P.; Wang, L. Z.; Wang, Q. M. Design, synthesis, and anti-tobacco mosaic virus (TMV) activity of phenanthroindolizidines and their analogues. J. Agric. Food Chem. 2012, 60, 10212-10219.

(2) Gooding, G. V., Jr.; Hebert, T. T. A simple technique for purification of tobacco mosaic virus in large quantities. Phytopathology 1967, 57, 1285-1290.

(3) Li, S. Z.; Wang, D. M.; Jiao, S. M. In Pesticide Experiment Methods-Fungicide Sector; Li, S. Z., Ed.; Agriculture Press of China: Beijing, China, 1991; 93-94.

(4) Leberman, R. Isolation of plant viruses by means of simple coacervates. Virol 1966, 30, $341-347$.

(5) Fraenkel Conrat, H.; Williams, R. C. Reconstitution of active tobacco mosaic virus fromits inactive protein and nucleic acid components. Proc. Natl. Acad. Sci. U S A 1955, 41, 690-698.

(6) Zhao, H. P.; Liu, Y. X.; Cui, Z. P.; Beattie, D.; Gu, Y. C.; Wang, Q. M. Design, synthesis, and biological activities of arylmethylamine substituted chlorotriazine and methylthiotriazine compounds. J. Agric. Food Chem. 2011, 59, 11711-11717. 

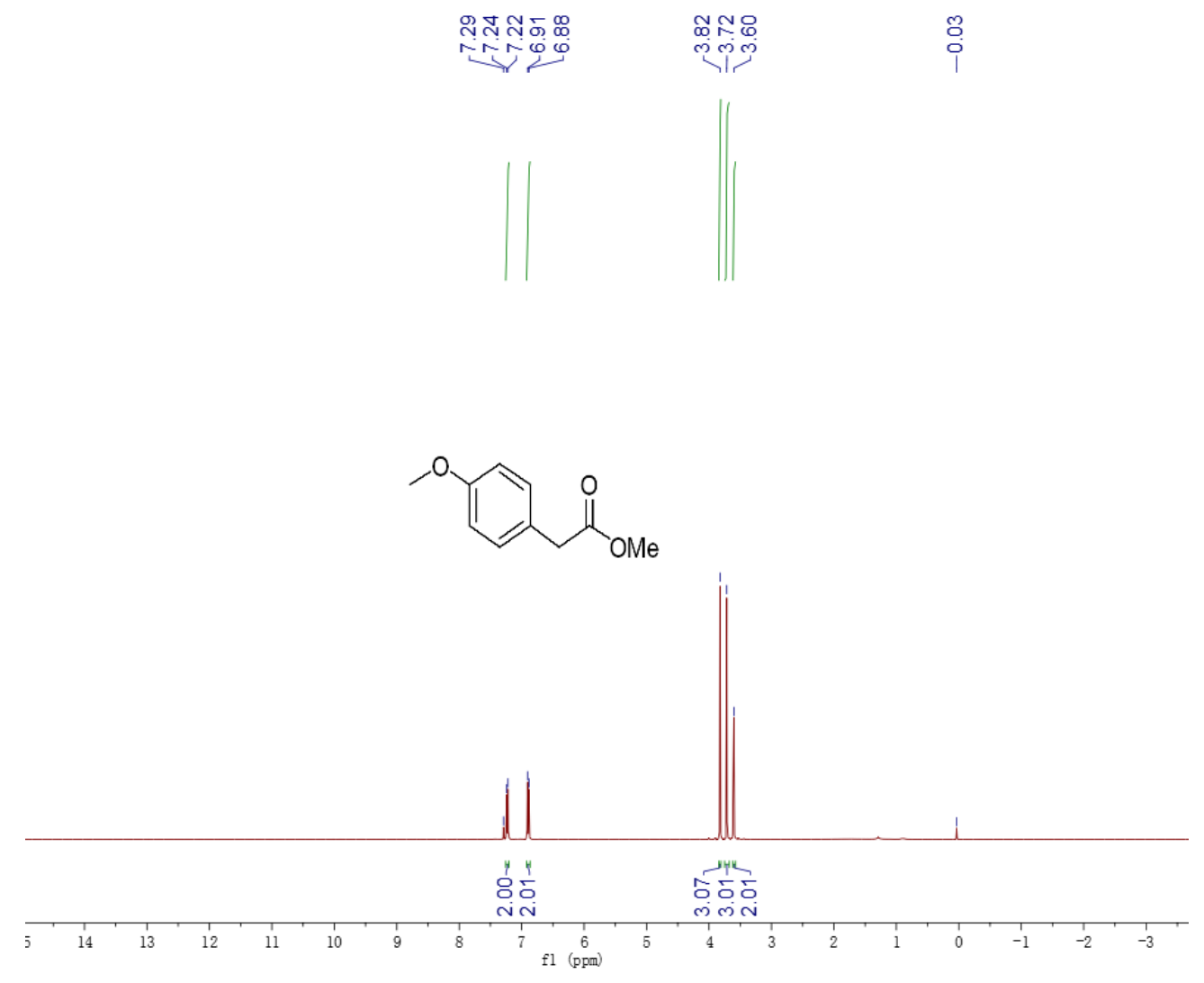

${ }^{1} \mathrm{H}$ NMR spectrum of 2
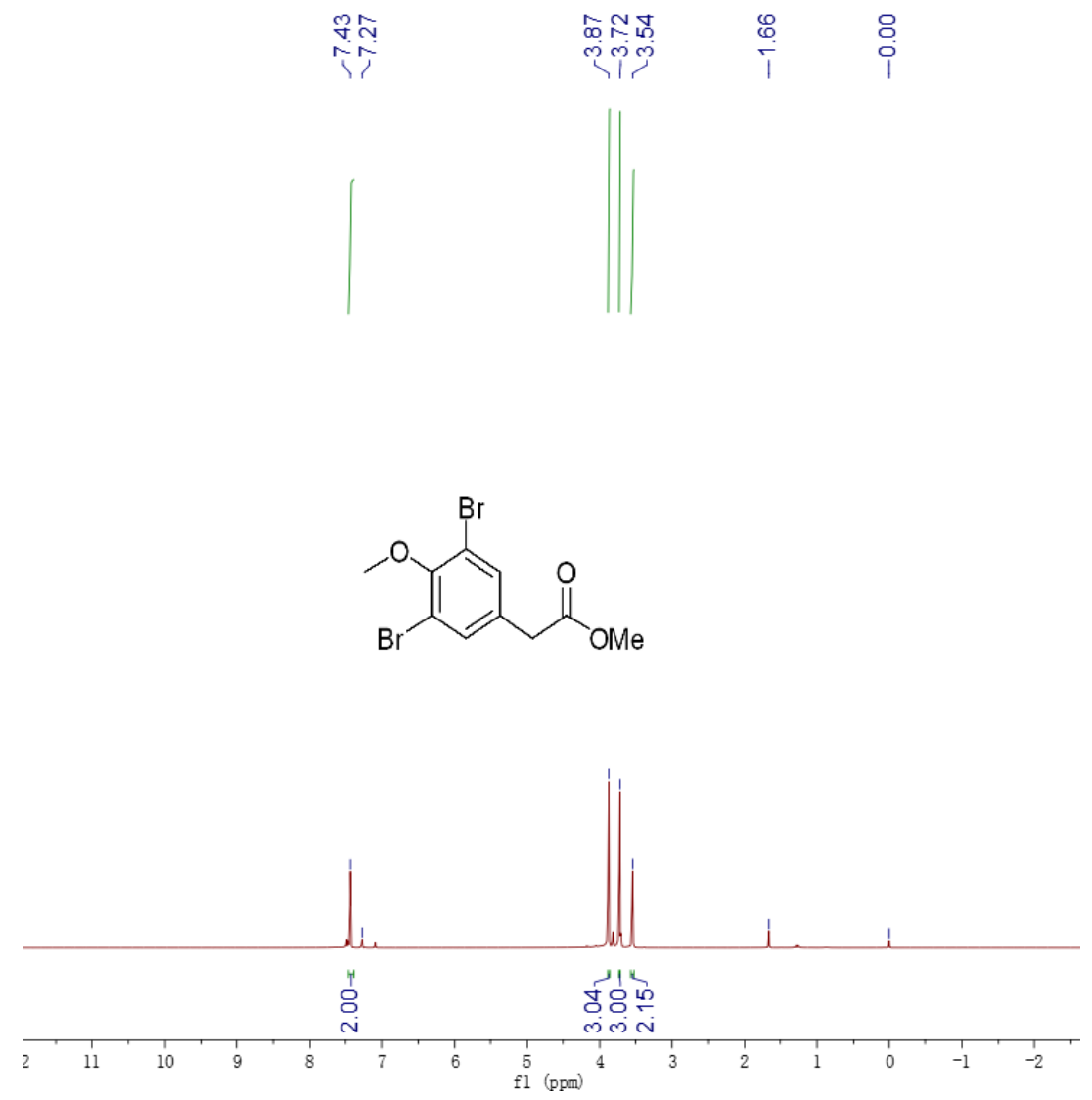

${ }^{1} \mathrm{H}$ NMR spectrum of 3 

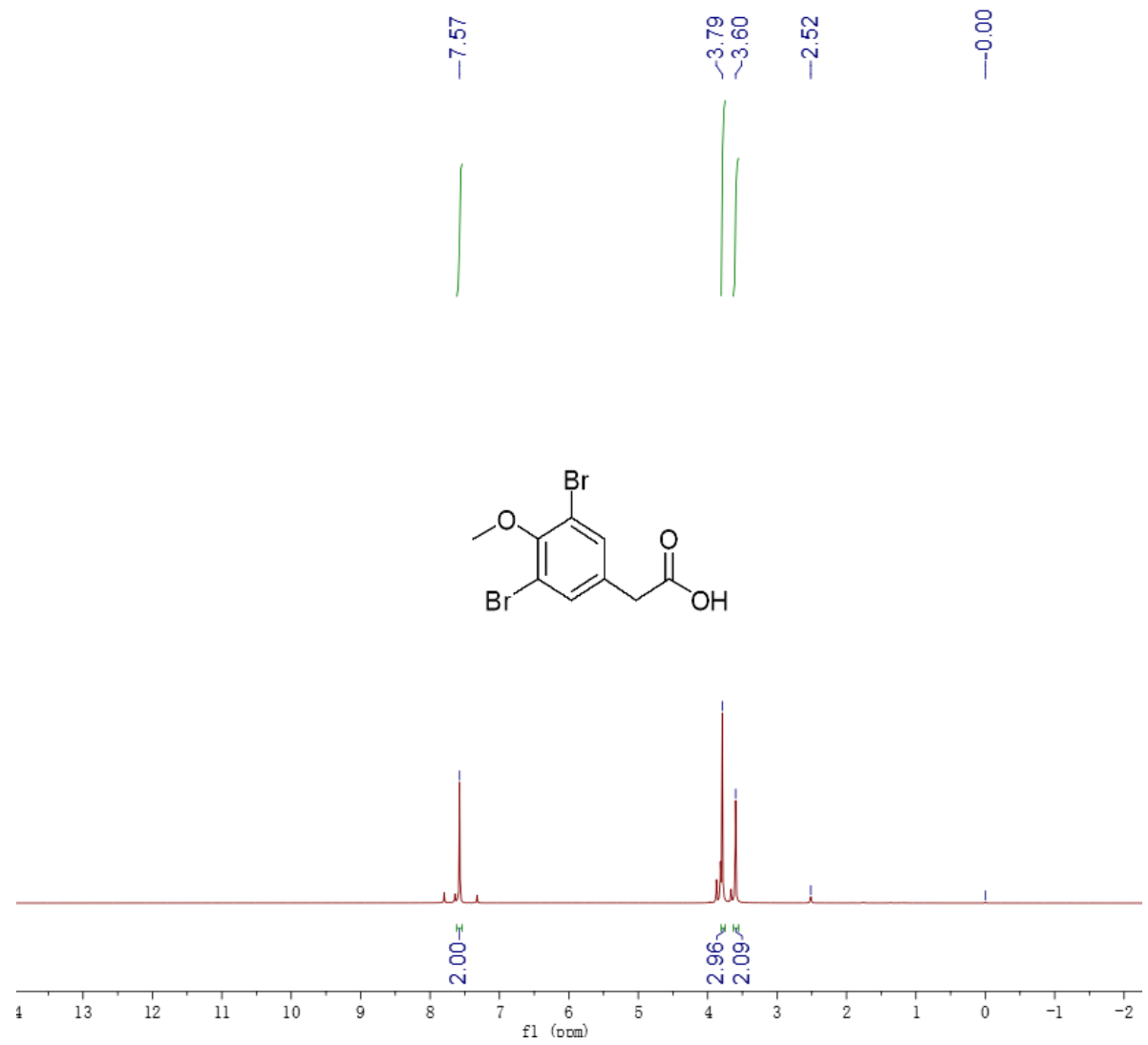

${ }^{1} \mathrm{H}$ NMR spectrum of 4

\begin{tabular}{|c|c|c|c|}
\hline 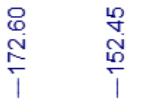 & 离 & 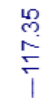 & 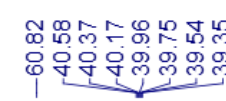 \\
\hline
\end{tabular}<smiles>COc1c(Br)cc(CC(=O)O)cc1Br</smiles>

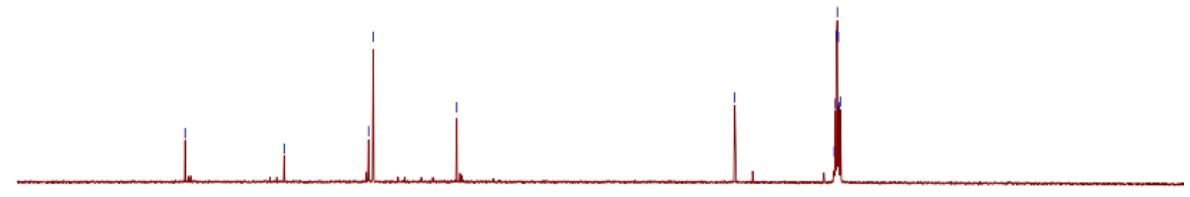

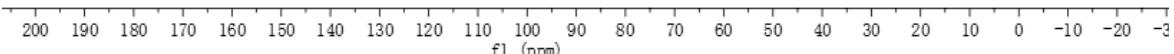

${ }^{13} \mathrm{C}$ NMR spectrum of 4 

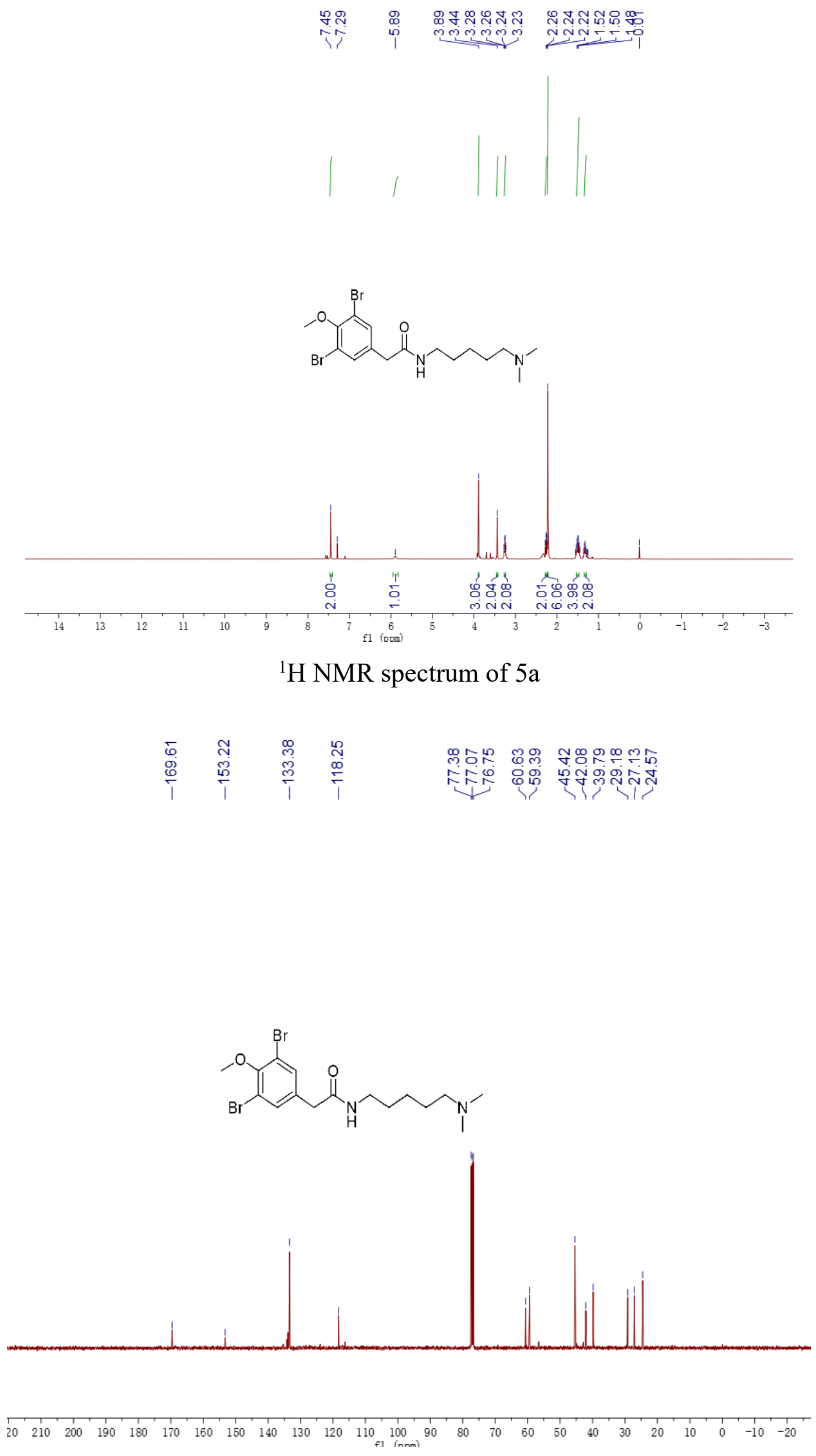

${ }^{13} \mathrm{C}$ NMR spectrum of $5 \mathrm{a}$

S29 


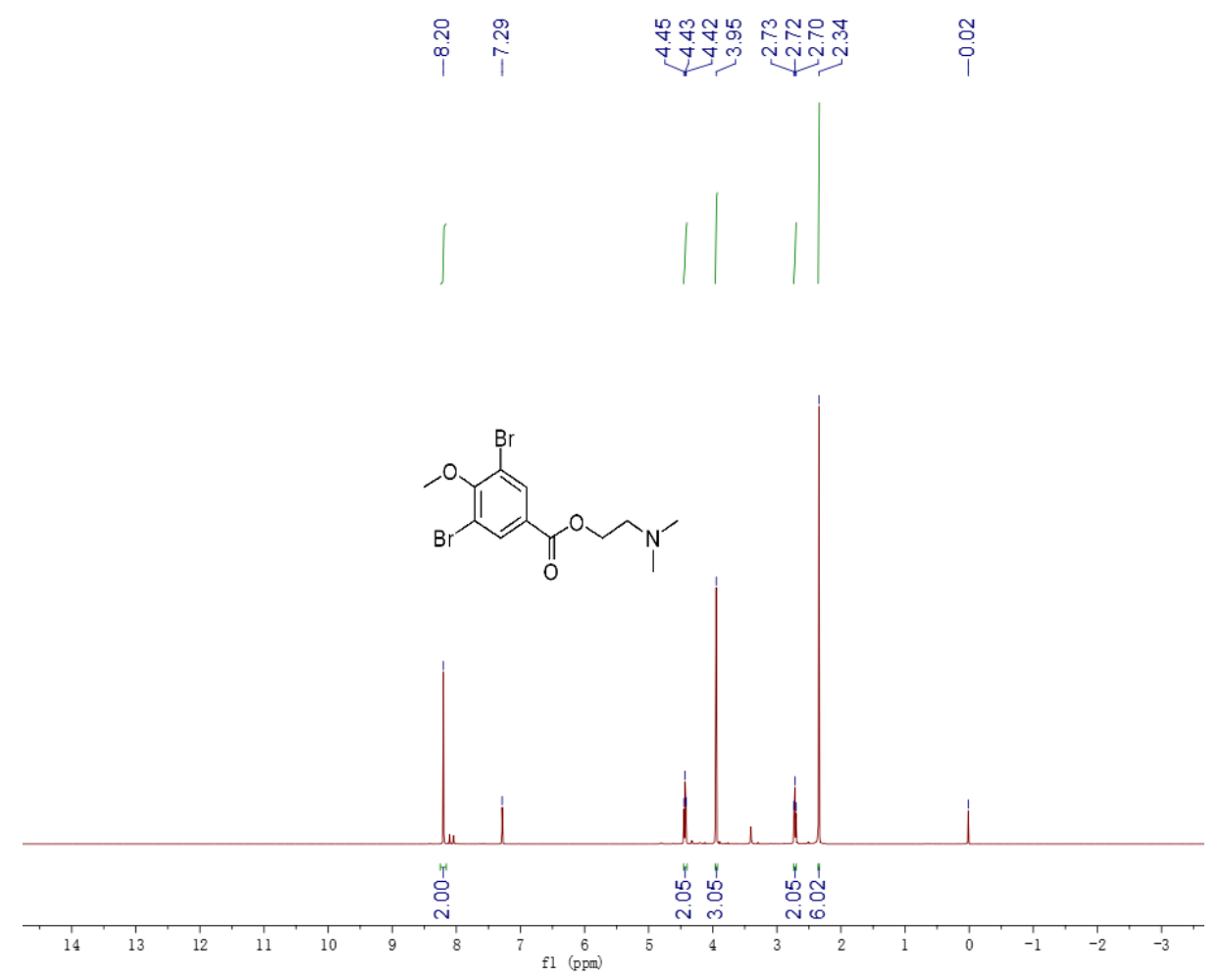

${ }^{1} \mathrm{H}$ NMR spectrum of $5 b$

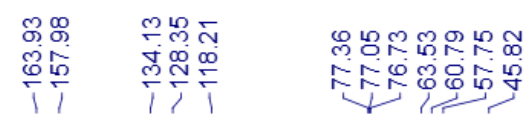<smiles>COc1c(Br)cc(C(=O)OCCN(C)C)cc1Br</smiles>
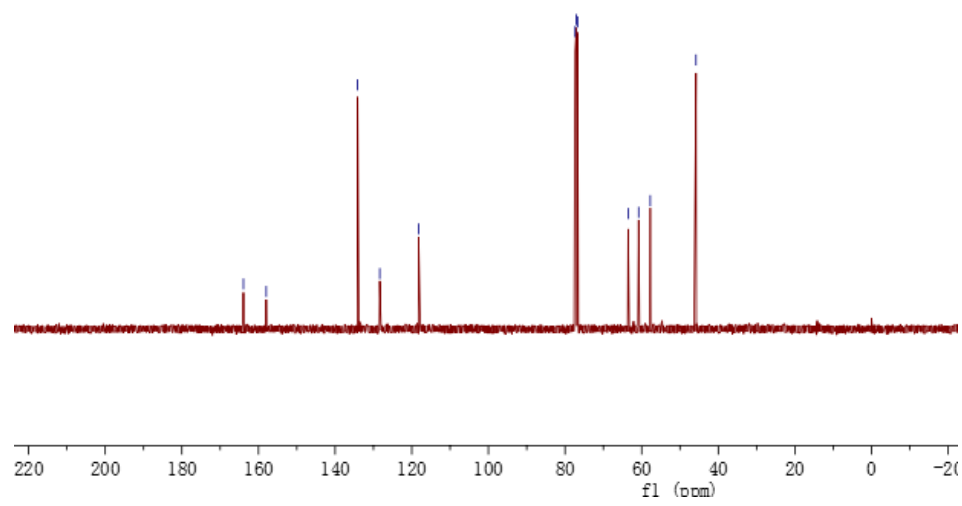

${ }^{13} \mathrm{C}$ NMR spectrum of $5 \mathrm{~b}$ 
i)<smiles>CN(C)CCOC(=O)c1cc(Br)c(O)c(Br)c1</smiles>

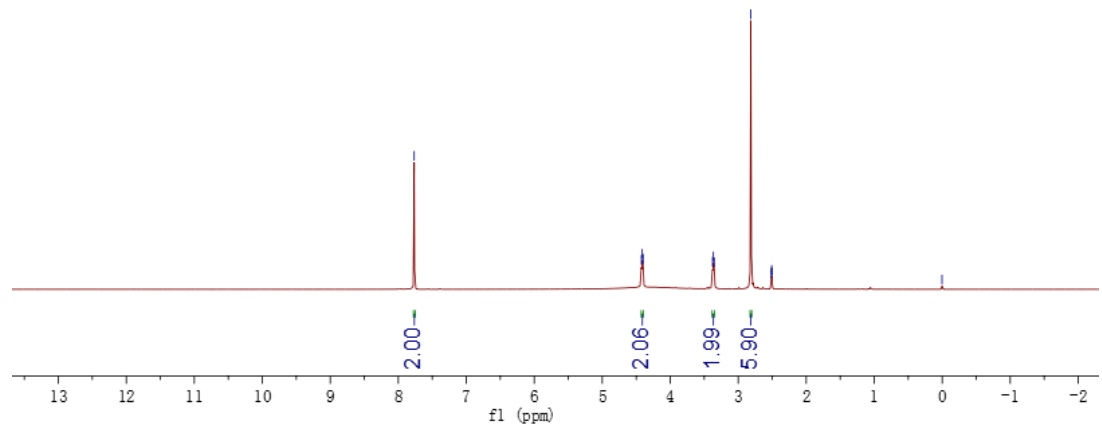

${ }^{1} \mathrm{H}$ NMR spectrum of $5 \mathrm{c}$

V)<smiles>CN(C)CCOC(=O)c1cc(Br)c(O)c(Br)c1</smiles>
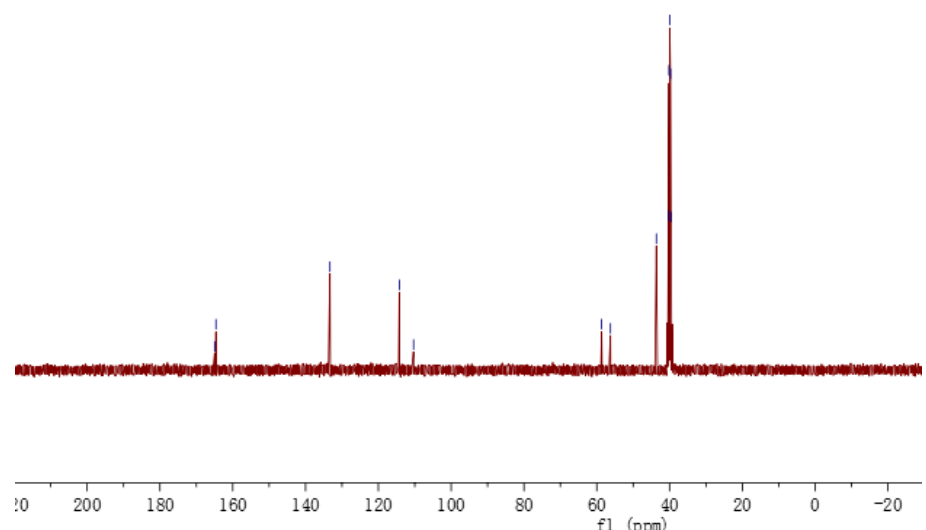

${ }^{13} \mathrm{C}$ NMR spectrum of $5 \mathrm{c}$ 


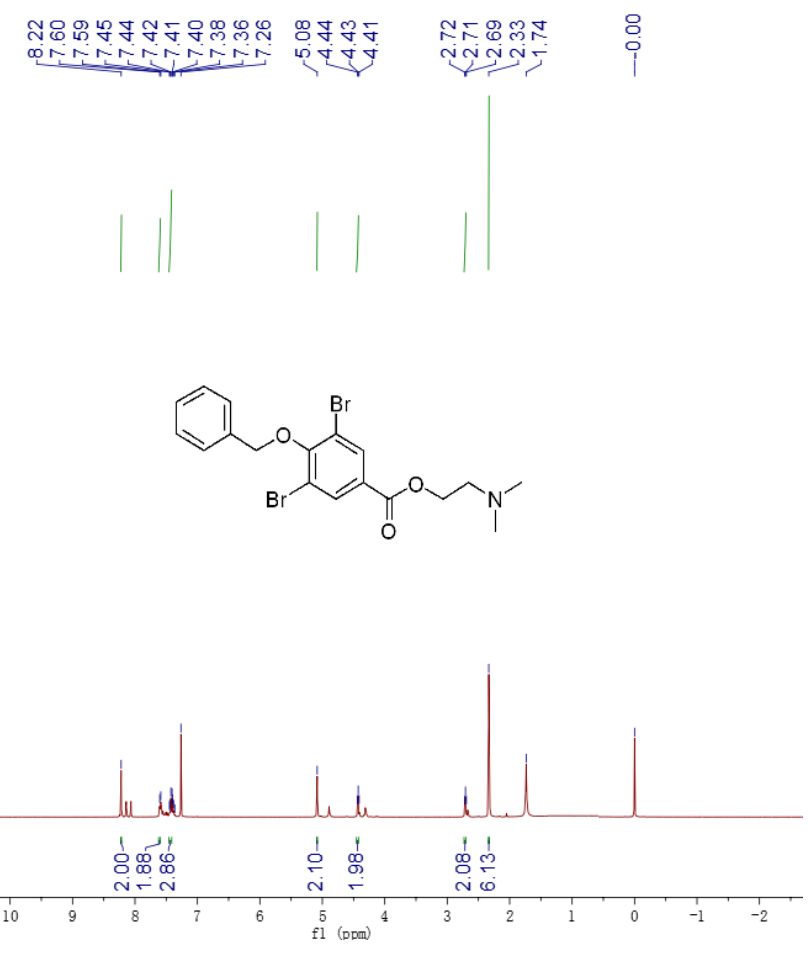

${ }^{1} \mathrm{H}$ NMR spectrum of $5 \mathrm{~d}$
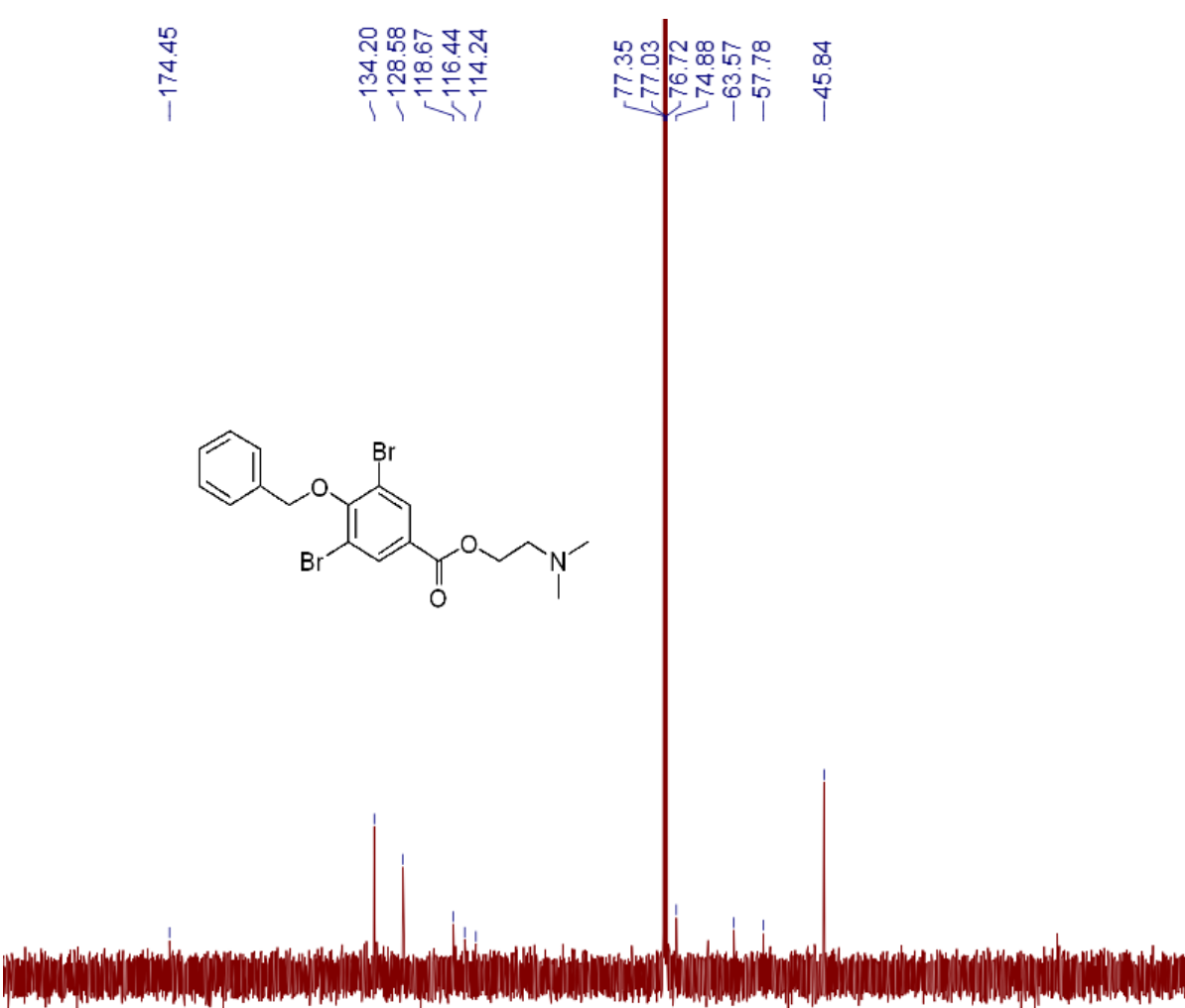

$\begin{array}{lllllllllllllllllllllll}200 & 190 & 180 & 170 & 160 & 150 & 140 & 130 & 120 & 110 & 100 & 90 & 80 & 70 & 60 & 50 & 40 & 30 & 20 & 10 & 0 & -10 & -20\end{array}$

${ }^{13} \mathrm{C}$ NMR spectrum of $5 \mathrm{~d}$ 
o

$\mid$ | || $\mid$<smiles>C=CCOc1c(Br)cc(C(=O)OCCN(C)C)cc1Br</smiles>

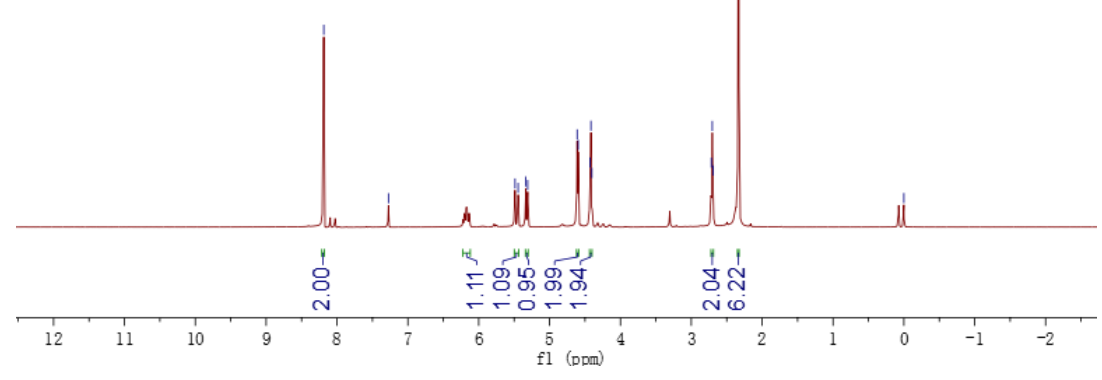

${ }^{1} \mathrm{H}$ NMR spectrum of $5 \mathrm{e}$

మ⿻

@i

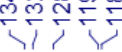

ल

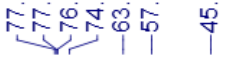
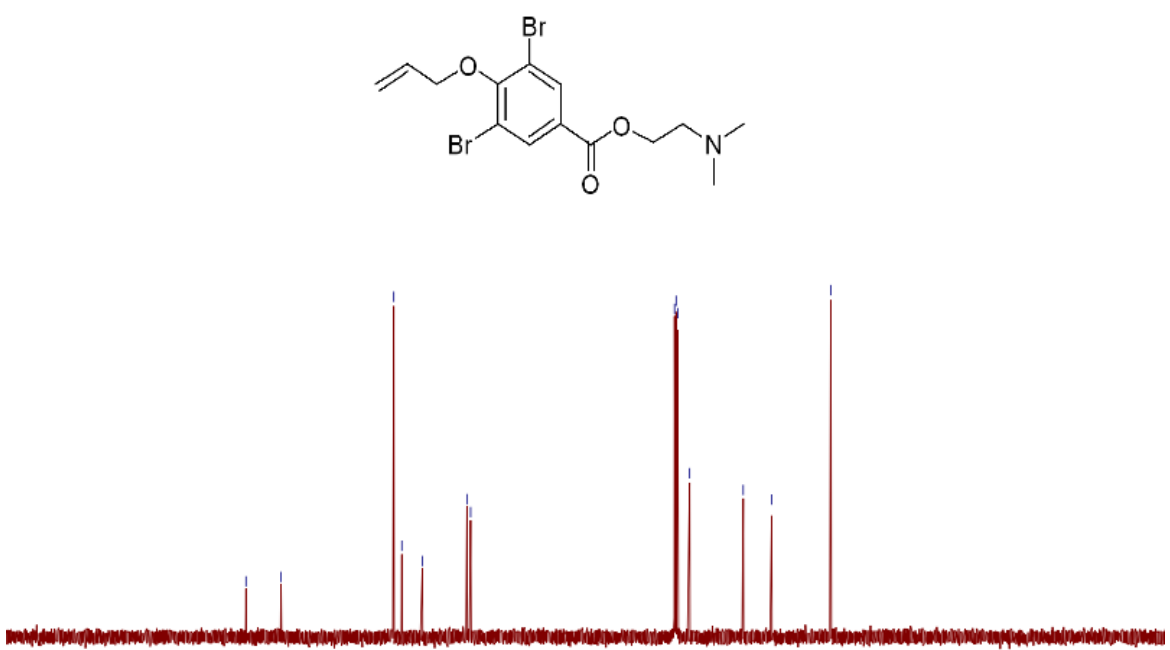

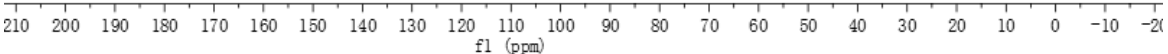

${ }^{13} \mathrm{C}$ NMR spectrum of $5 \mathrm{e}$ 

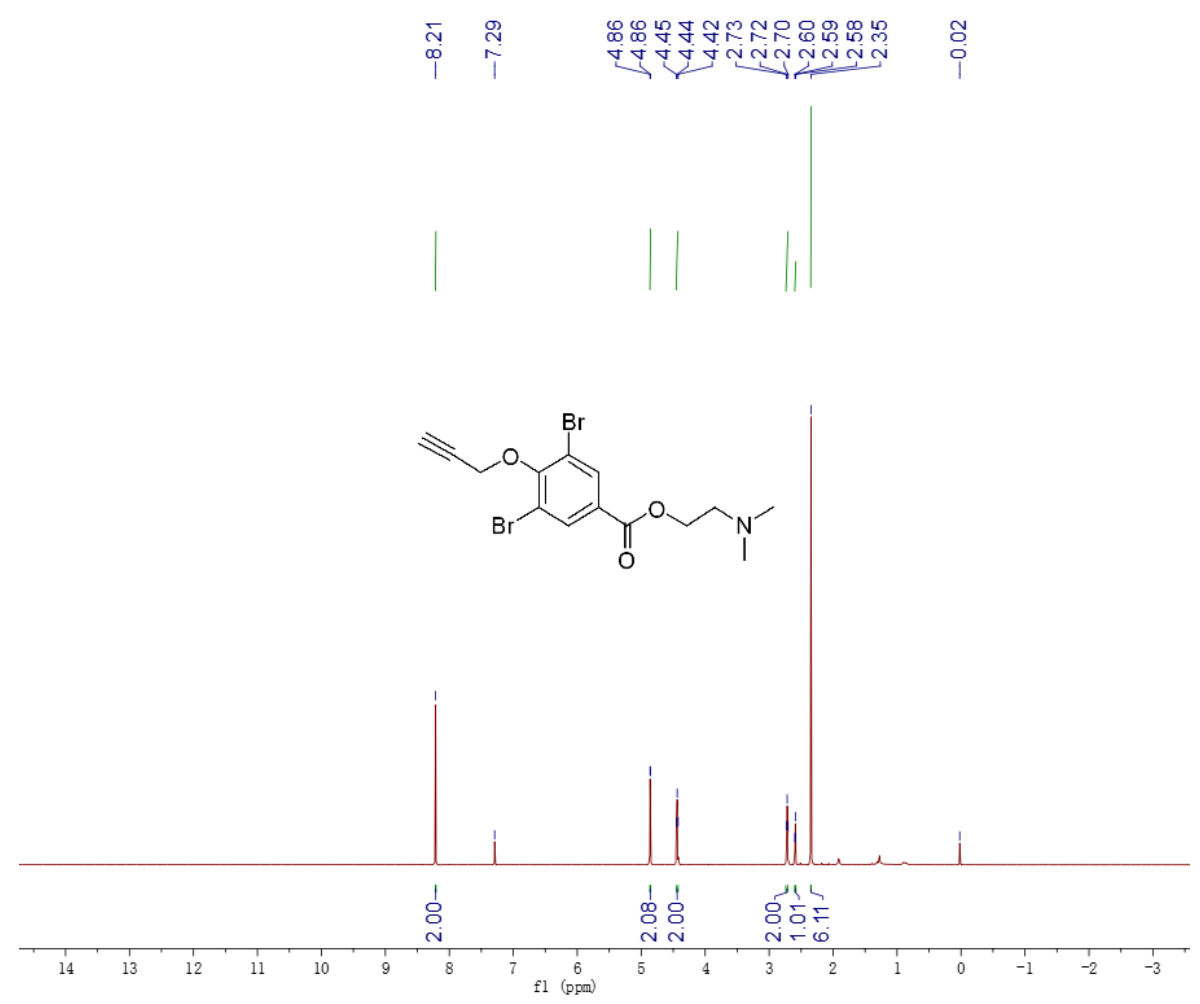

${ }^{1} \mathrm{H}$ NMR spectrum of $5 \mathrm{f}$

\begin{tabular}{|c|c|c|}
\hline 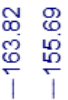 & 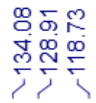 & 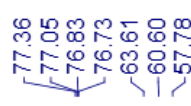 \\
\hline
\end{tabular}

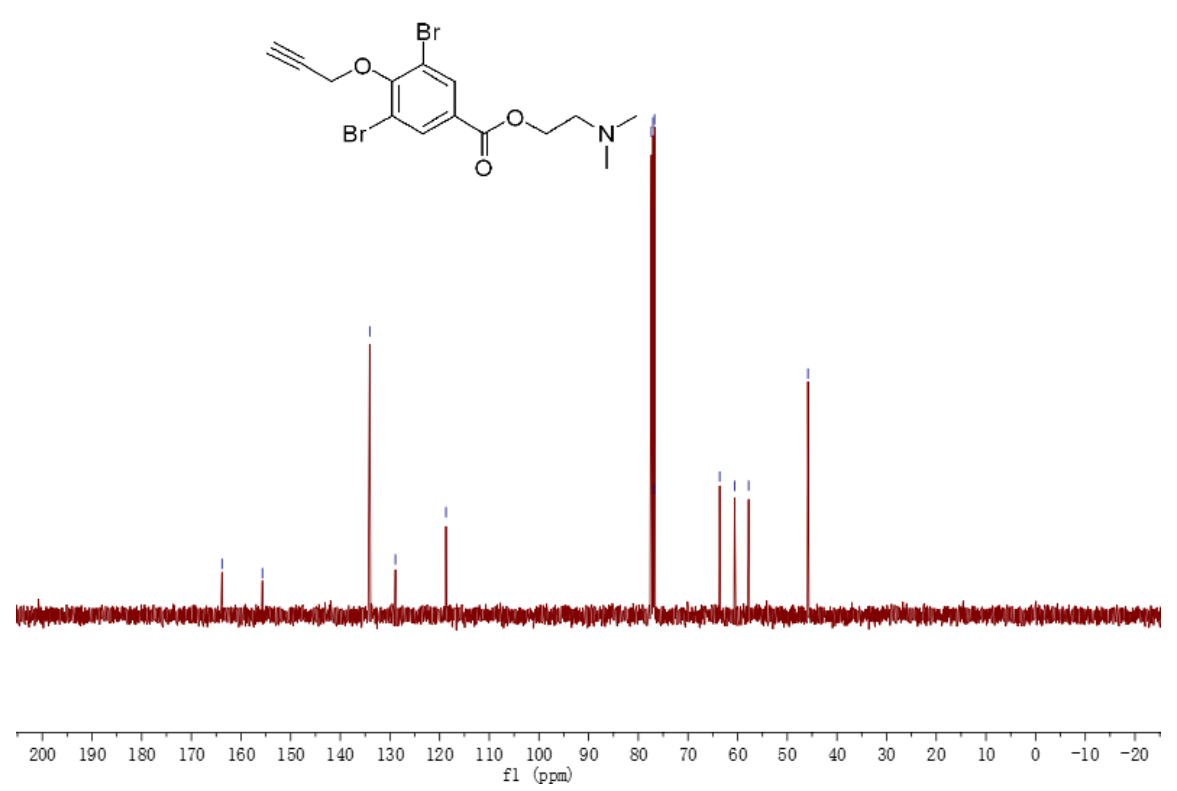

${ }^{13} \mathrm{C}$ NMR spectrum of $5 \mathrm{f}$ 


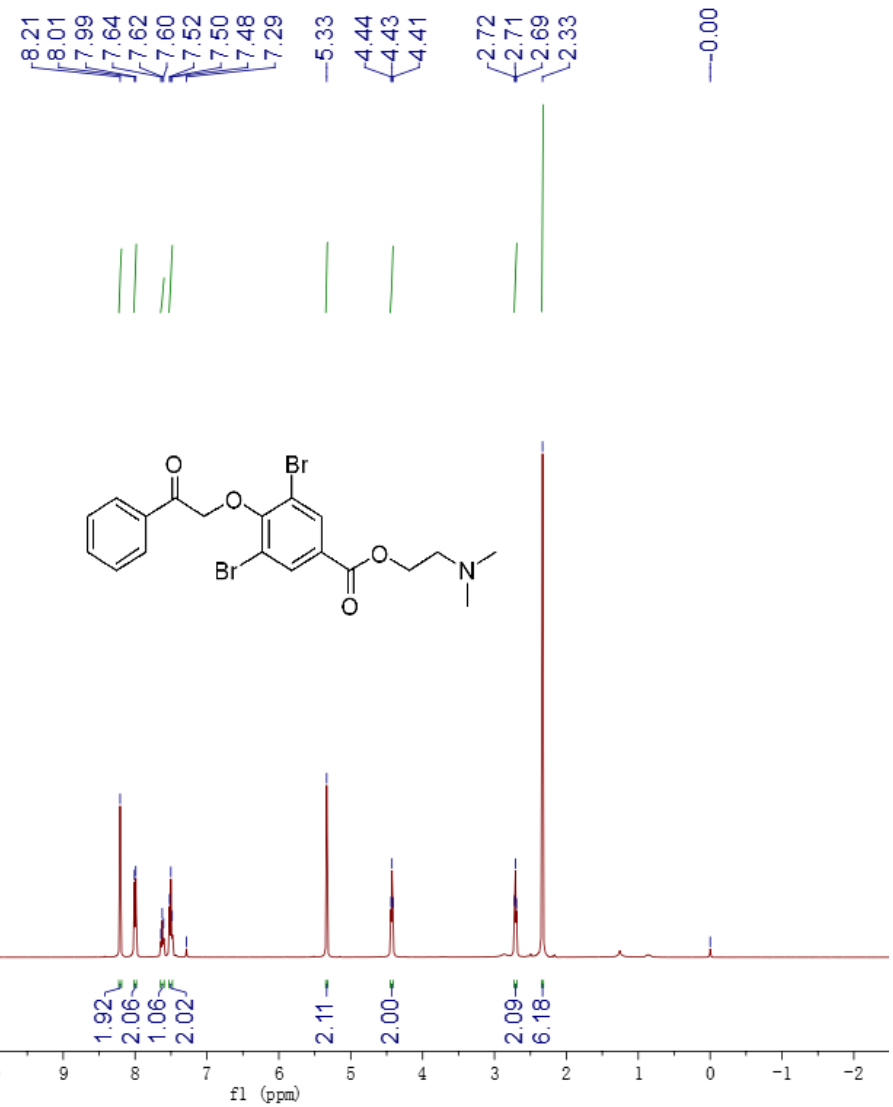

${ }^{1} \mathrm{H}$ NMR spectrum of $5 \mathrm{~g}$
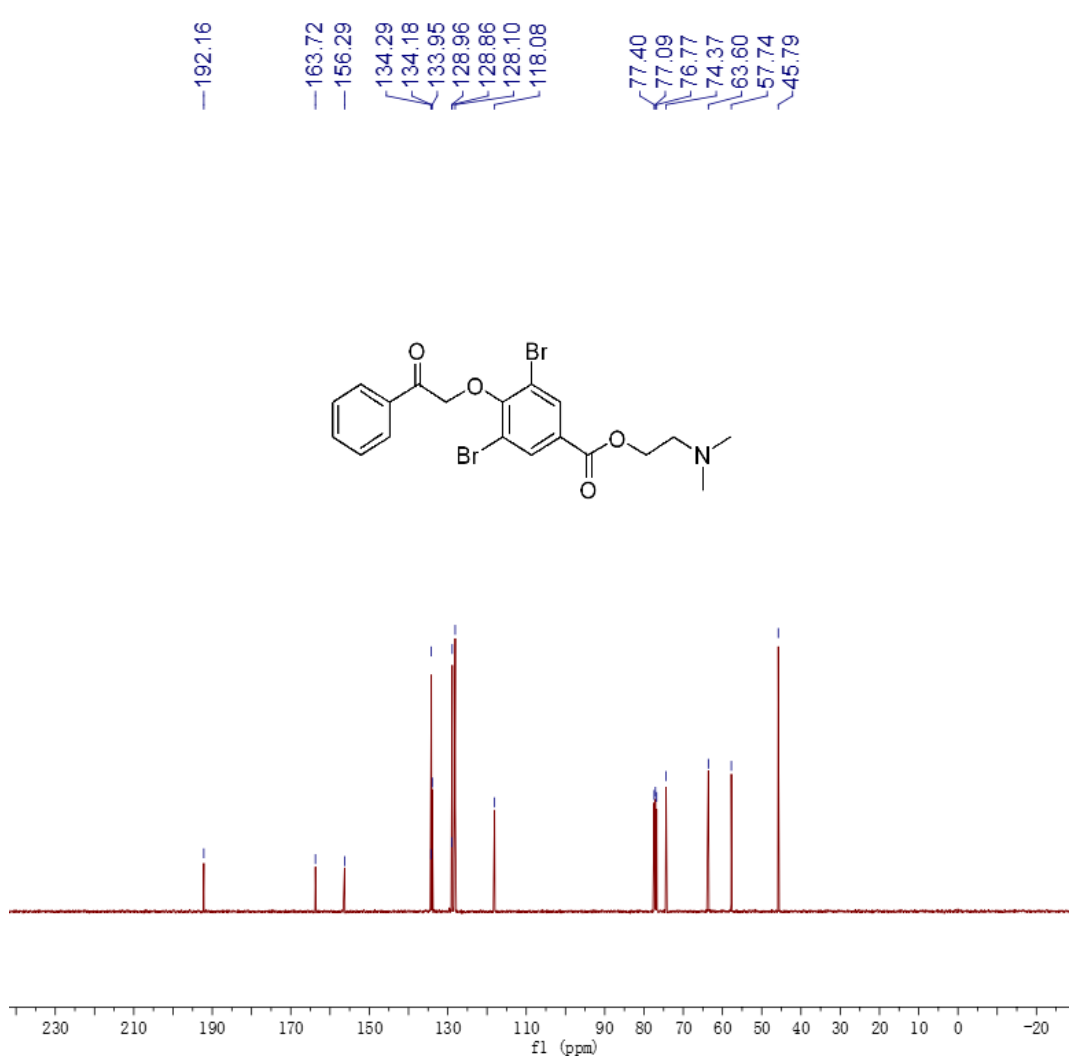

${ }^{13} \mathrm{C}$ NMR spectrum of $5 \mathrm{~g}$ 

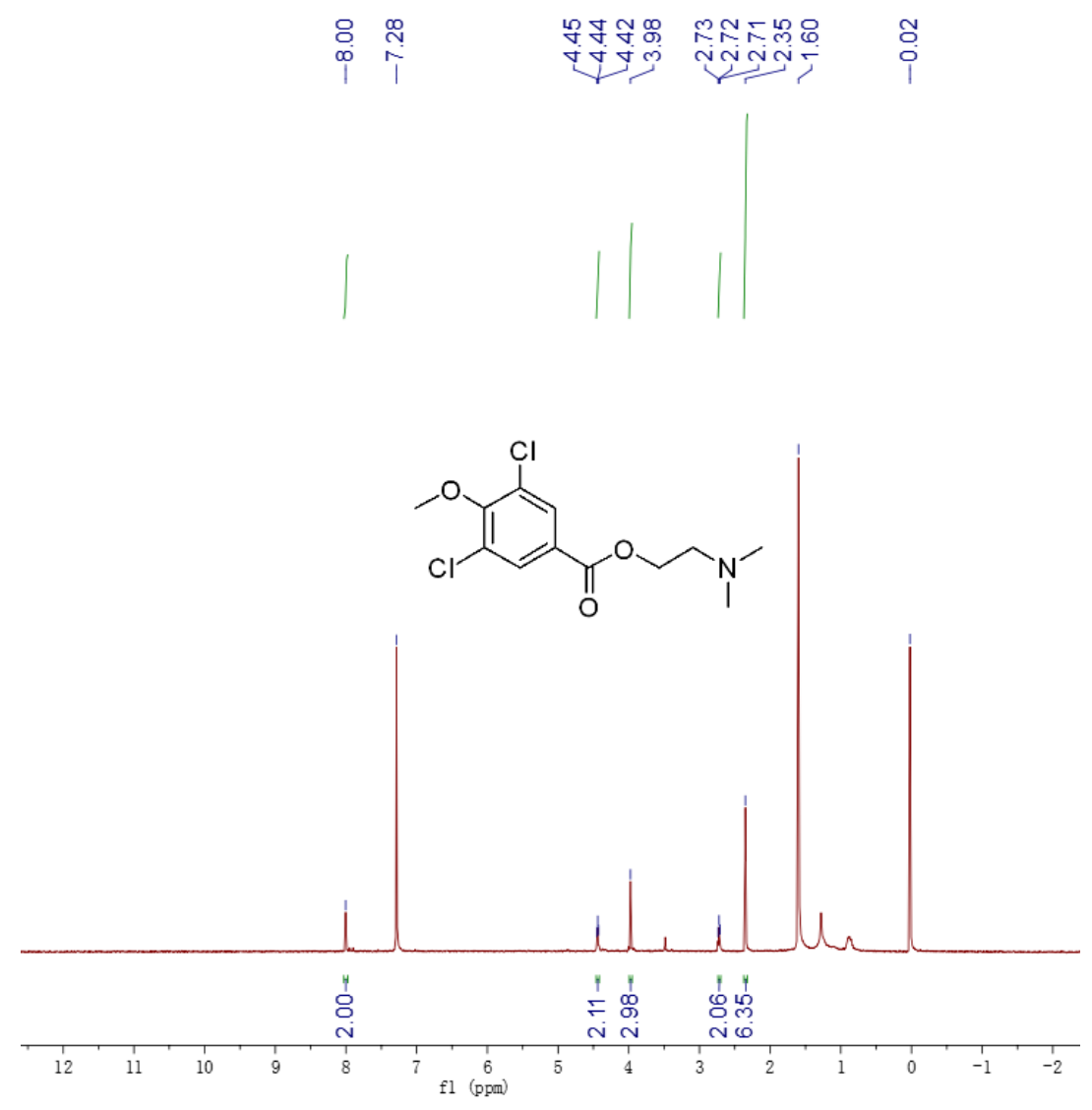

${ }^{1} \mathrm{H}$ NMR spectrum of $5 \mathrm{~h}$
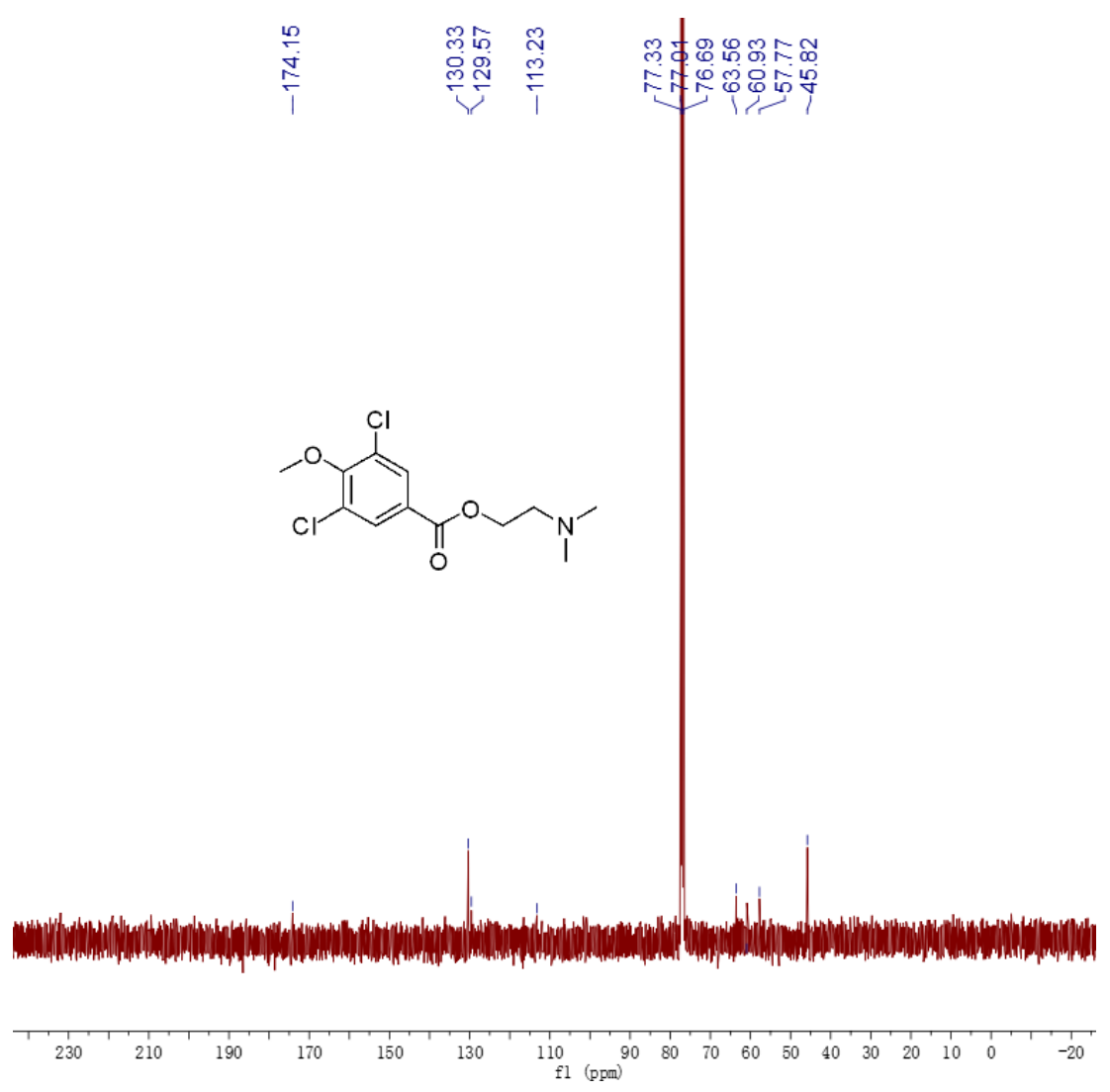

${ }^{13} \mathrm{C}$ NMR spectrum of $5 \mathrm{~h}$ 


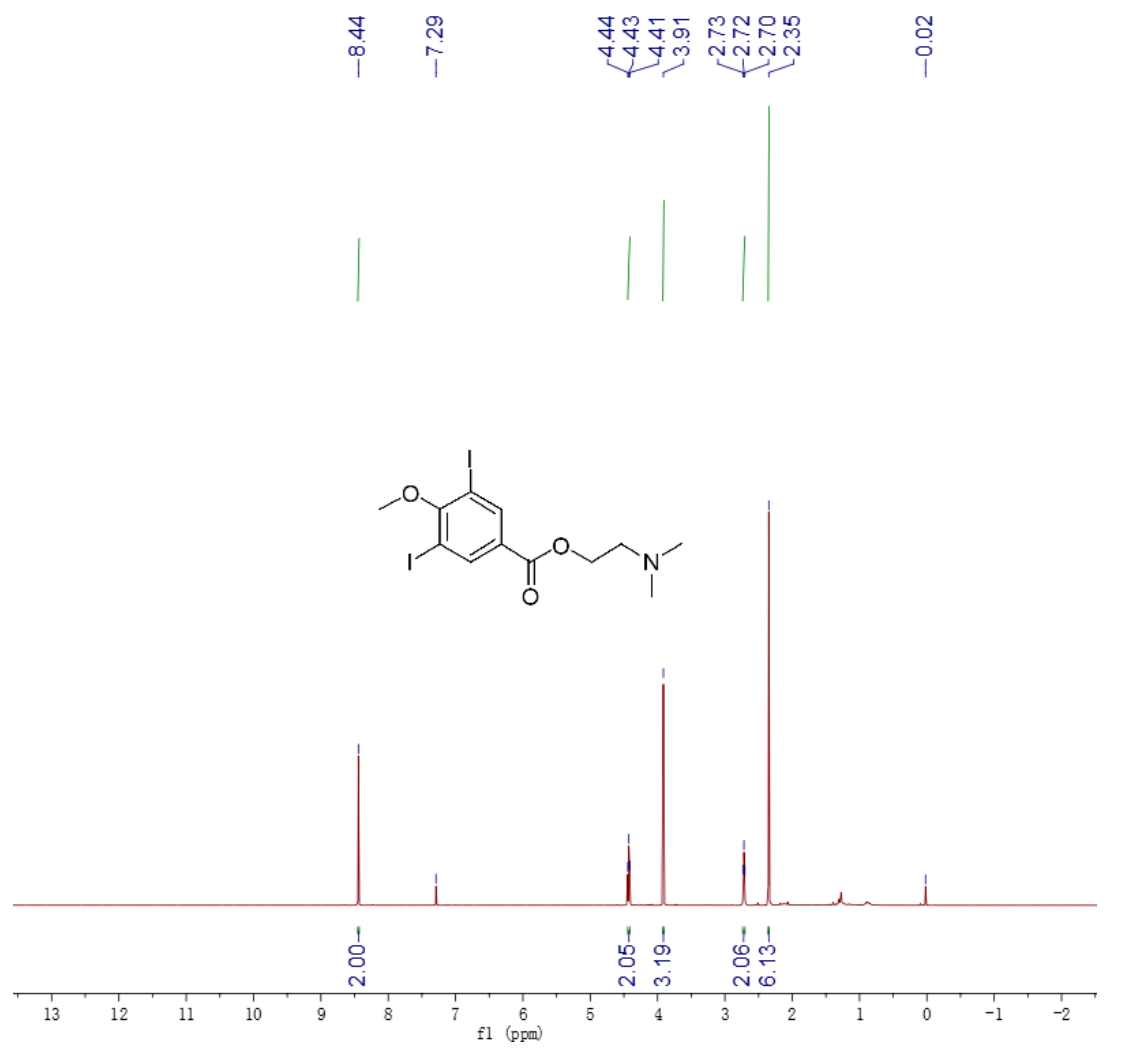

${ }^{1} \mathrm{H}$ NMR spectrum of $5 \mathrm{i}$

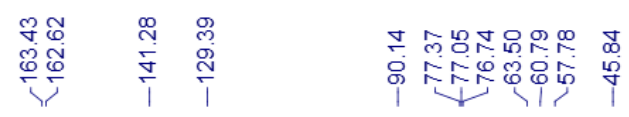<smiles>COc1c(I)cc(C(=O)OCCN(C)C)cc1I</smiles>

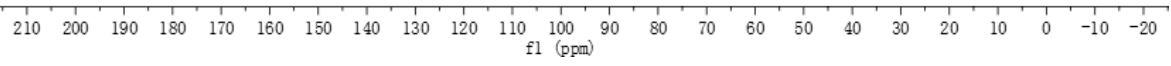

${ }^{13} \mathrm{C}$ NMR spectrum of $5 \mathrm{i}$ 


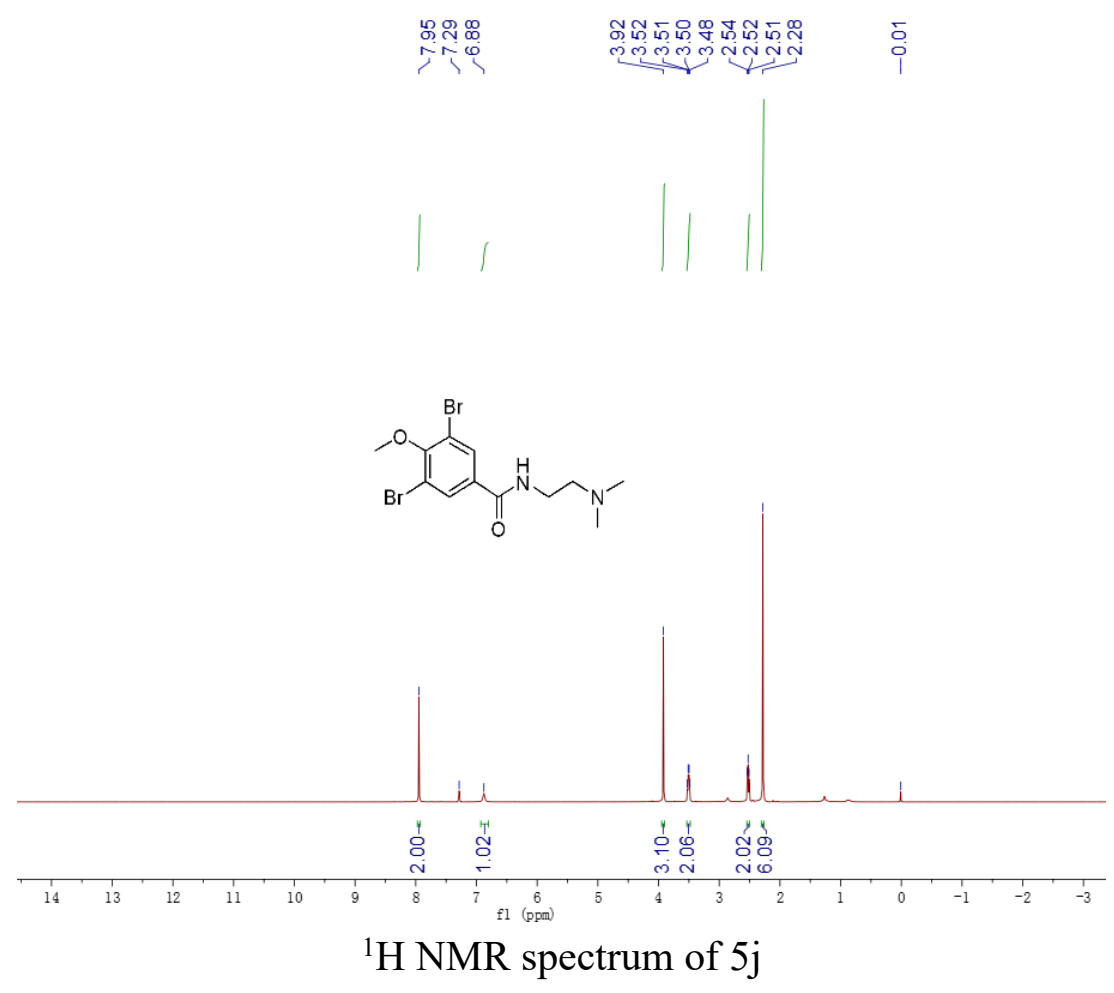

党<smiles>COc1c(Br)cc(C(=O)NCCN(C)C)cc1Br</smiles>
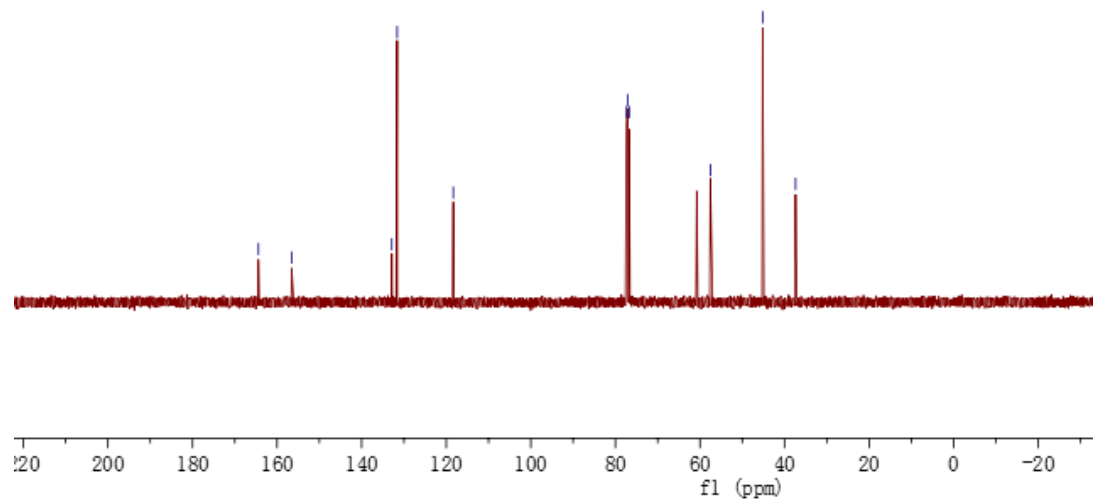

${ }^{13} \mathrm{C}$ NMR spectrum of $5 \mathrm{j}$ 

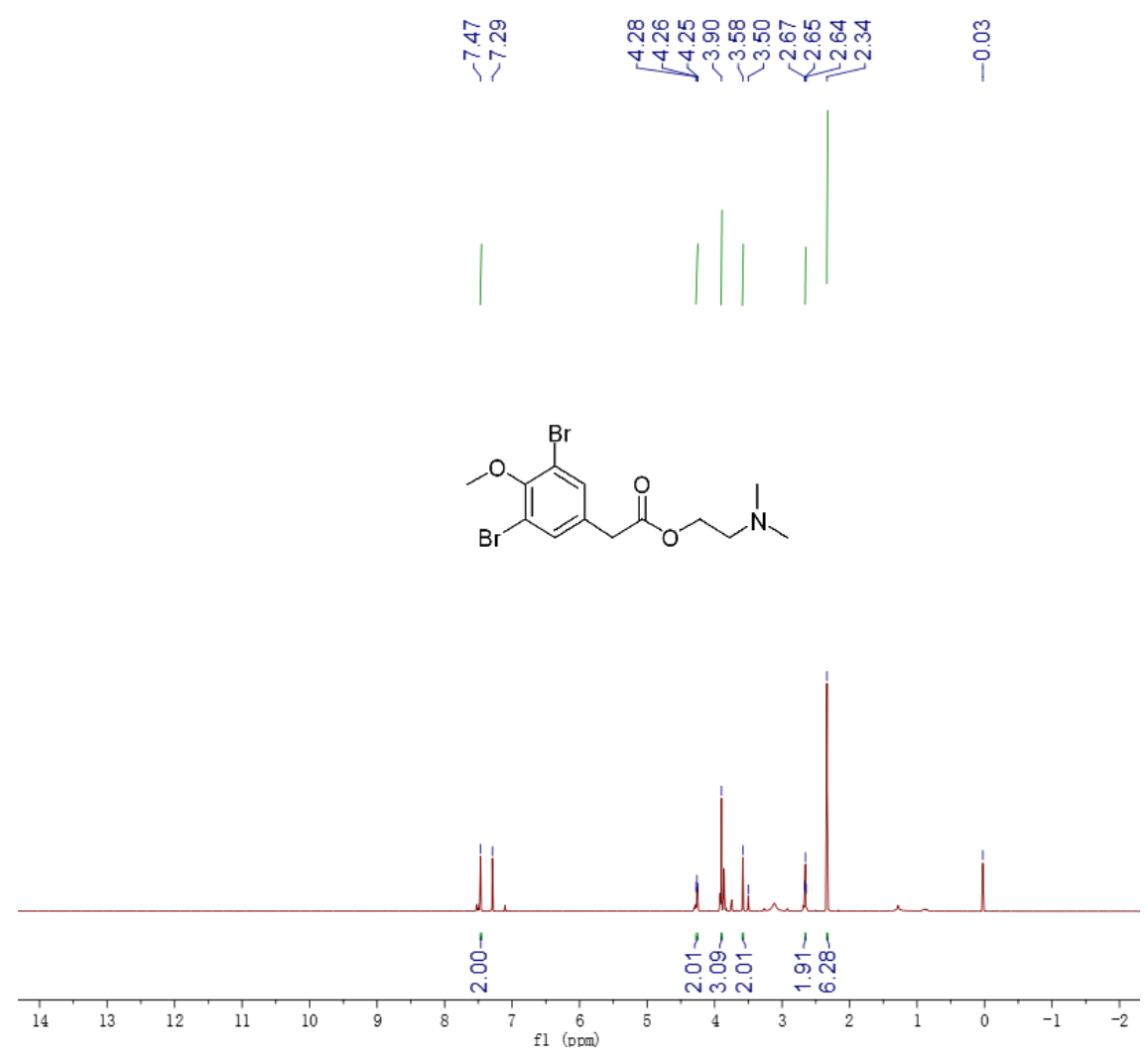

${ }^{1} \mathrm{H}$ NMR spectrum of $5 \mathrm{k}$

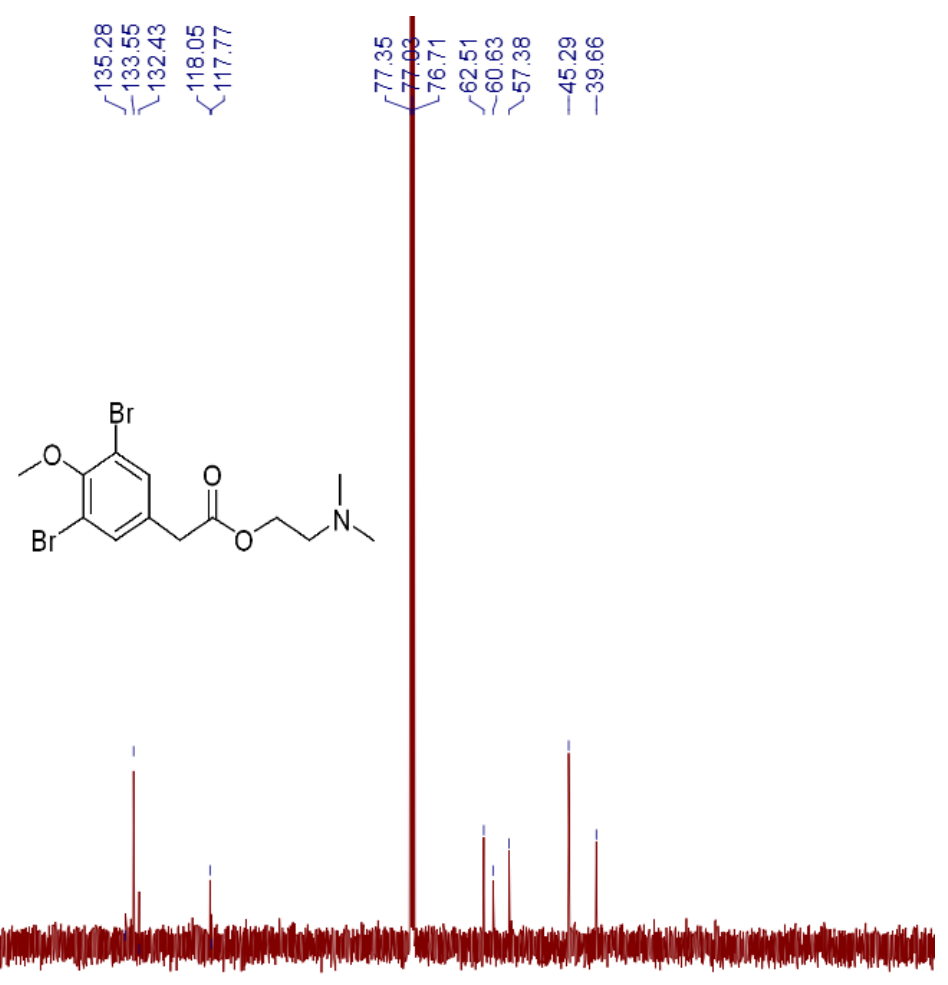

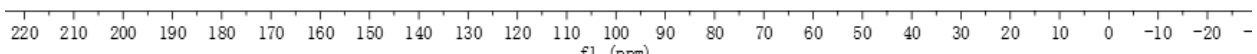
${ }^{13} \mathrm{C}$ NMR spectrum of $5 \mathrm{k}$ 

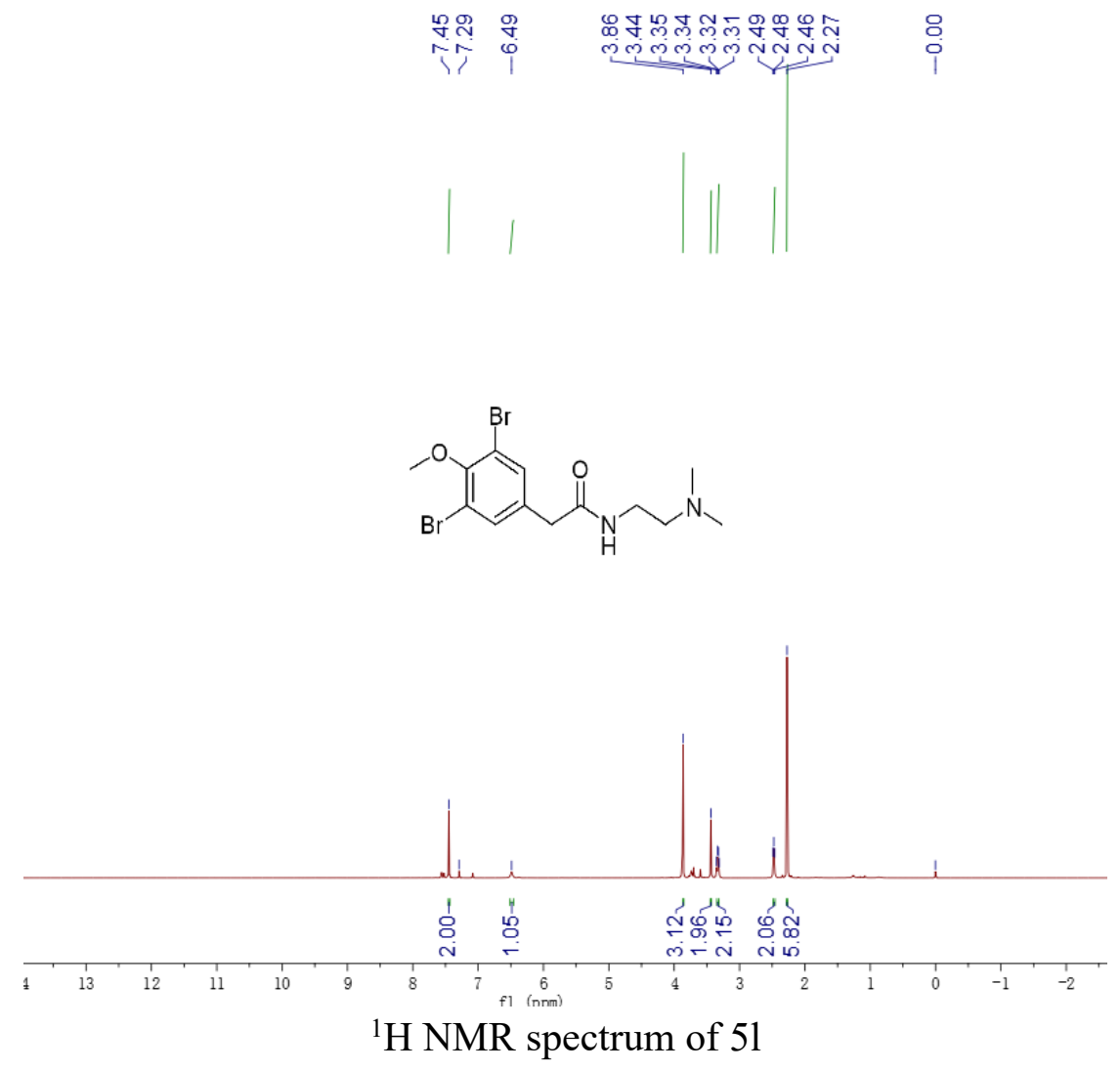

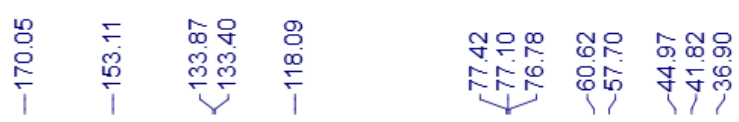<smiles>COc1c(Br)cc(CC(=O)NCCN(C)C)cc1Br</smiles>

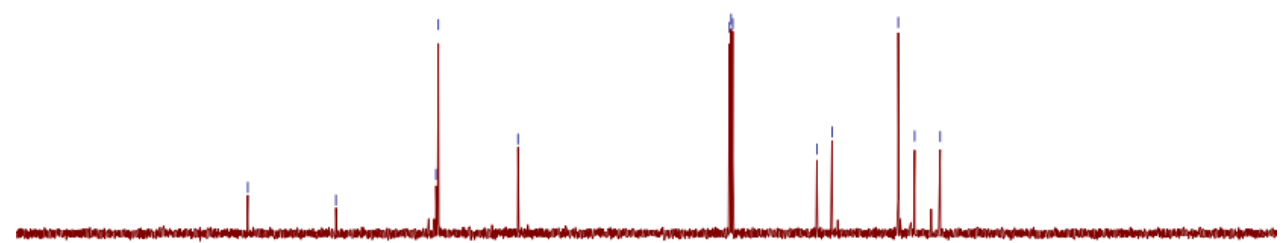

$\begin{array}{lllllllllllllllllllllllllllllllllll}1 & 1 & 200 & 190 & 180 & 170 & 160 & 150 & 140 & 130 & 120 & 110 & 100 & 90 & 80 & 70 & 60 & 50 & 40 & 30 & 20 & 10 & 0 & -10 & -20\end{array}$

${ }^{13} \mathrm{C}$ NMR spectrum of 51 

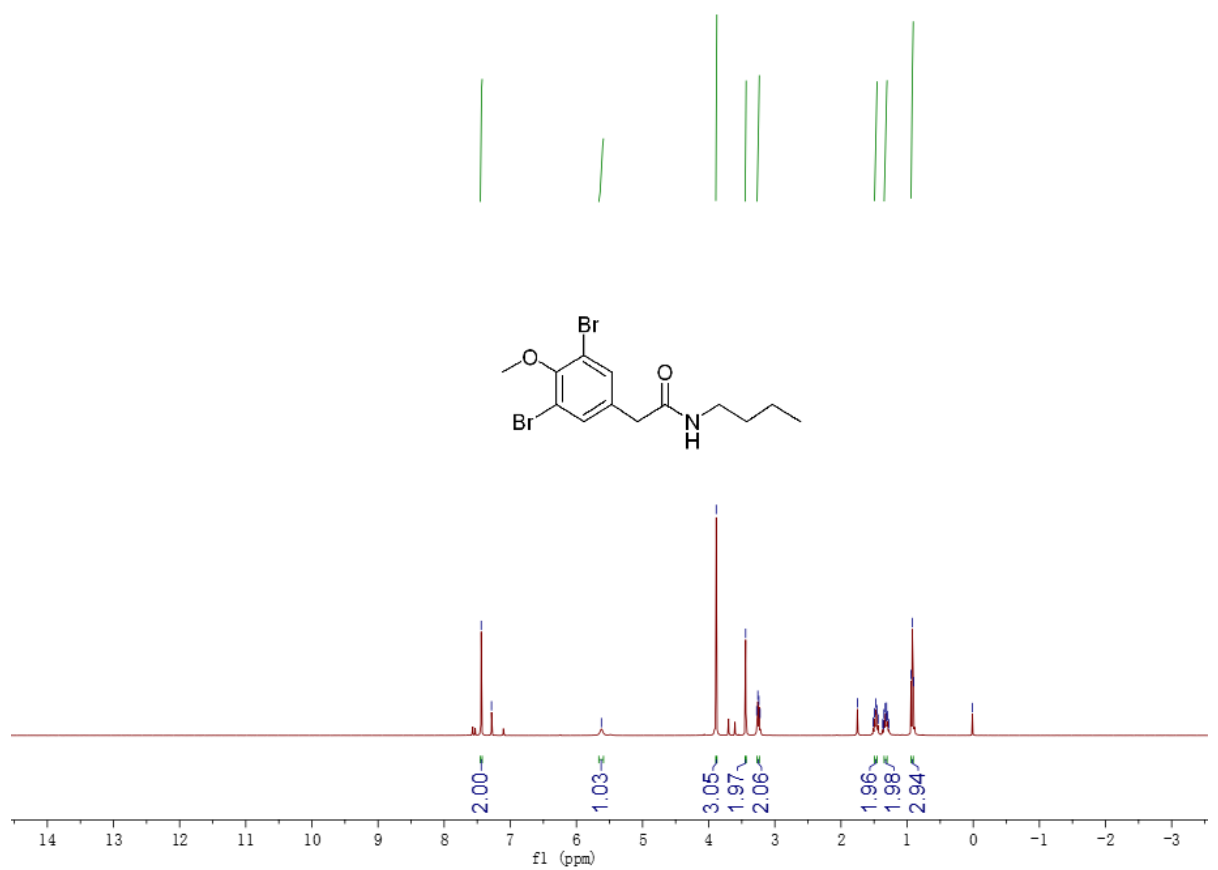

${ }^{1} \mathrm{H}$ NMR spectrum of $5 \mathrm{~m}$

।
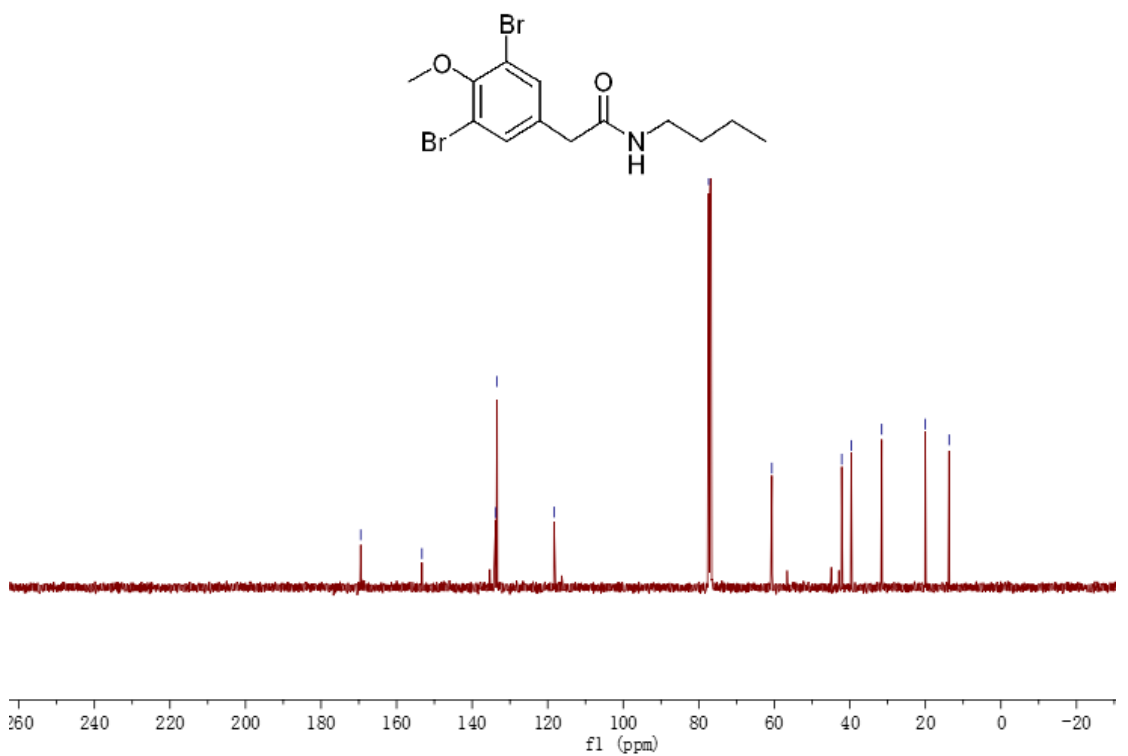

${ }^{13} \mathrm{C}$ NMR spectrum of $5 \mathrm{~m}$ 


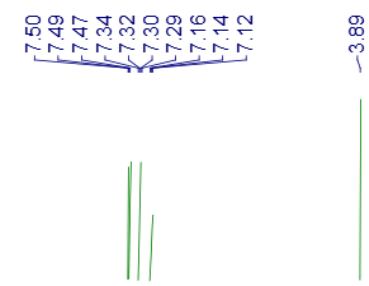

शिं

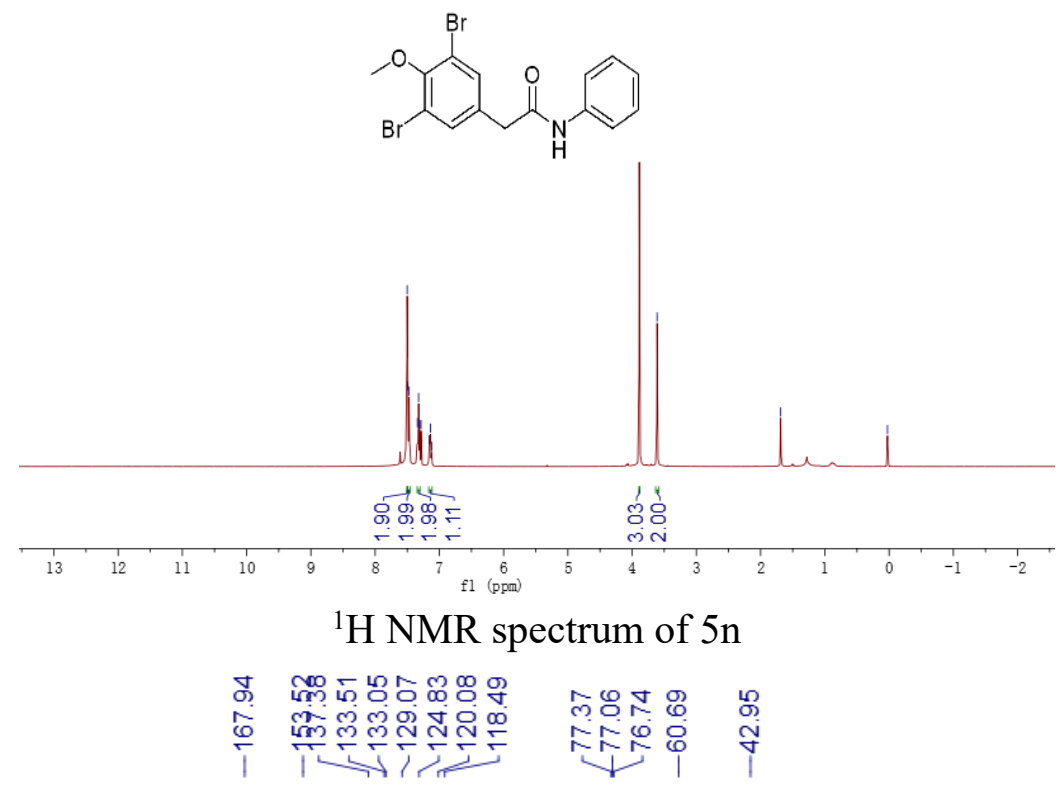<smiles>COc1c(Br)cc(CC(=O)Nc2ccccc2)cc1Br</smiles>
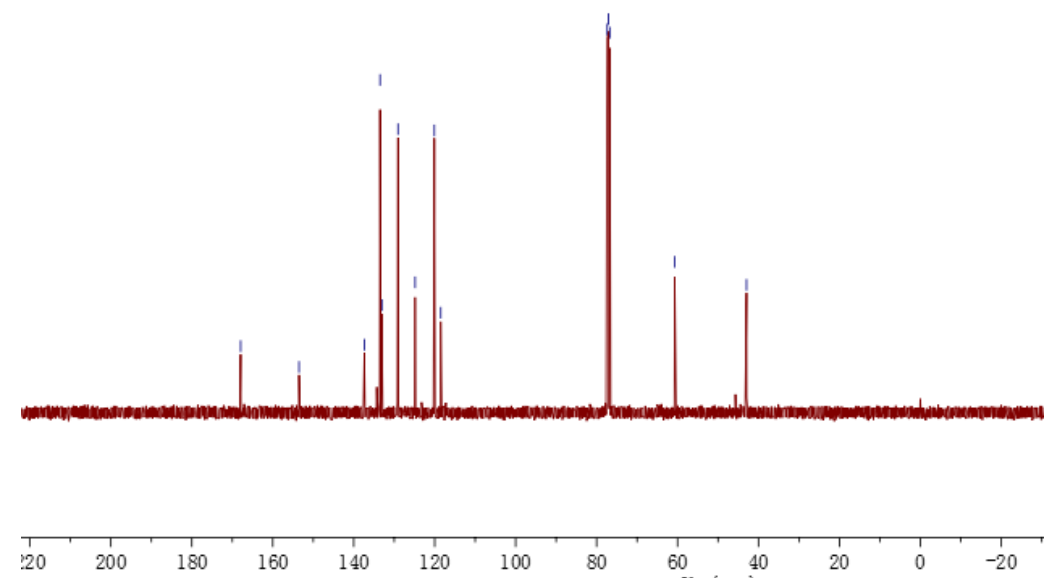


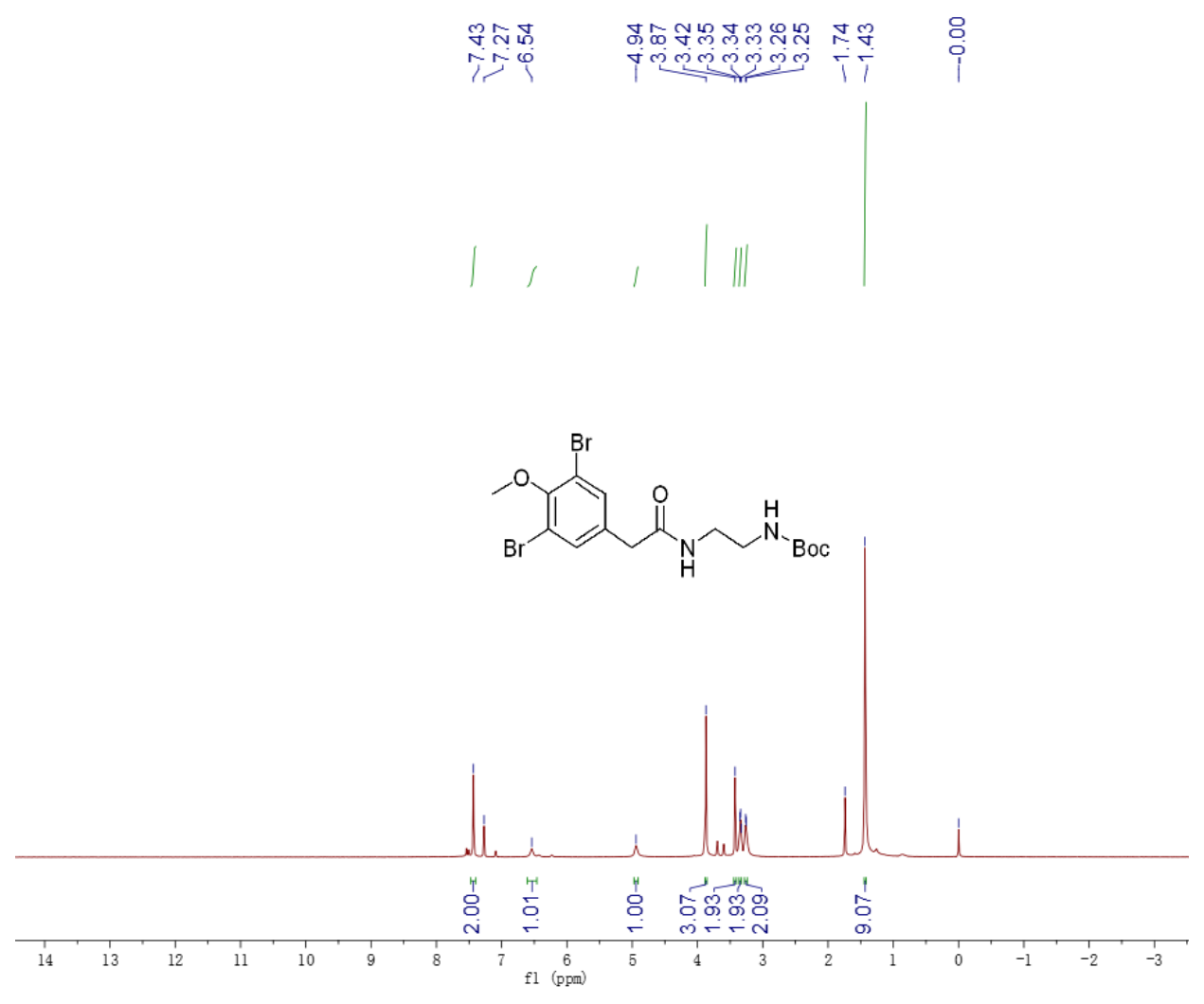

${ }^{1} \mathrm{H}$ NMR spectrum of 50

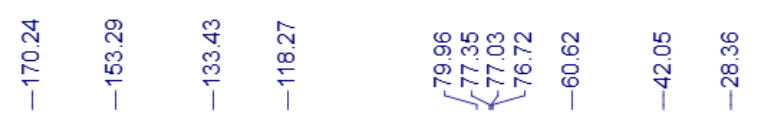

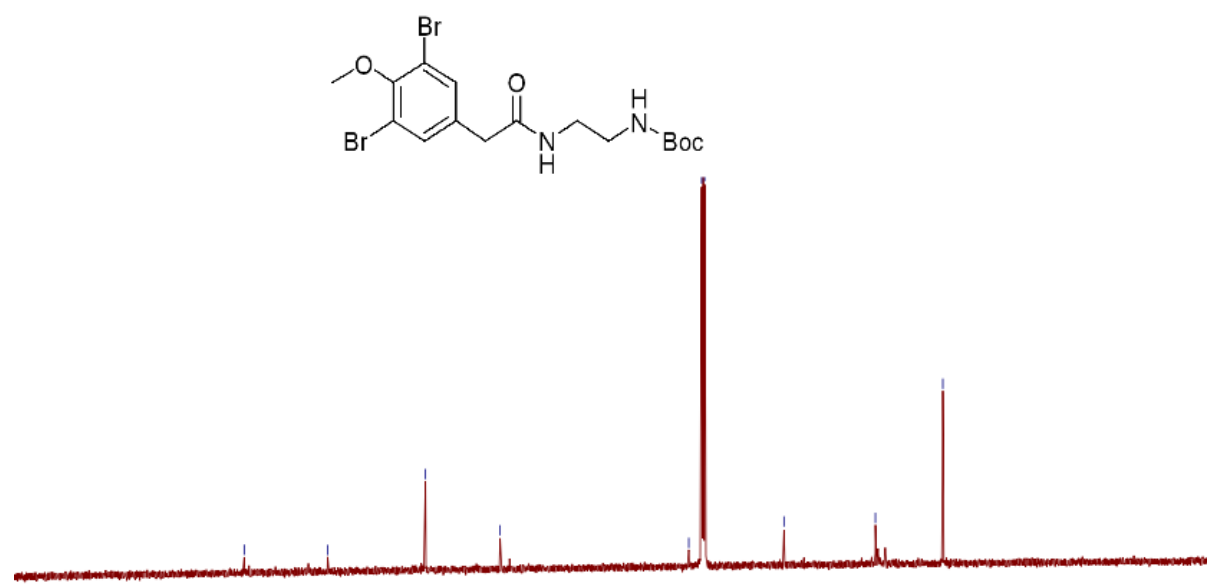

\begin{tabular}{rlllllllllllllllllllllllllllllllllll}
\hline & 1 \\
210 & 200 & 190 & 180 & 170 & 160 & 150 & 140 & 130 & 120 & 110 & 100 & 90 & 80 & 70 & 60 & 50 & 40 & 30 & 20 & 10 & 0 & -10 & -20
\end{tabular}

${ }^{13} \mathrm{C}$ NMR spectrum of 50 

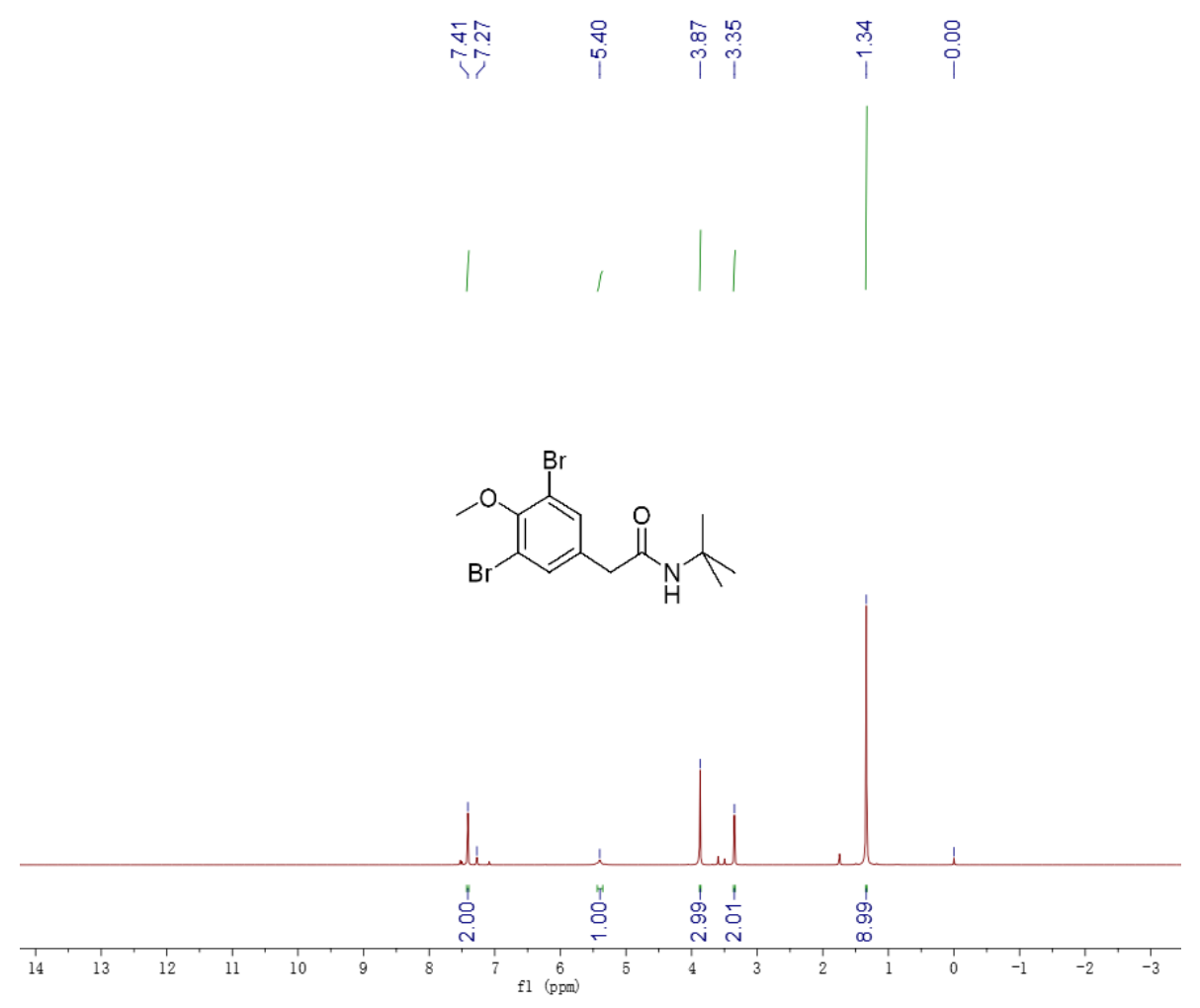

${ }^{1} \mathrm{H}$ NMR spectrum of $5 \mathrm{p}$

1
$\frac{1}{\infty}$
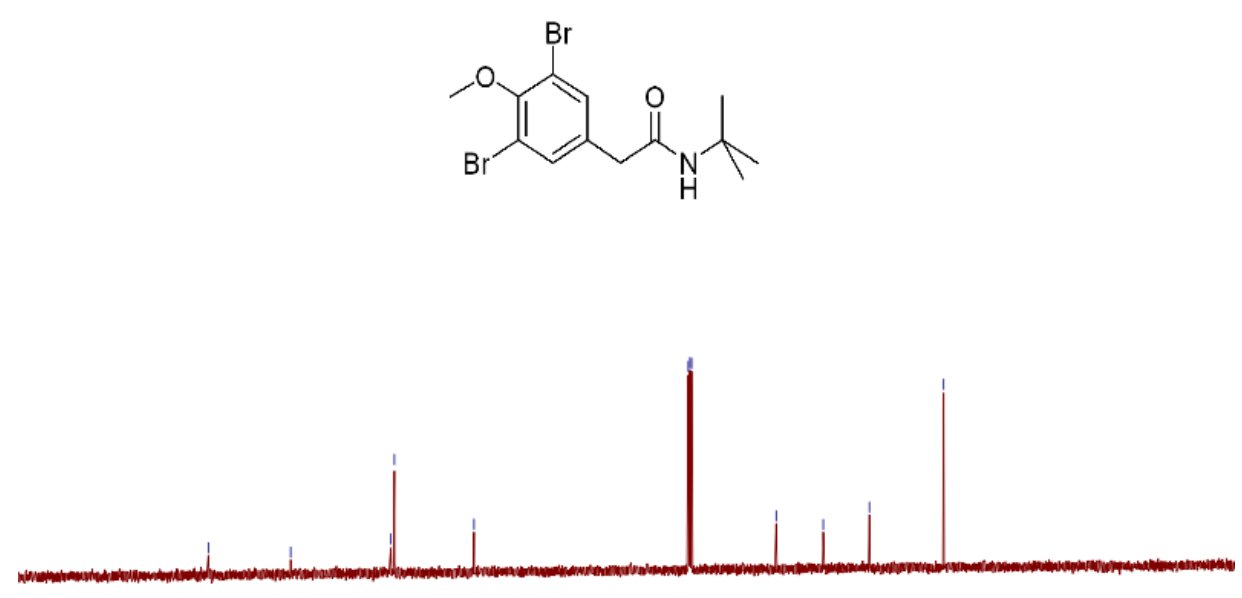

$\begin{array}{lllllllllllllllllllllllllllllll}200 & 190 & 180 & 170 & 160 & 150 & 140 & 130 & 120 & 110 & 100 & 90 & 80 & 70 & 60 & 50 & 40 & 30 & 20 & 10 & 0 & -10 & -20\end{array}$

${ }^{13} \mathrm{C}$ NMR spectrum of $5 \mathrm{p}$ 


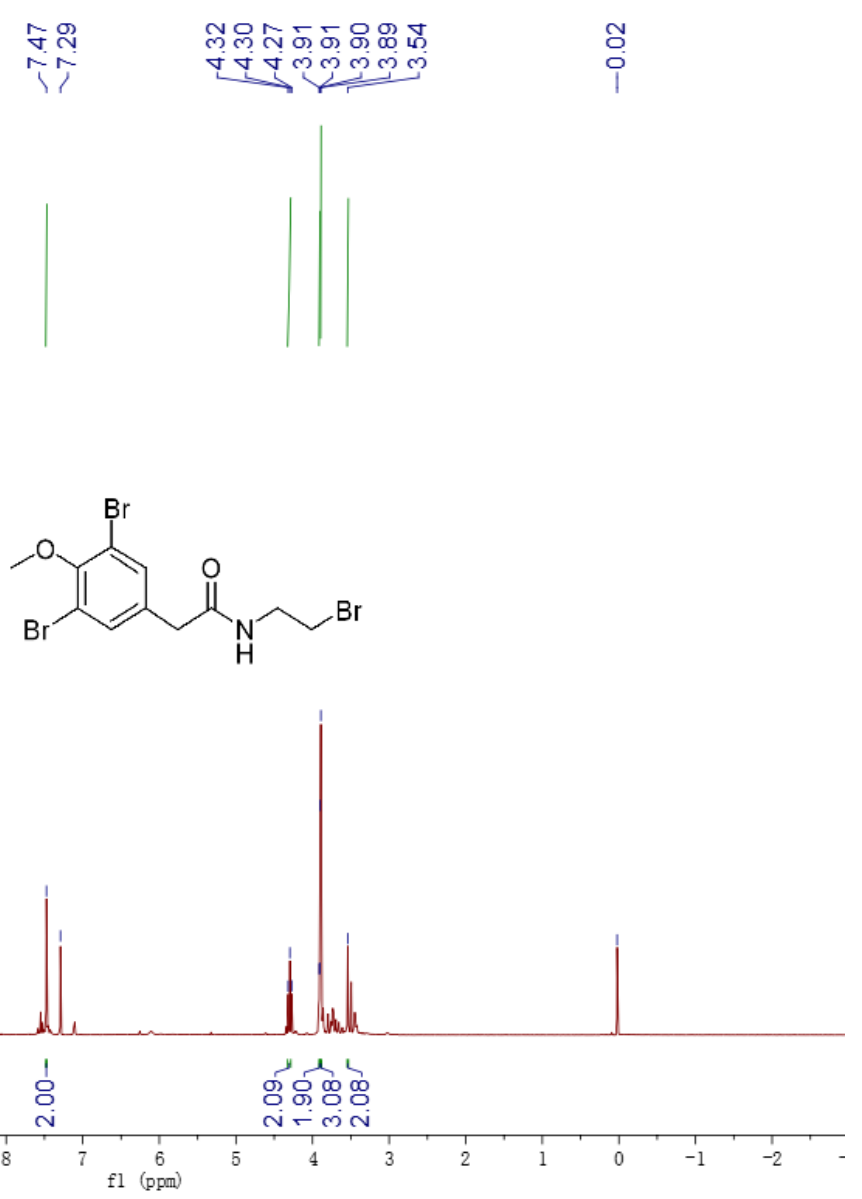

${ }^{1} \mathrm{H}$ NMR spectrum of $5 \mathrm{q}$

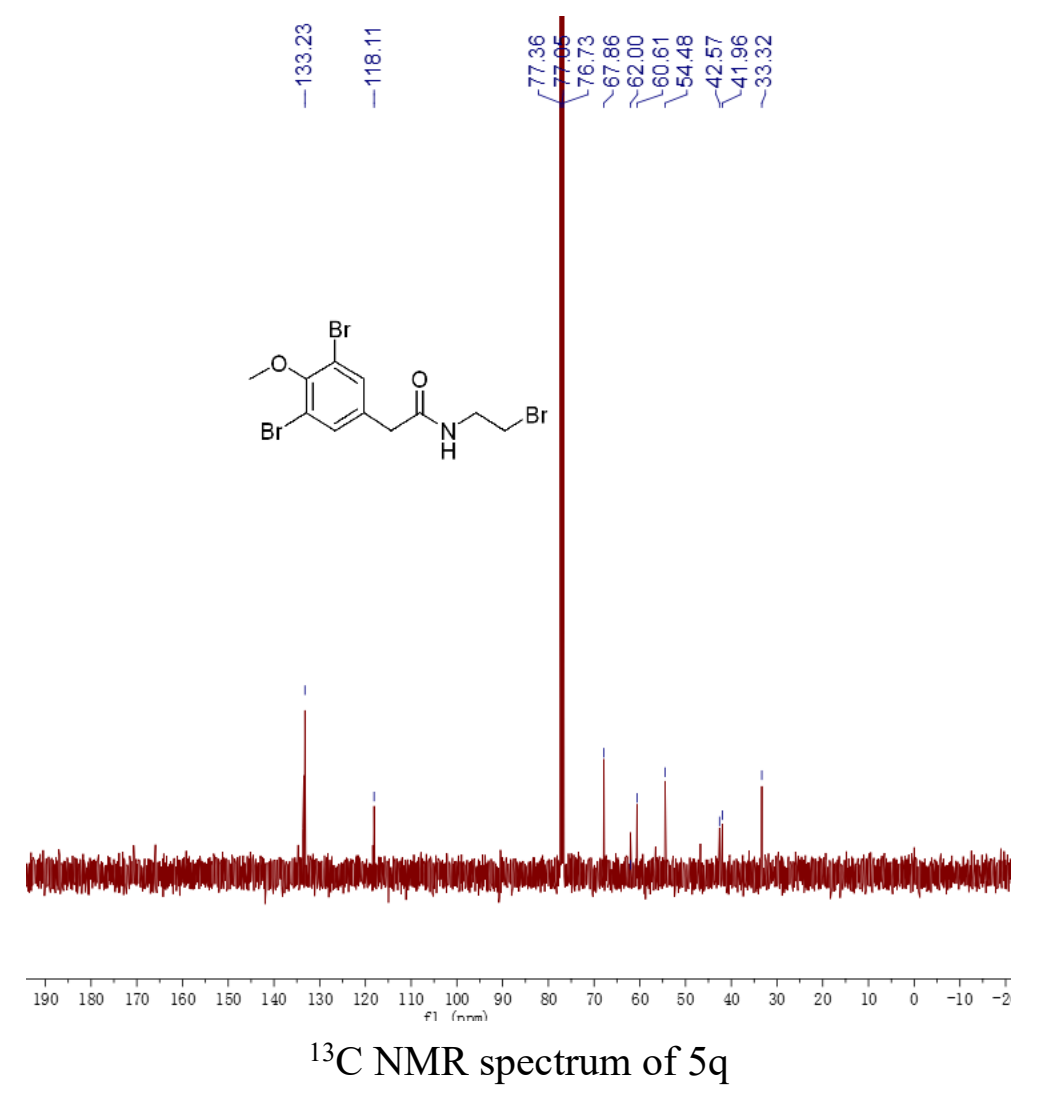



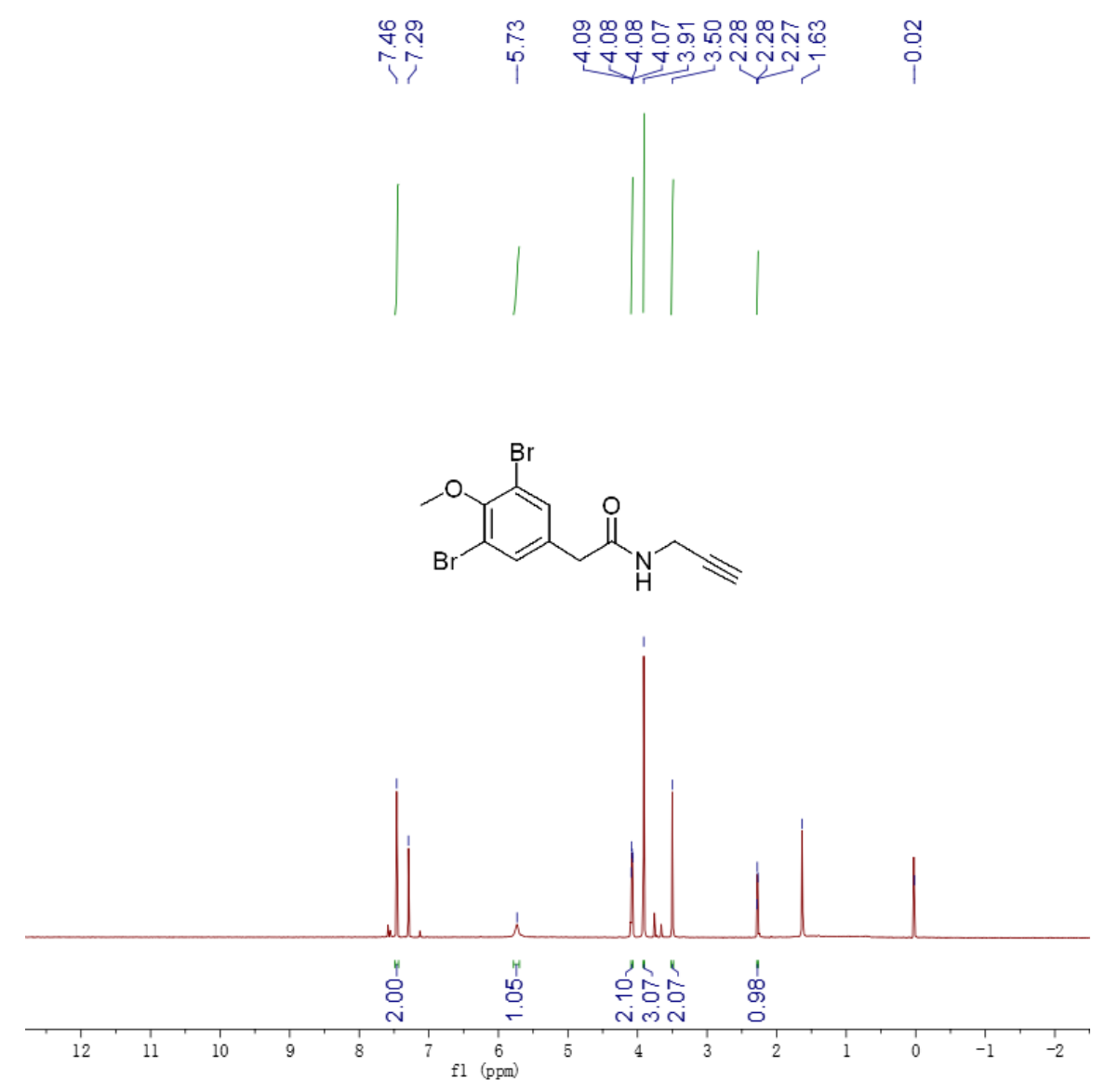

${ }^{1} \mathrm{H}$ NMR spectrum of $5 \mathrm{r}$
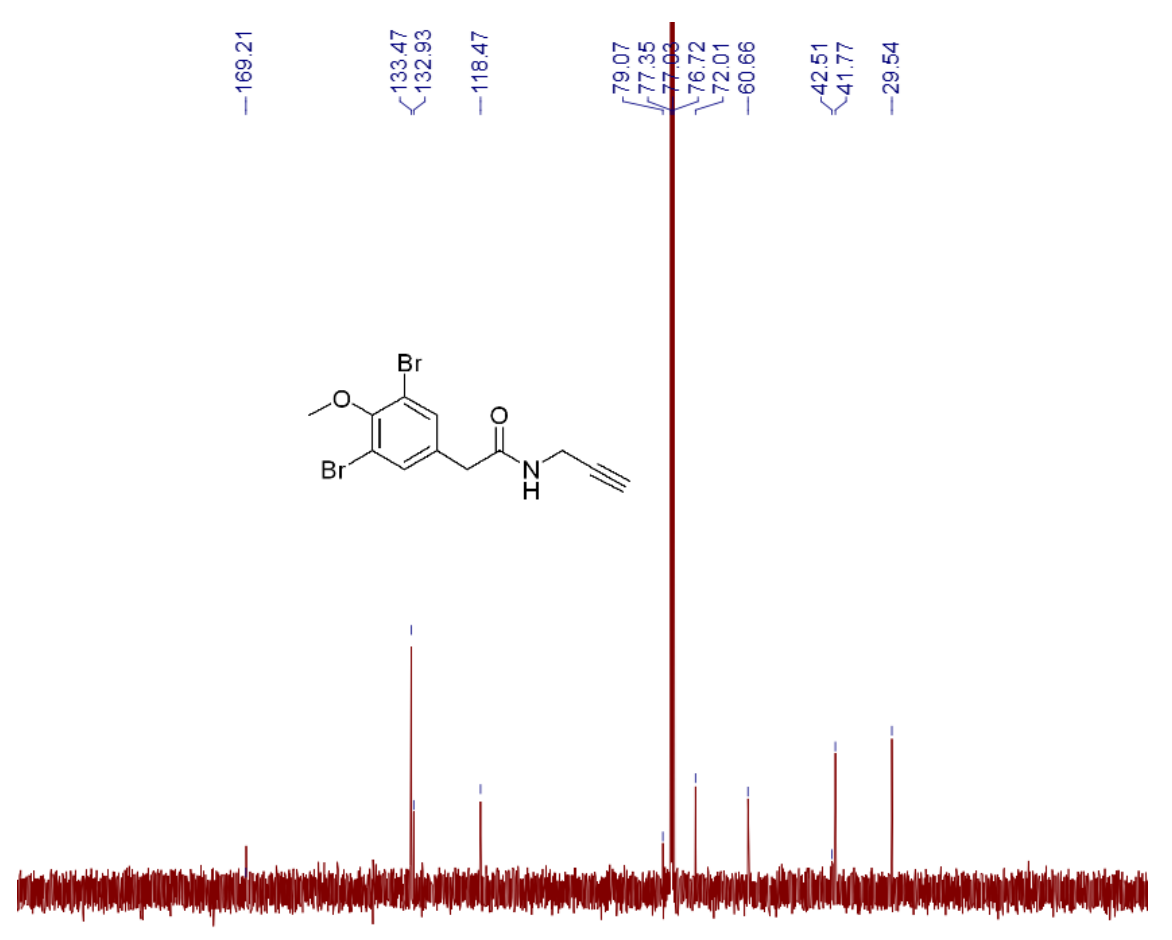

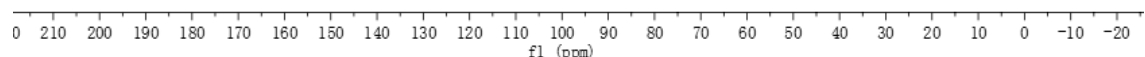

${ }^{13} \mathrm{C}$ NMR spectrum of $5 \mathrm{r}$ 

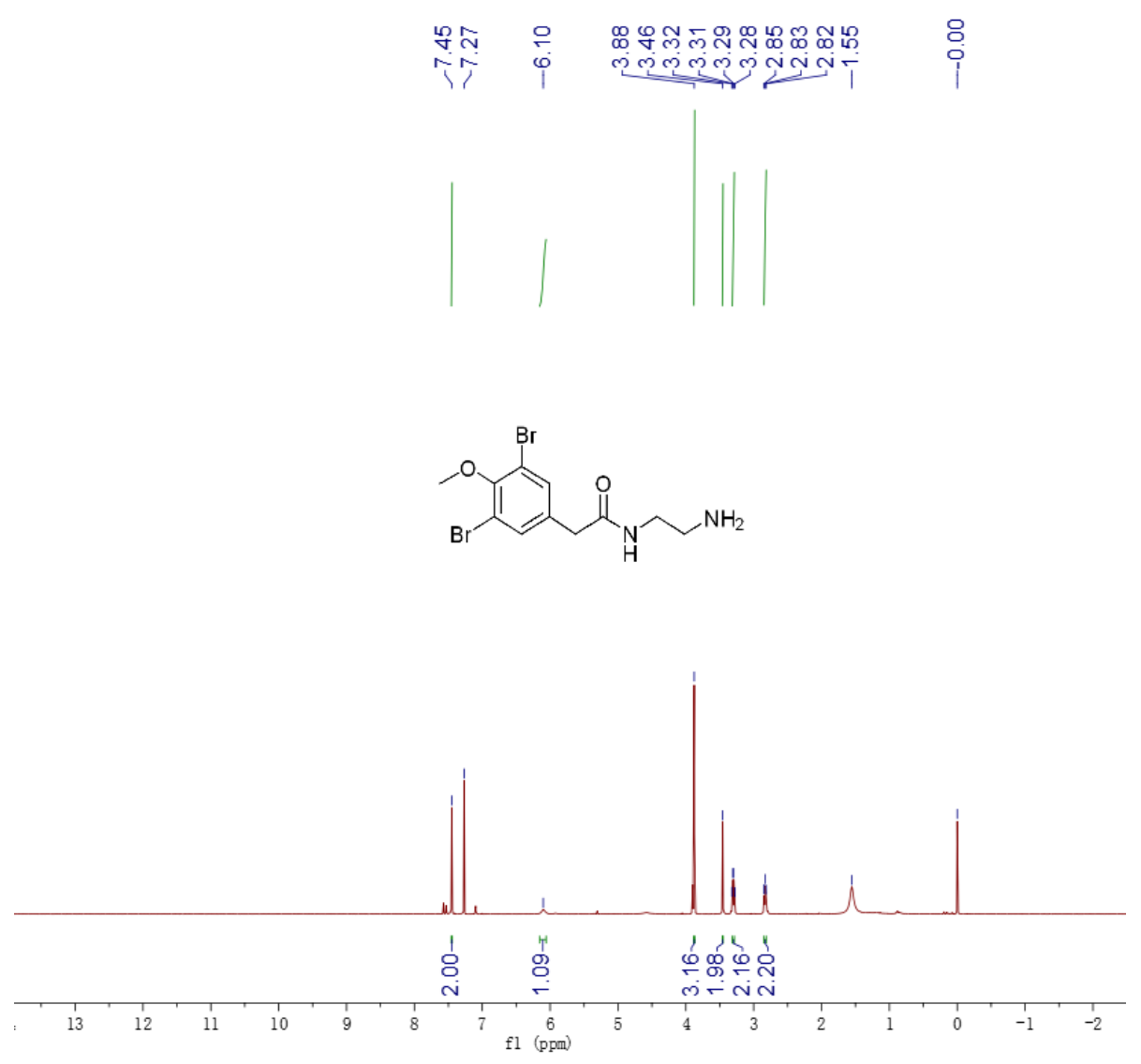

${ }^{1} \mathrm{H}$ NMR spectrum of $5 \mathrm{~s}$

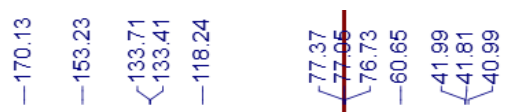
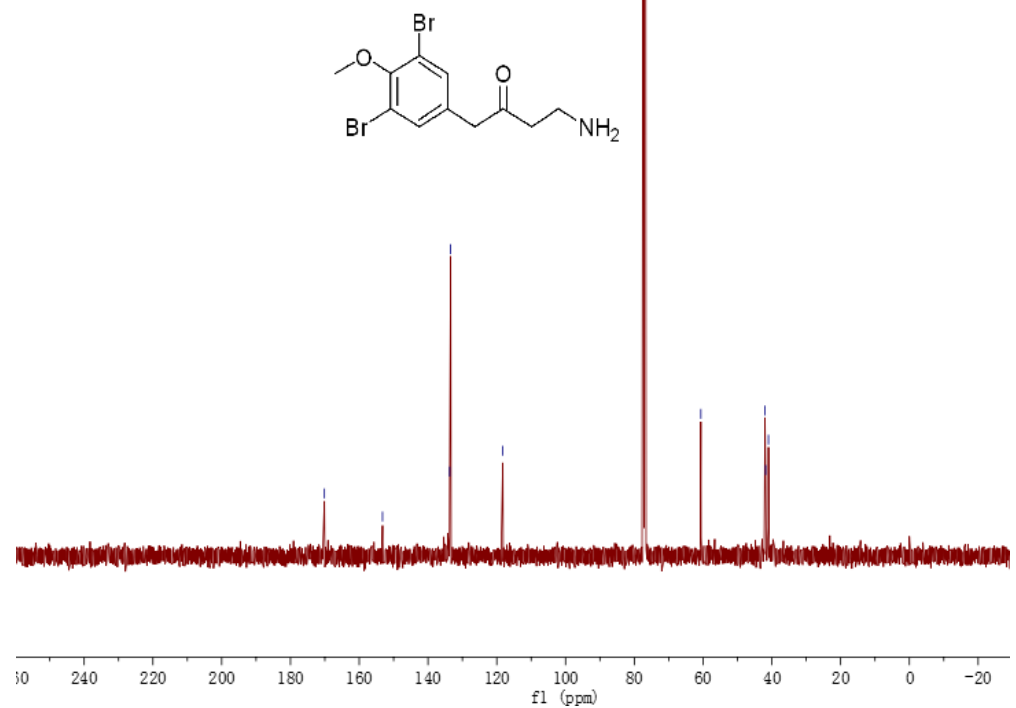

${ }^{13} \mathrm{C}$ NMR spectrum of $5 \mathrm{~s}$ 


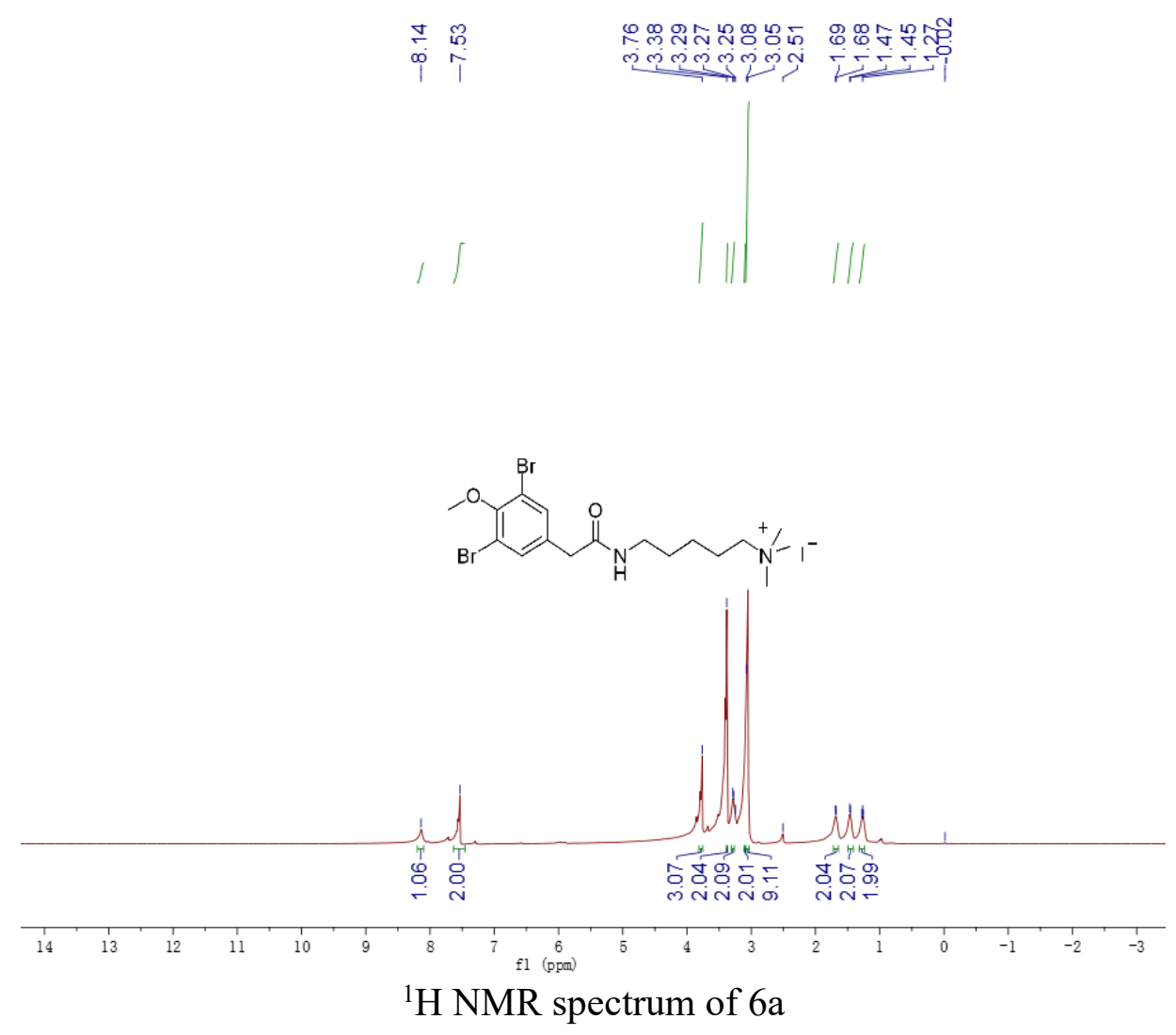

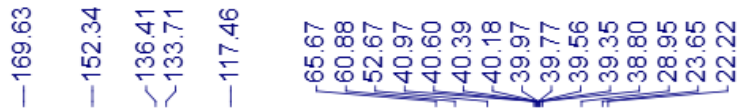
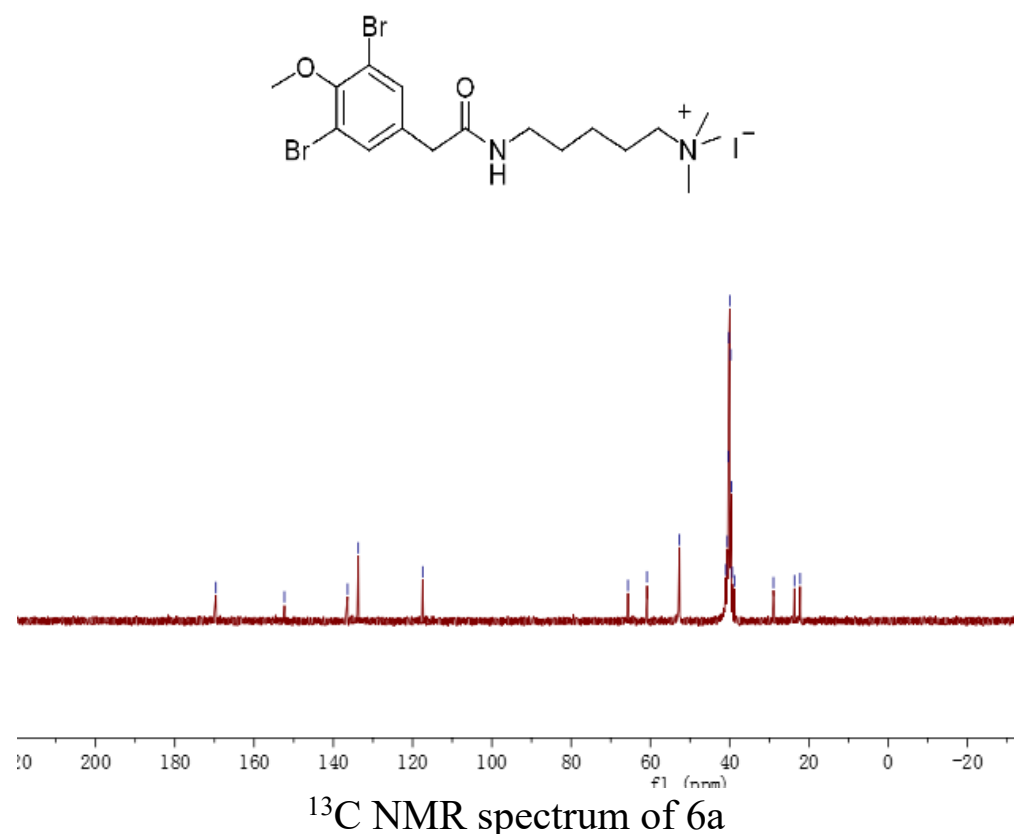

${ }^{13} \mathrm{C}$ NMR spectrum of $6 \mathrm{a}$ 

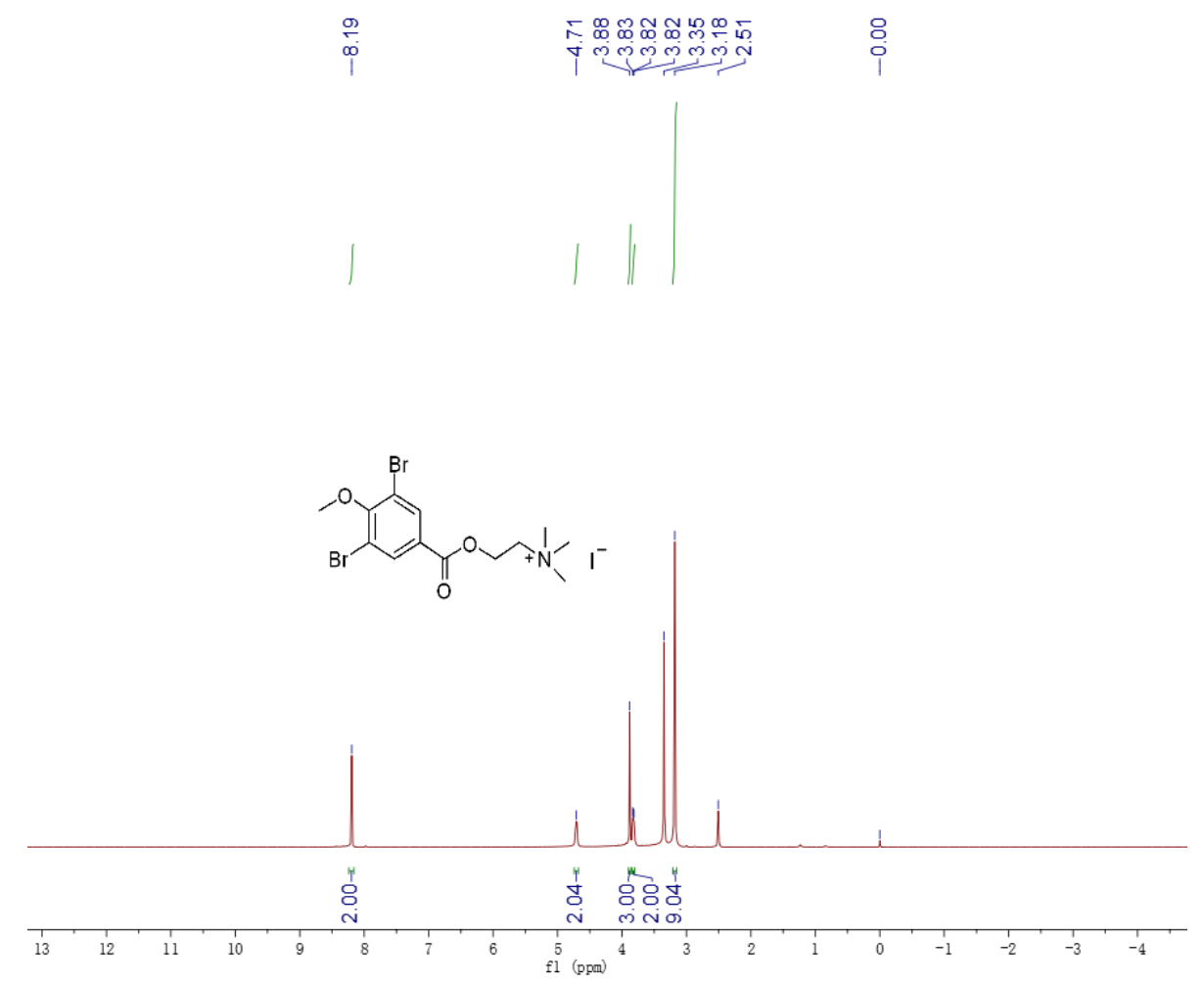

${ }^{1} \mathrm{H}$ NMR spectrum of $6 \mathrm{~b}$

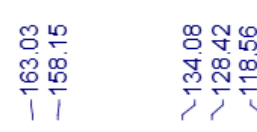
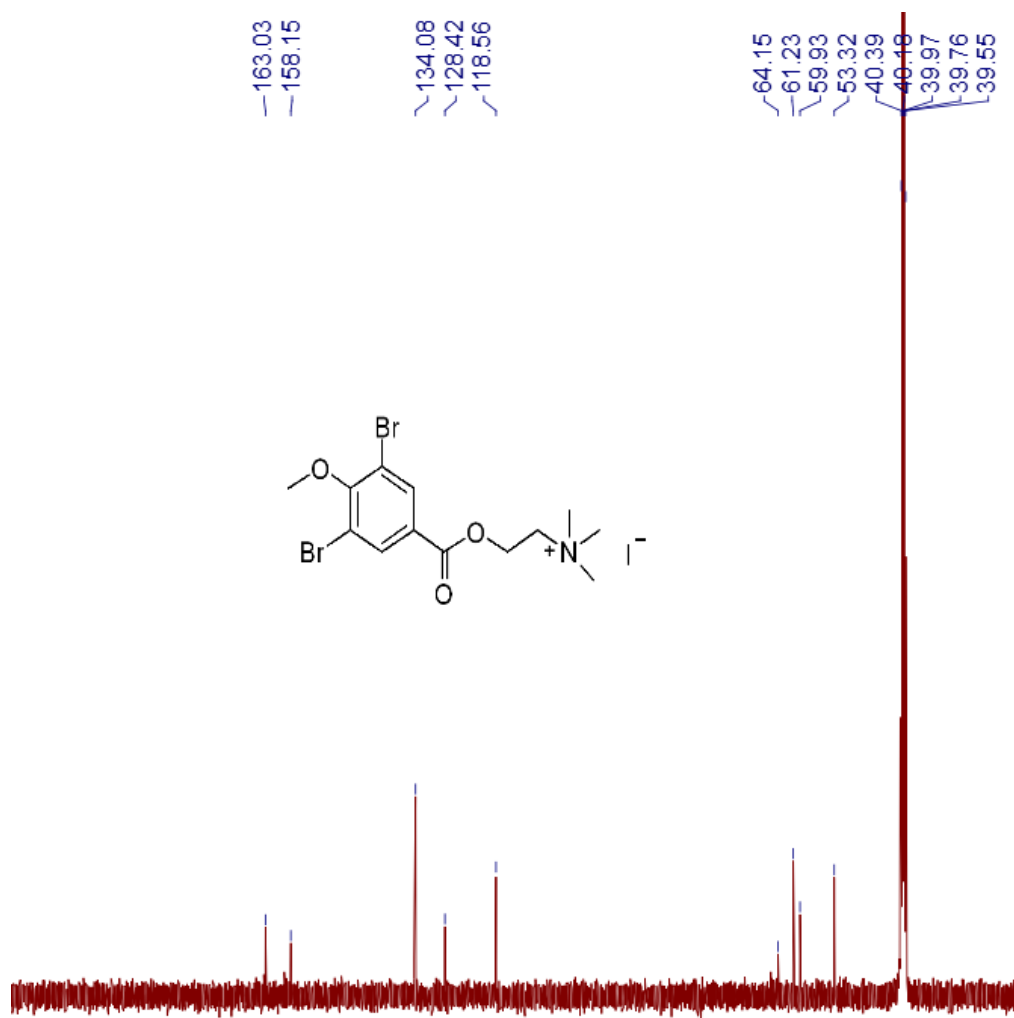

$\begin{array}{llllllllllllllllllllllllllllll} & 210 & 200 & 190 & 180 & 170 & 160 & 150 & 140 & 130 & 120 & 110 & 100 & 90 & 80 & 70 & 60 & 50 & 40 & 30 & 20 & 10 & 0 & -10 & -\end{array}$

${ }^{13} \mathrm{C}$ NMR spectrum of $6 \mathrm{~b}$ 


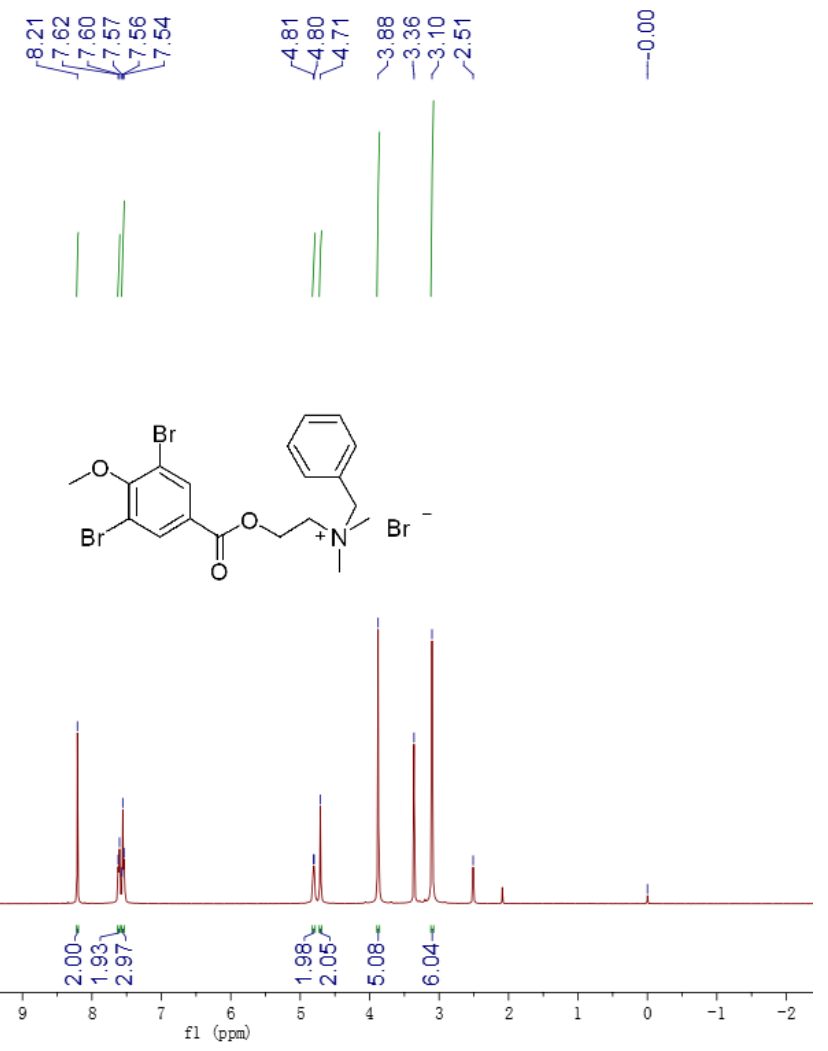

${ }^{1} \mathrm{H}$ NMR spectrum of $6 \mathrm{c}$

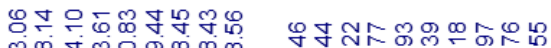

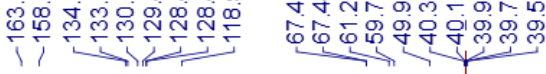
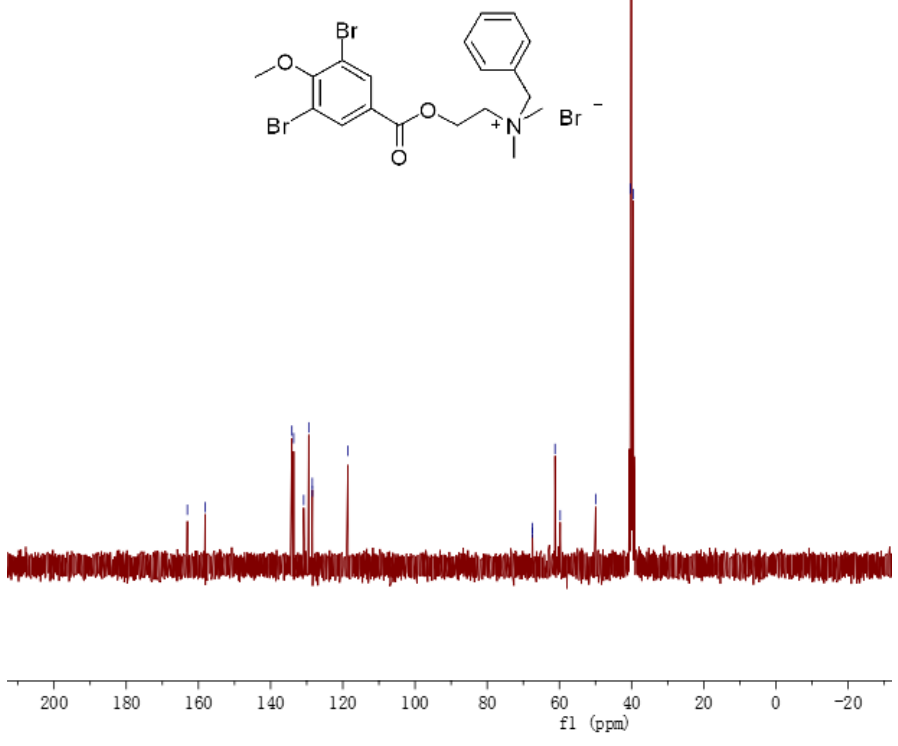

${ }^{13} \mathrm{C}$ NMR spectrum of $6 \mathrm{c}$ 


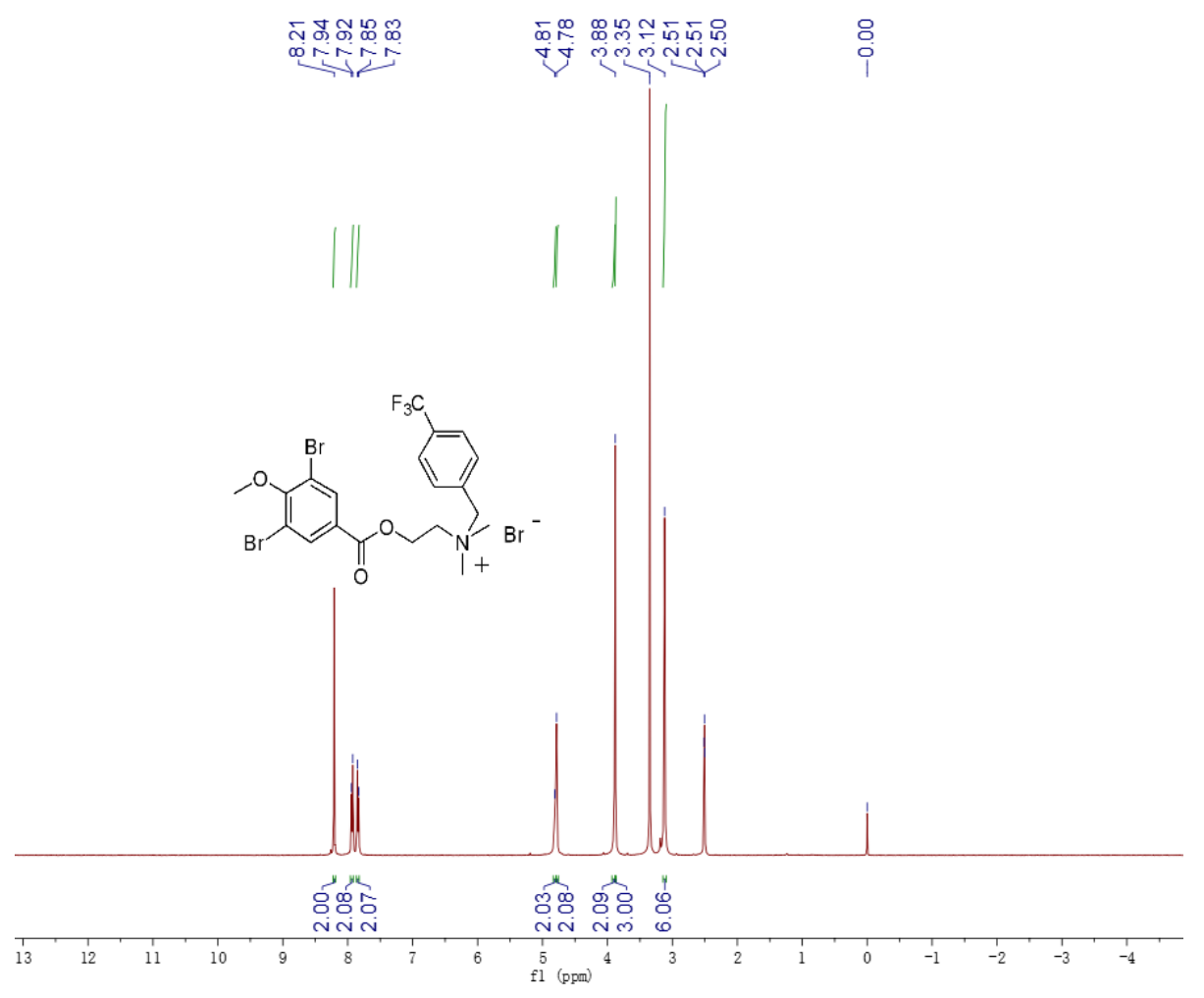

${ }^{1} \mathrm{H}$ NMR spectrum of $6 \mathrm{~d}$

\begin{tabular}{|c|c|c|}
\hline 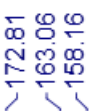 & 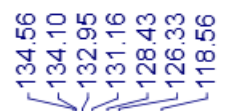 & 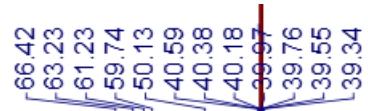 \\
\hline
\end{tabular}<smiles>COc1c(Br)cc(C(=O)OCCN([NH3+])Cc2ccc(C(F)(F)F)cc2)cc1Br</smiles>

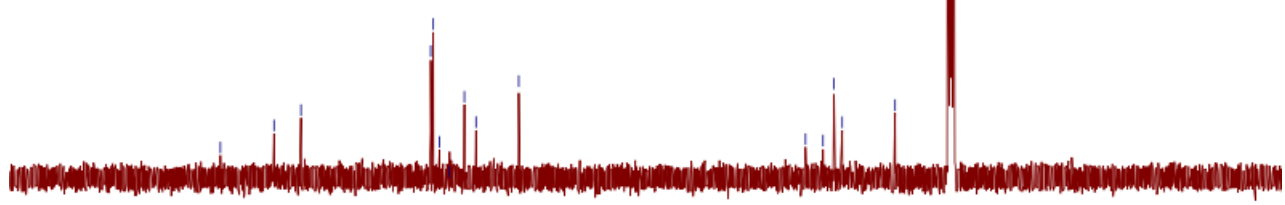

$\begin{array}{llllllllllllllllllllllllllll}10 & 200 & 190 & 180 & 170 & 160 & 150 & 140 & 130 & 120 & 110 & 100 & 90 & 80 & 70 & 60 & 50 & 40 & 30 & 20 & 10 & 0 & -10 & -2\end{array}$

${ }^{13} \mathrm{C}$ NMR spectrum of $6 \mathrm{~d}$ 

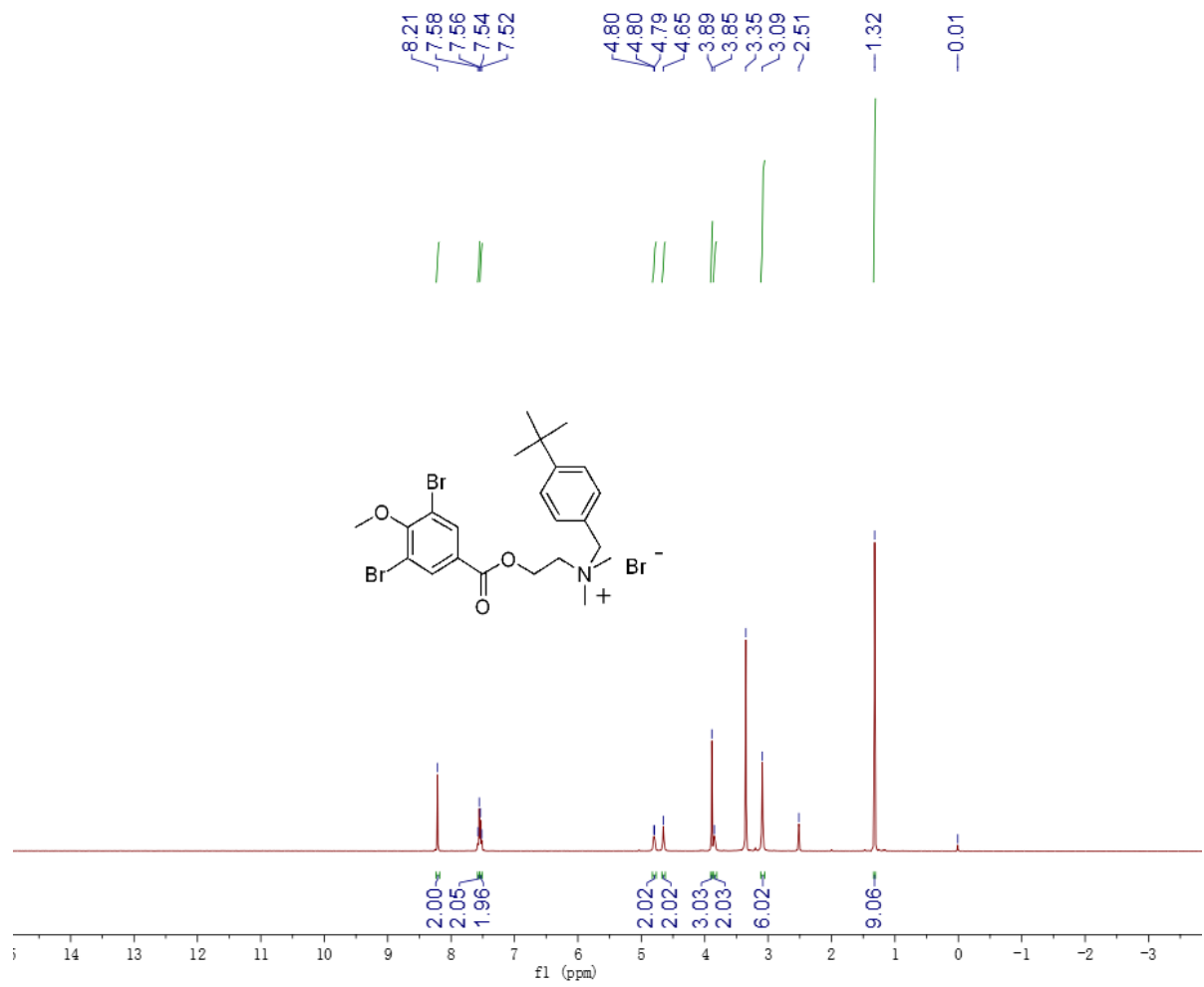

${ }^{1} \mathrm{H}$ NMR spectrum of $6 \mathrm{e}$

\begin{tabular}{|c|c|c|}
\hline 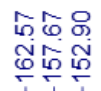 & 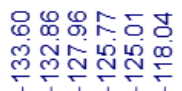 & 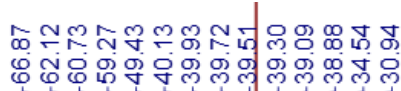 \\
\hline
\end{tabular}
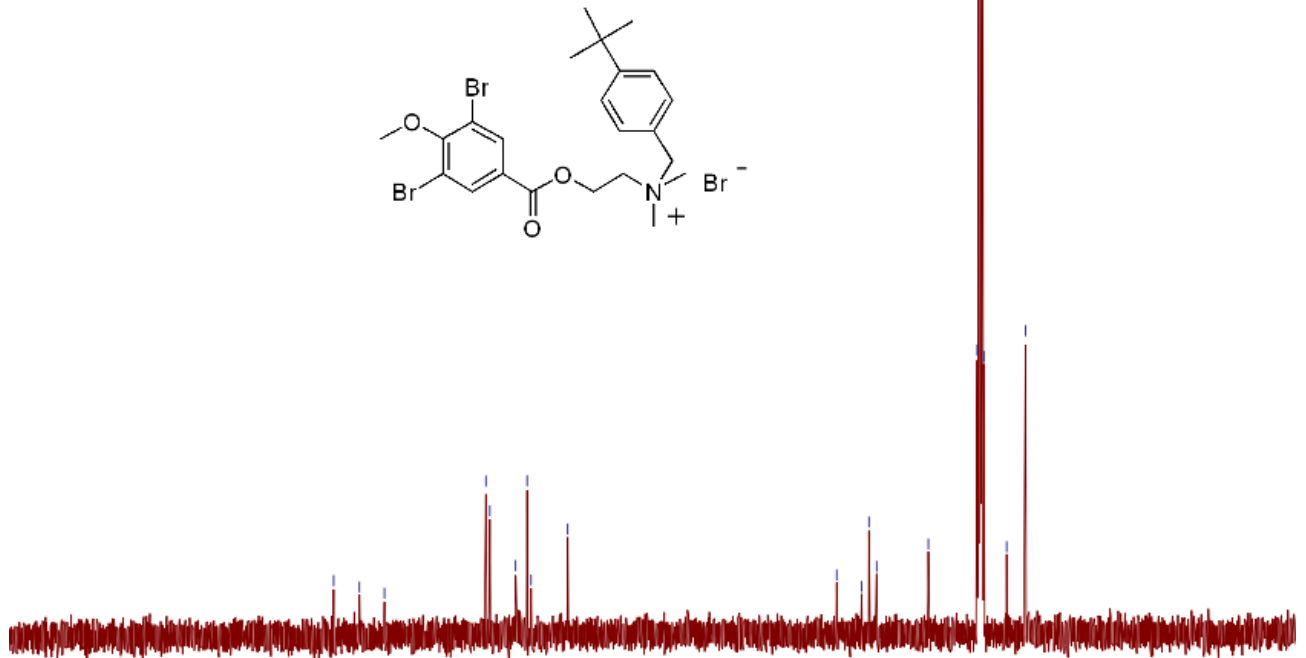

$\begin{array}{llllllllllllllllllllllllllllllllllllllllll}220 & 210 & 200 & 190 & 180 & 170 & 160 & 150 & 140 & 130 & 120 & 110 & 100 & 90 & 80 & 70 & 60 & 50 & 40 & 30 & 20 & 10 & 0 & -10 & -2\end{array}$

${ }^{13} \mathrm{C}$ NMR spectrum of $6 \mathrm{e}$ 

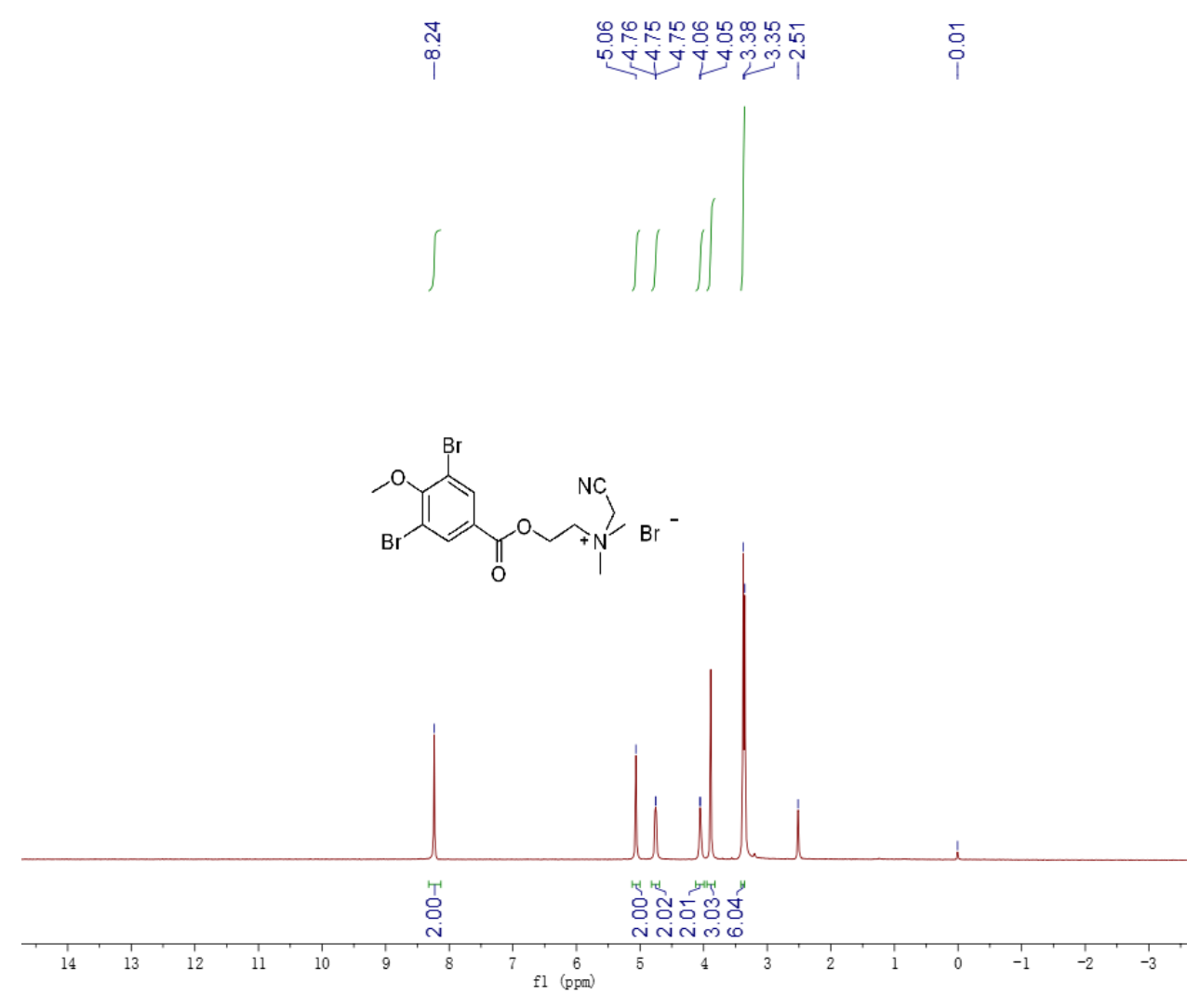

${ }^{1} \mathrm{H}$ NMR spectrum of $6 \mathrm{f}$

15

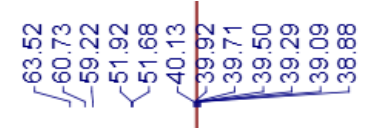<smiles>CC[N+](C)(CBr)CCOC(=O)c1cc(Br)c(OC)c(Br)c1</smiles>

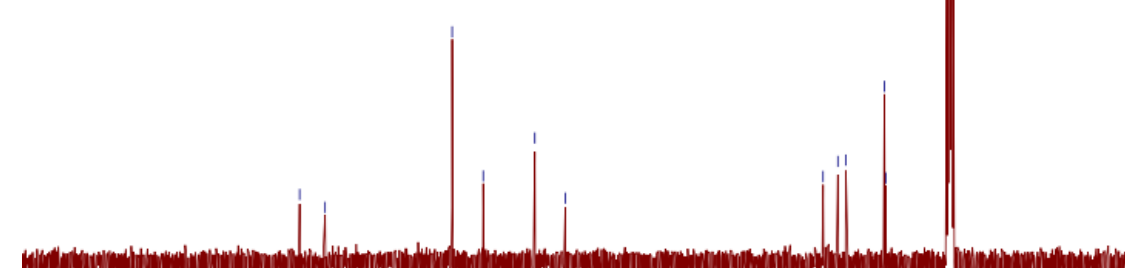

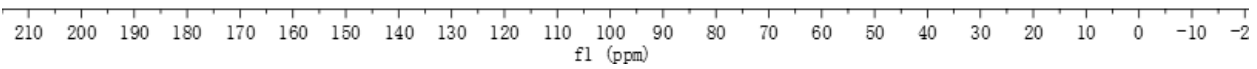

${ }^{13} \mathrm{H}$ NMR spectrum of $6 \mathrm{f}$ 


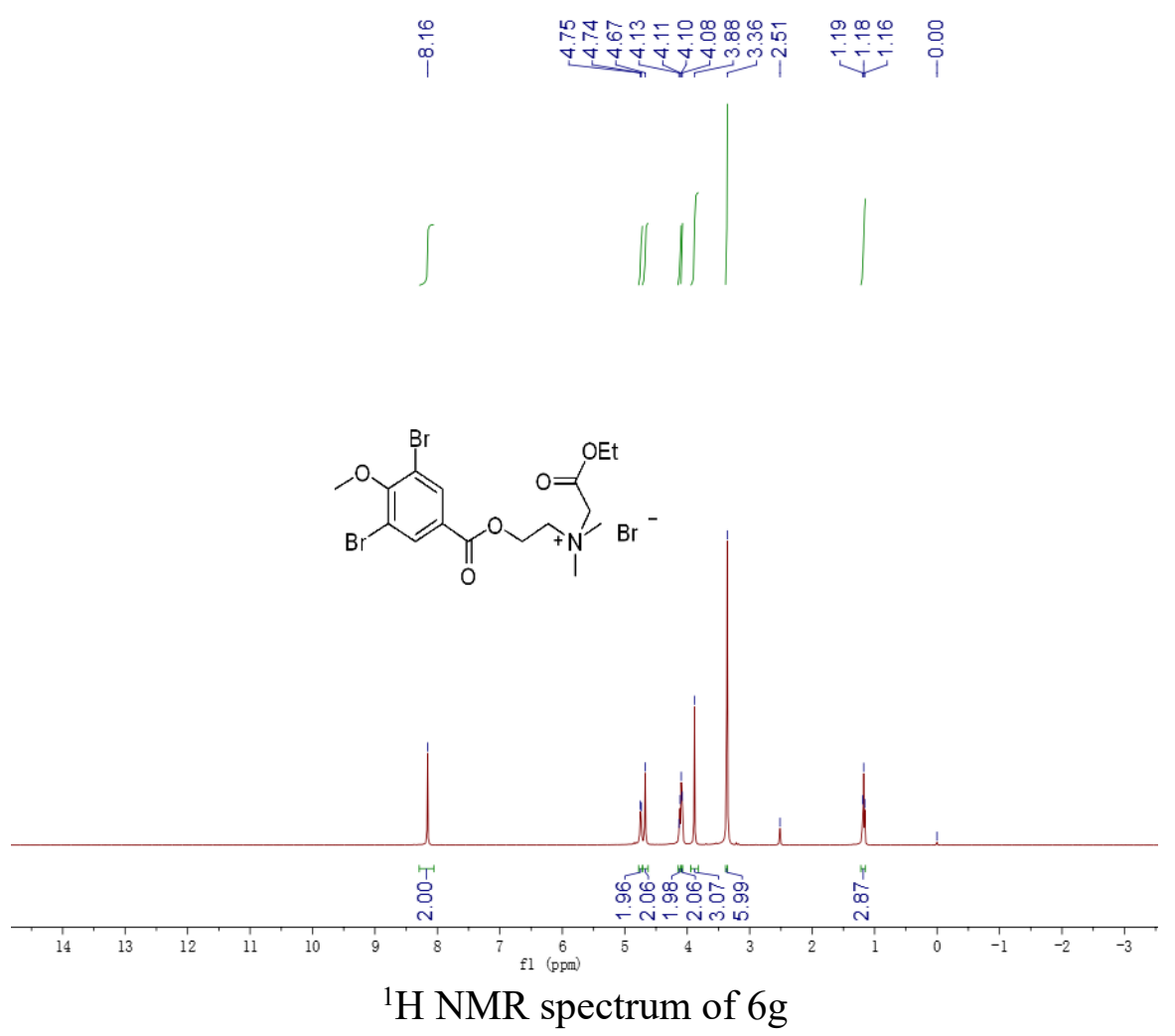

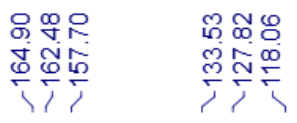

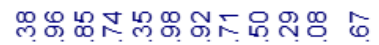

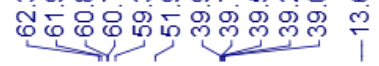<smiles>CCOC(=O)CN(C)CCOC(=O)c1cc(Br)c(OC)c(Br)c1</smiles>

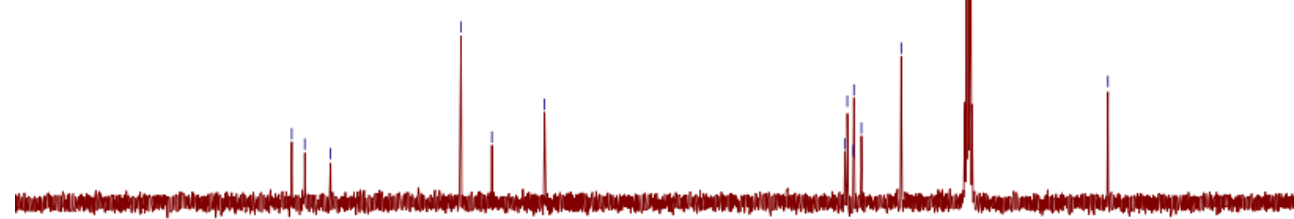

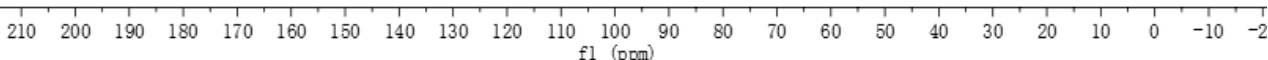

${ }^{13} \mathrm{C}$ NMR spectrum of $6 \mathrm{~g}$ 

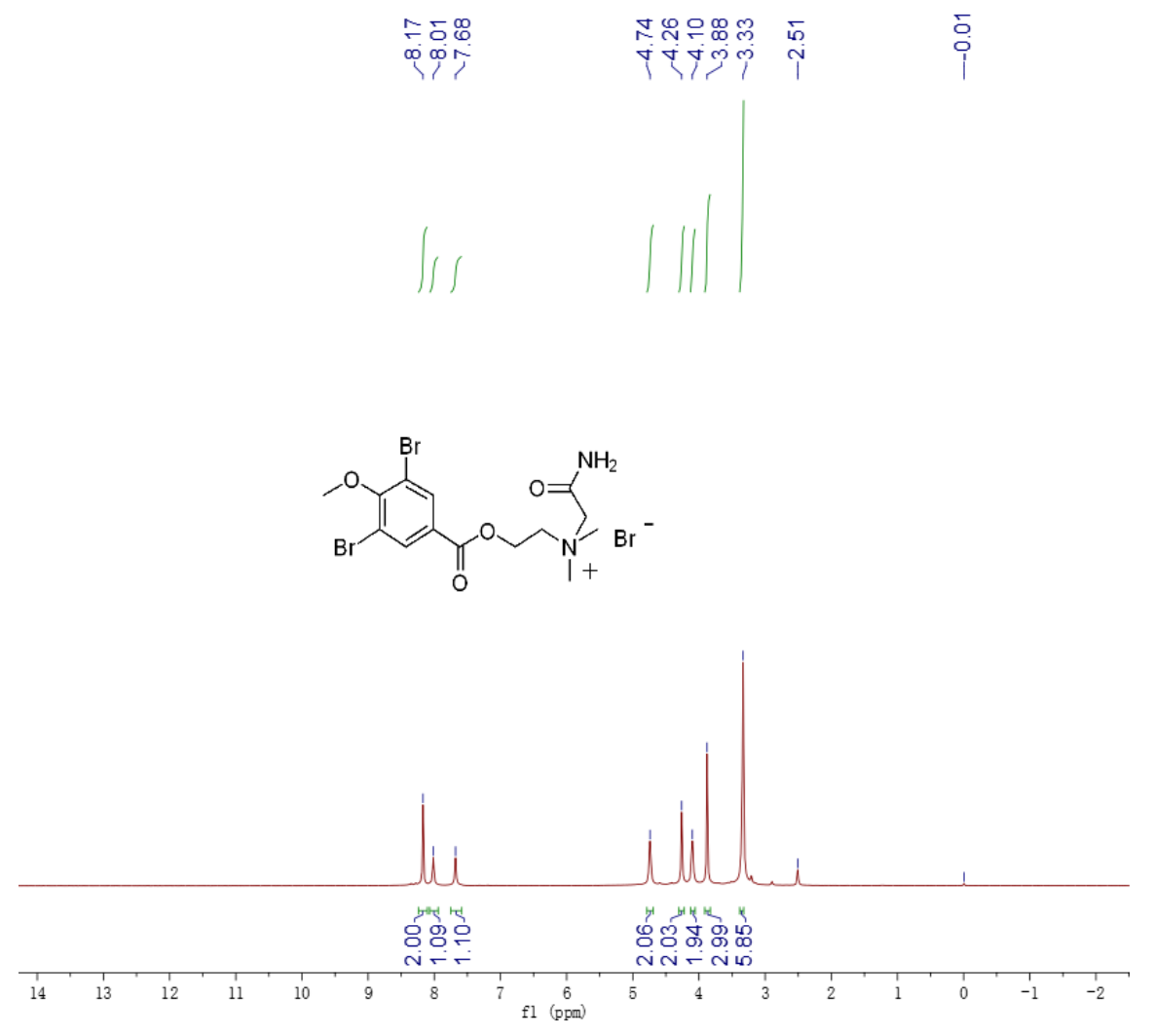

${ }^{1} \mathrm{H}$ NMR spectrum of $6 \mathrm{~h}$

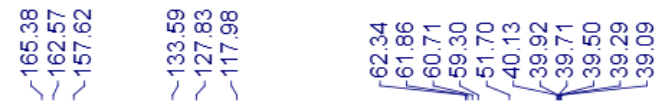
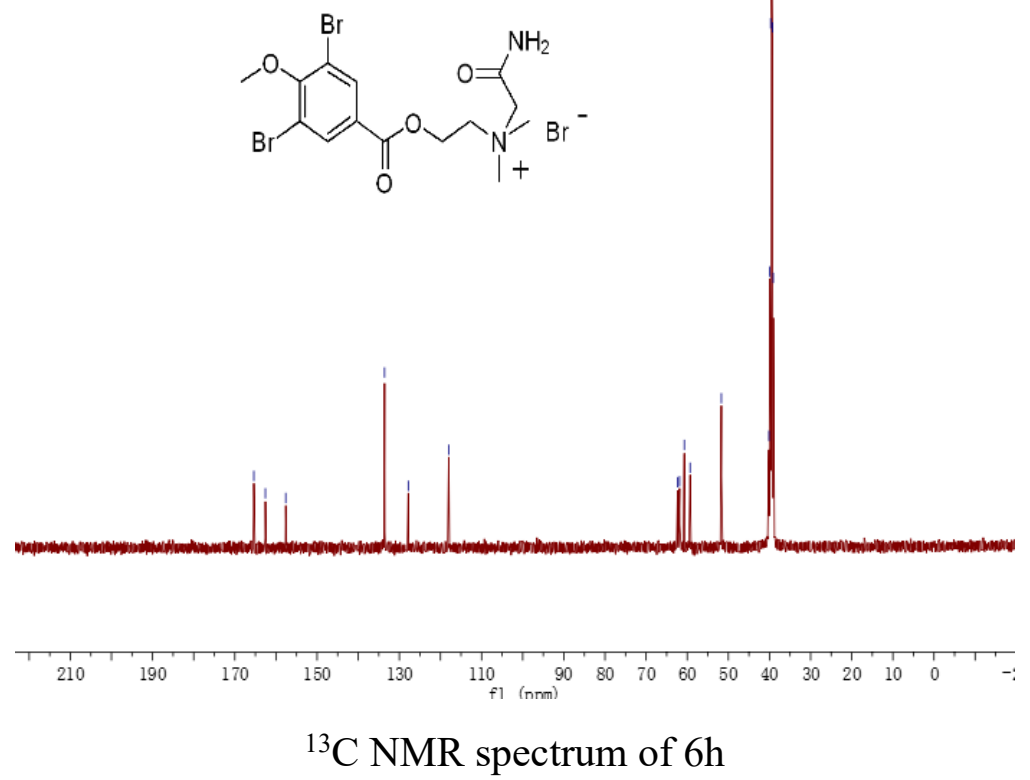


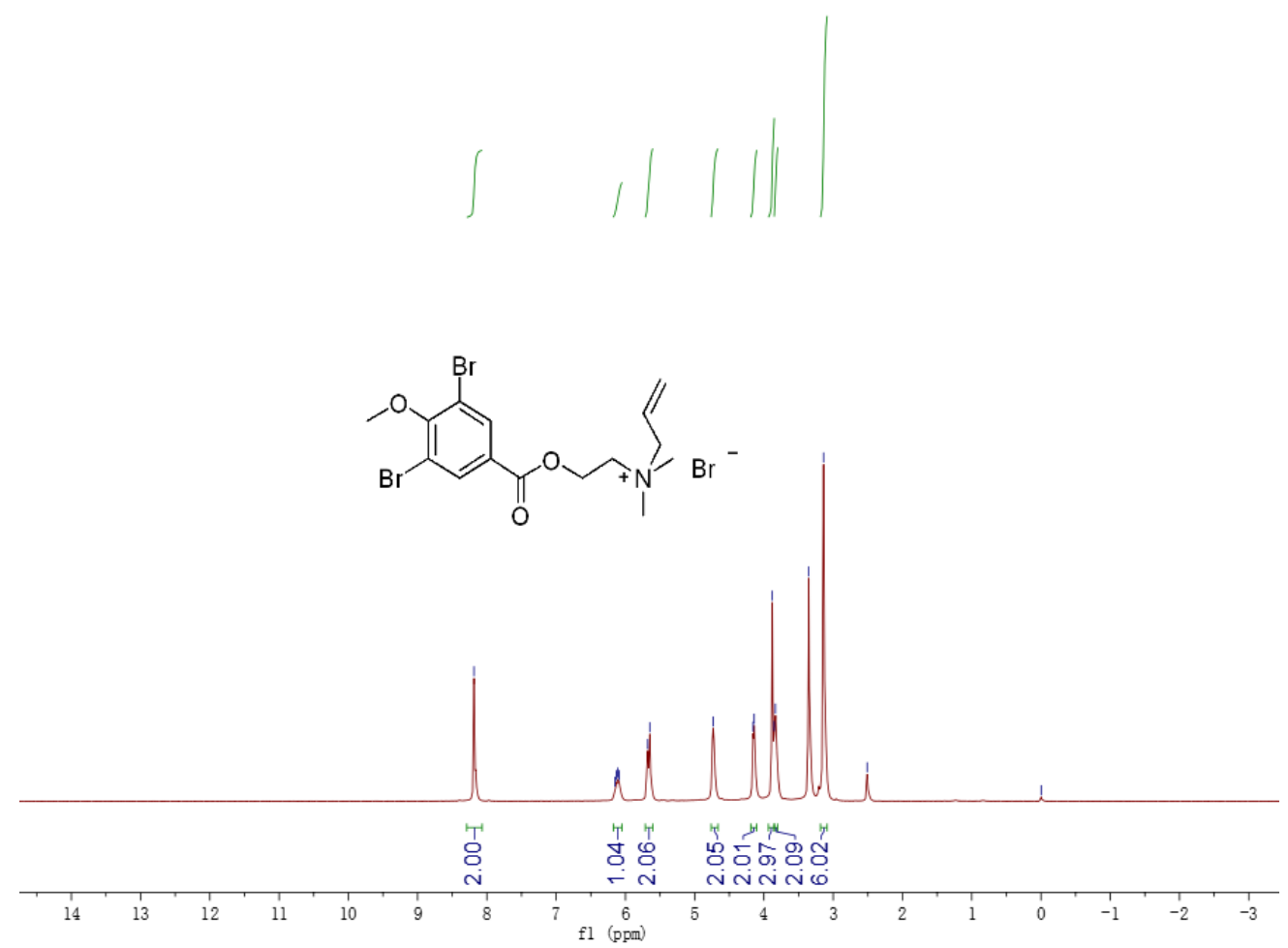

${ }^{1} \mathrm{H}$ NMR spectrum of $6 \mathrm{i}$

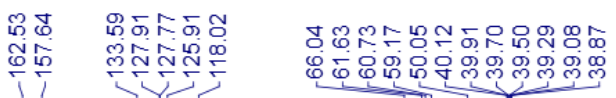
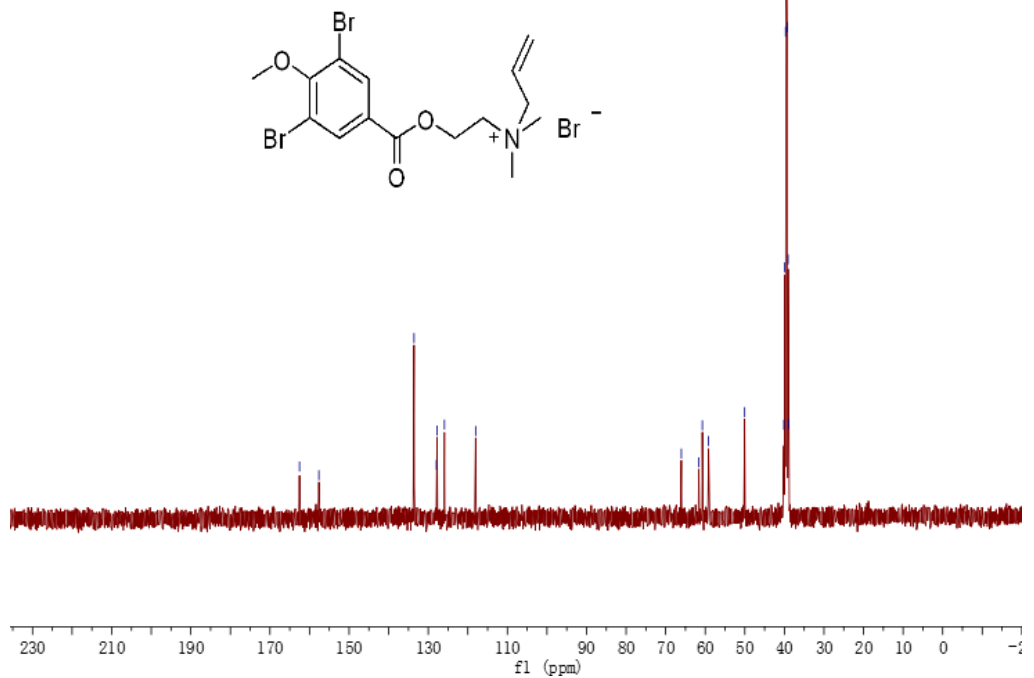

${ }^{13} \mathrm{C}$ NMR spectrum of $6 \mathrm{i}$ 

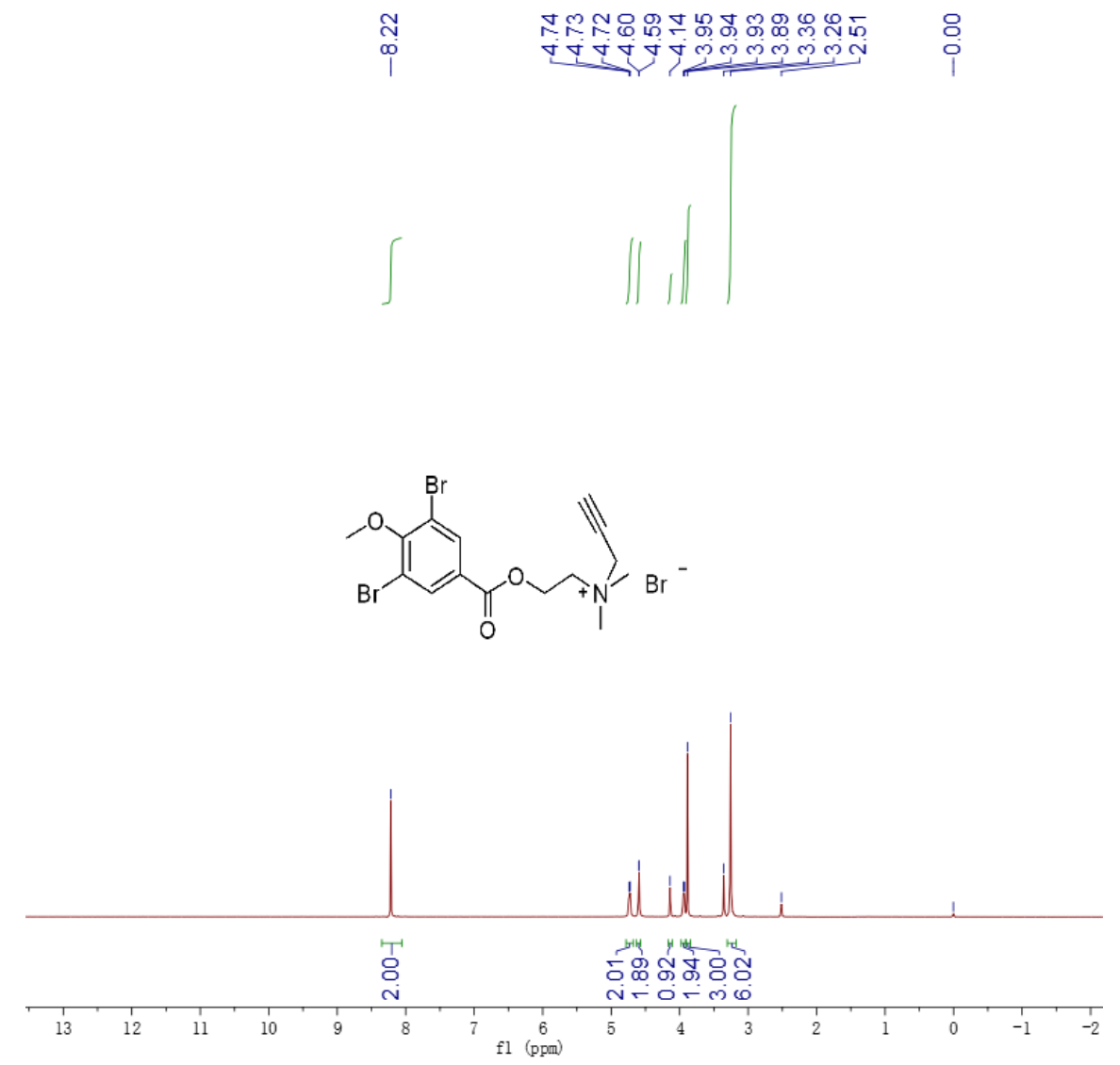

${ }^{1} \mathrm{H}$ NMR spectrum of $6 \mathrm{j}$

\begin{tabular}{|c|c|c|}
\hline 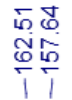 & 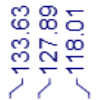 & 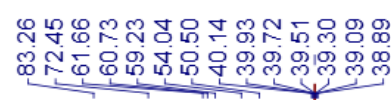 \\
\hline
\end{tabular}<smiles>C#CC[N+](C)(CBr)CCOC(=O)c1cc(Br)c(OC)c(Br)c1</smiles>

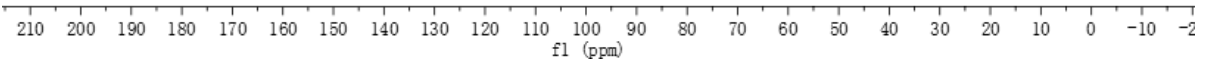

${ }^{13} \mathrm{C}$ NMR spectrum of $6 \mathrm{j}$ 

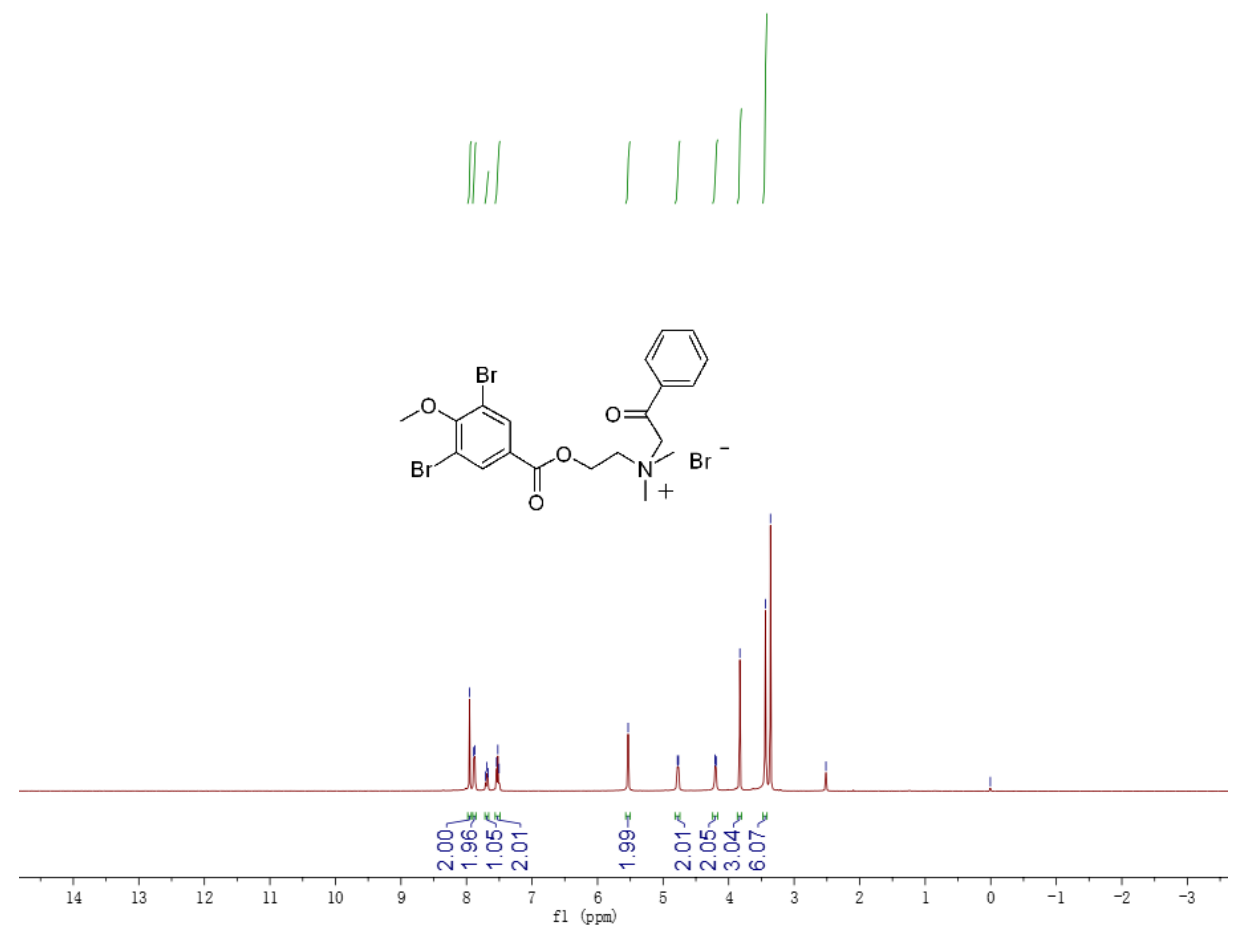

${ }^{1} \mathrm{H}$ NMR spectrum of $6 \mathrm{k}$

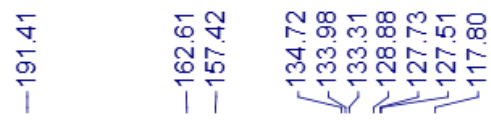

ำำ

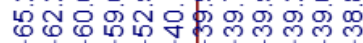<smiles>COc1c(Br)cc(C(=O)OCCN([I+])CC(=O)c2ccccc2)cc1Br</smiles>

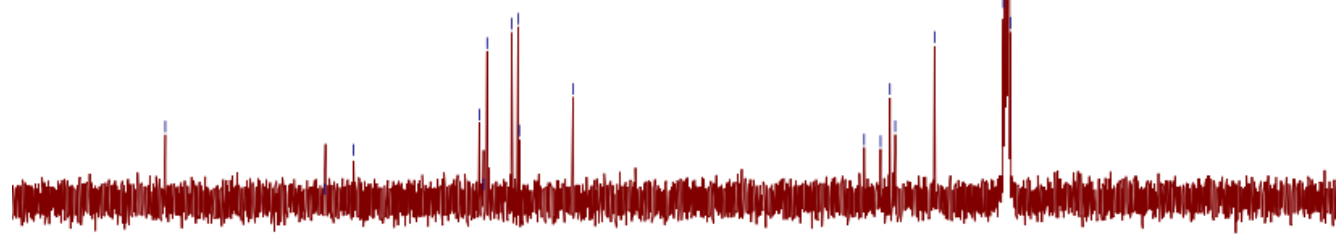

\begin{tabular}{lllllllllllllllllllllllllllllll}
\hline 0 & 210 & 200 & 190 & 180 & 170 & 160 & 150 & 140 & 130 & 120 & 110 & 100 & 90 & 80 & 70 & 60 & 50 & 40 & 10 & 20 & 10 & 0 & -10 & -2
\end{tabular}

${ }^{13} \mathrm{C}$ NMR spectrum of $6 \mathrm{k}$ 


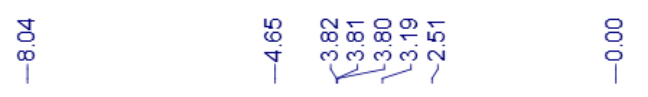<smiles>CN(C)CCOC(=O)c1cc(Br)c(O)c(Br)c1</smiles>

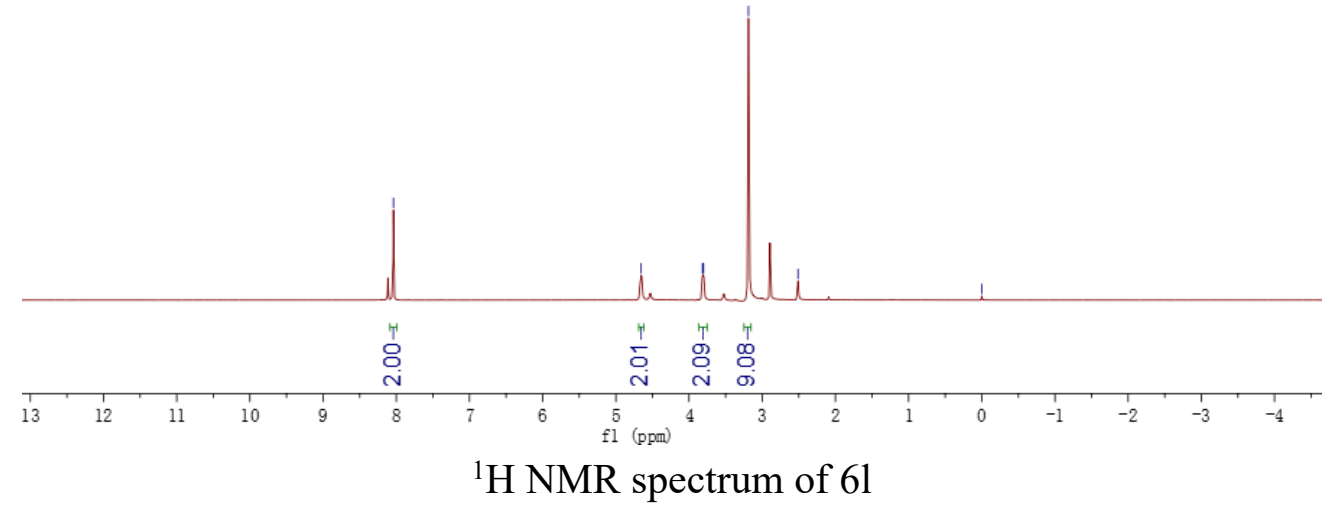<smiles>C[N+](C)(C)CCOC(=O)c1cc(Br)c(O)c(Br)c1</smiles>

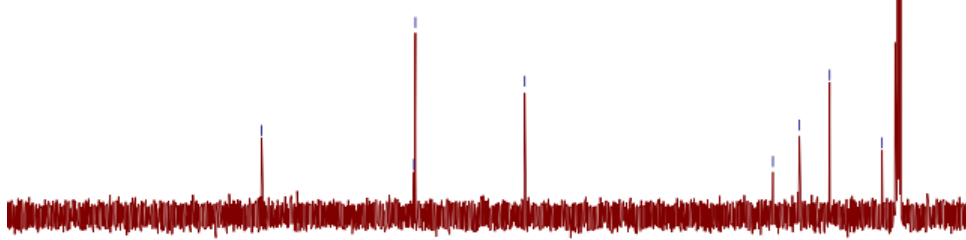

\begin{tabular}{rlllllllllllllllllllllllllllllll}
\hline & 210 & 200 & 190 & 180 & 170 & 160 & 150 & 140 & 130 & 120 & 110 & 100 & 90 & 80 & 70 & 60 & 50 & 40 & 30 & 20 & 10 & 0 & -10 & -2
\end{tabular}

${ }^{13} \mathrm{C}$ NMR spectrum of 61 


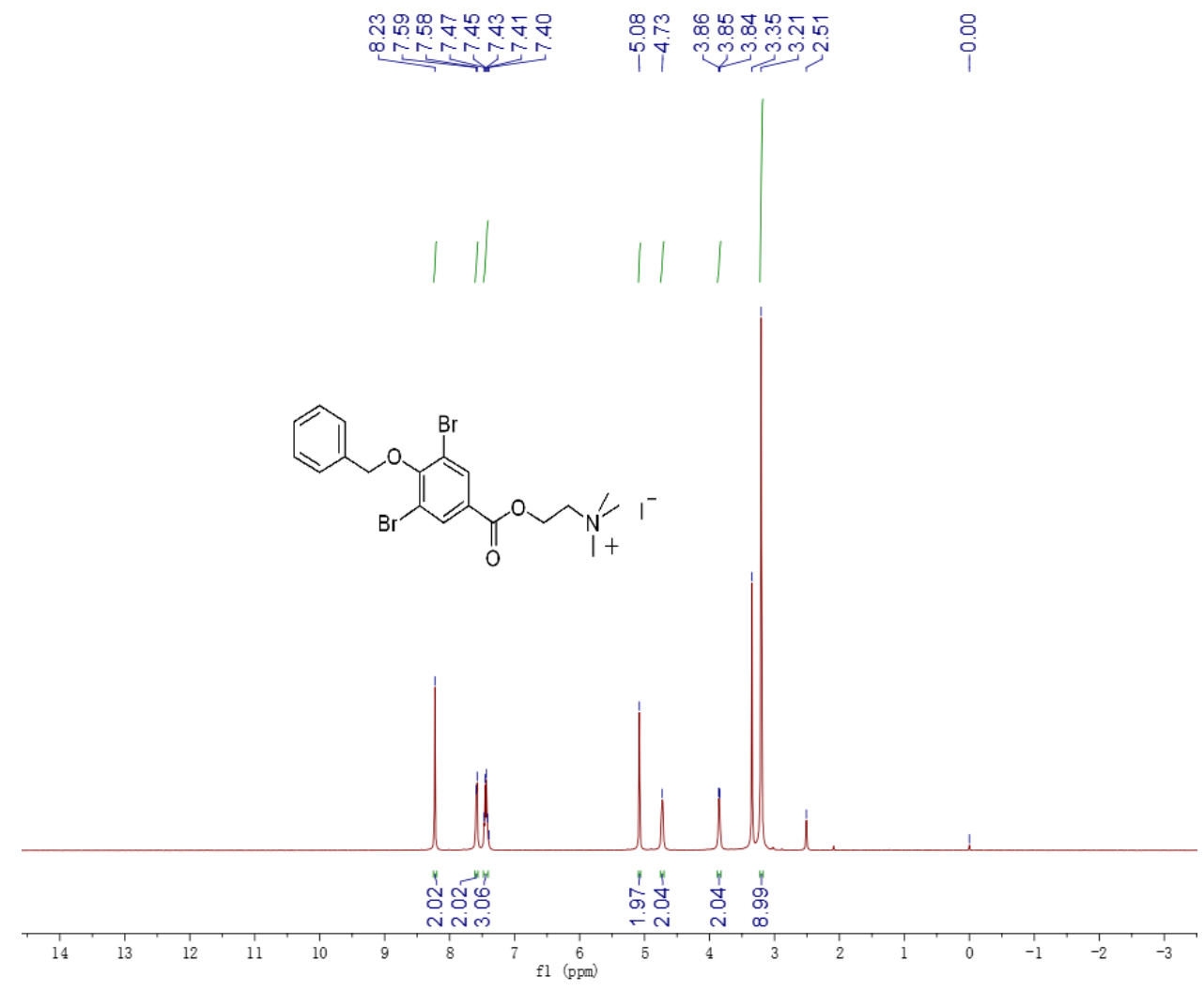

${ }^{1} \mathrm{H}$ NMR spectrum of $6 \mathrm{~m}$

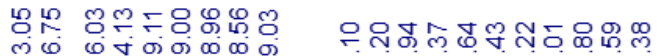

管<smiles>C[N+](C)([I-])CCOC(=O)c1cc(Br)c(OCc2ccccc2)c(Br)c1</smiles>
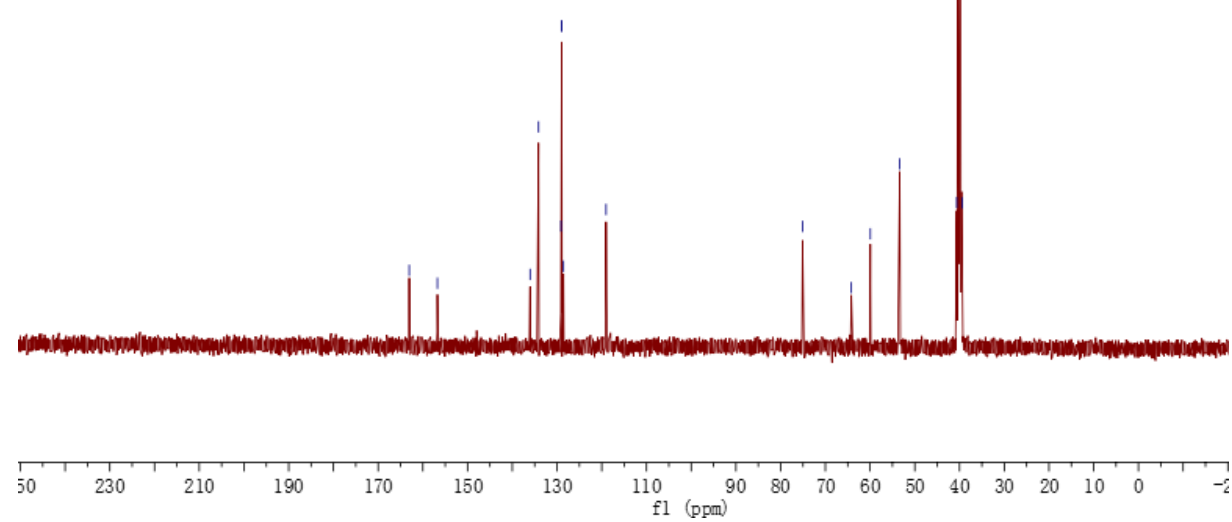

${ }^{13} \mathrm{C}$ NMR spectrum of $6 \mathrm{~m}$ 


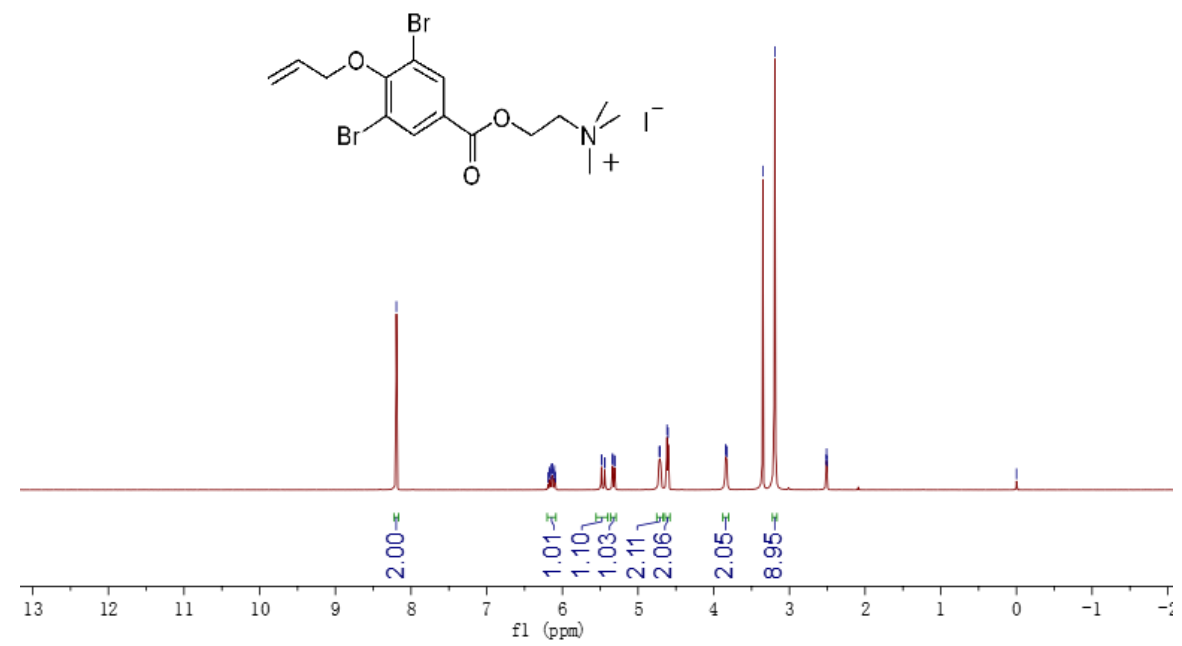

${ }^{1} \mathrm{H}$ NMR spectrum of $6 \mathrm{n}$

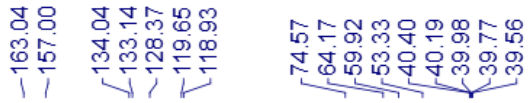
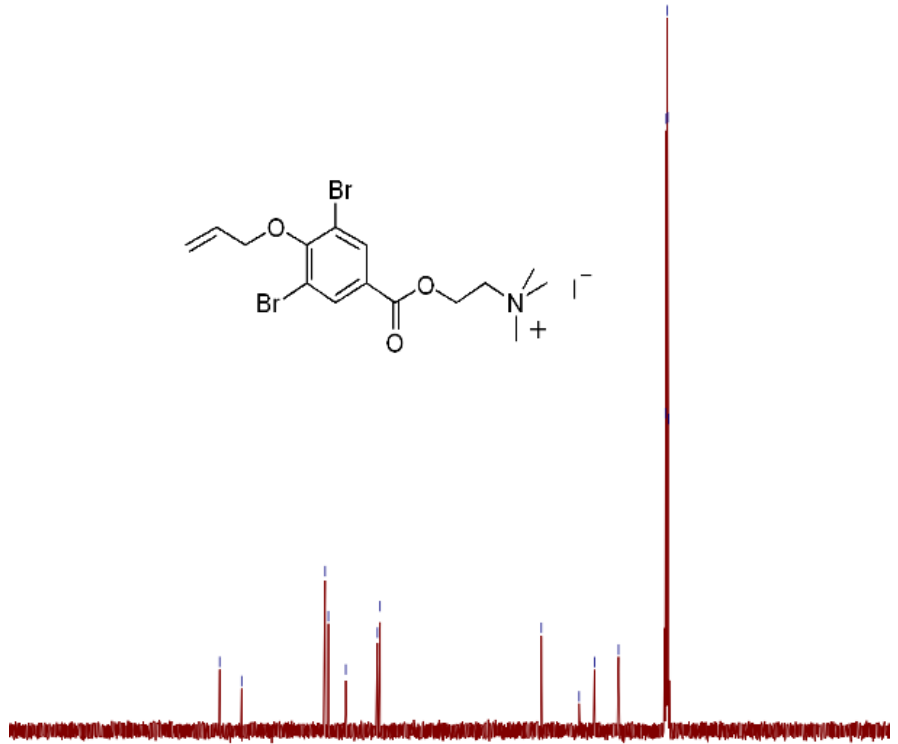

$20 \quad 200 \quad 180$

${ }^{13} \mathrm{C}$ NMR spectrum of $6 \mathrm{n}$ 

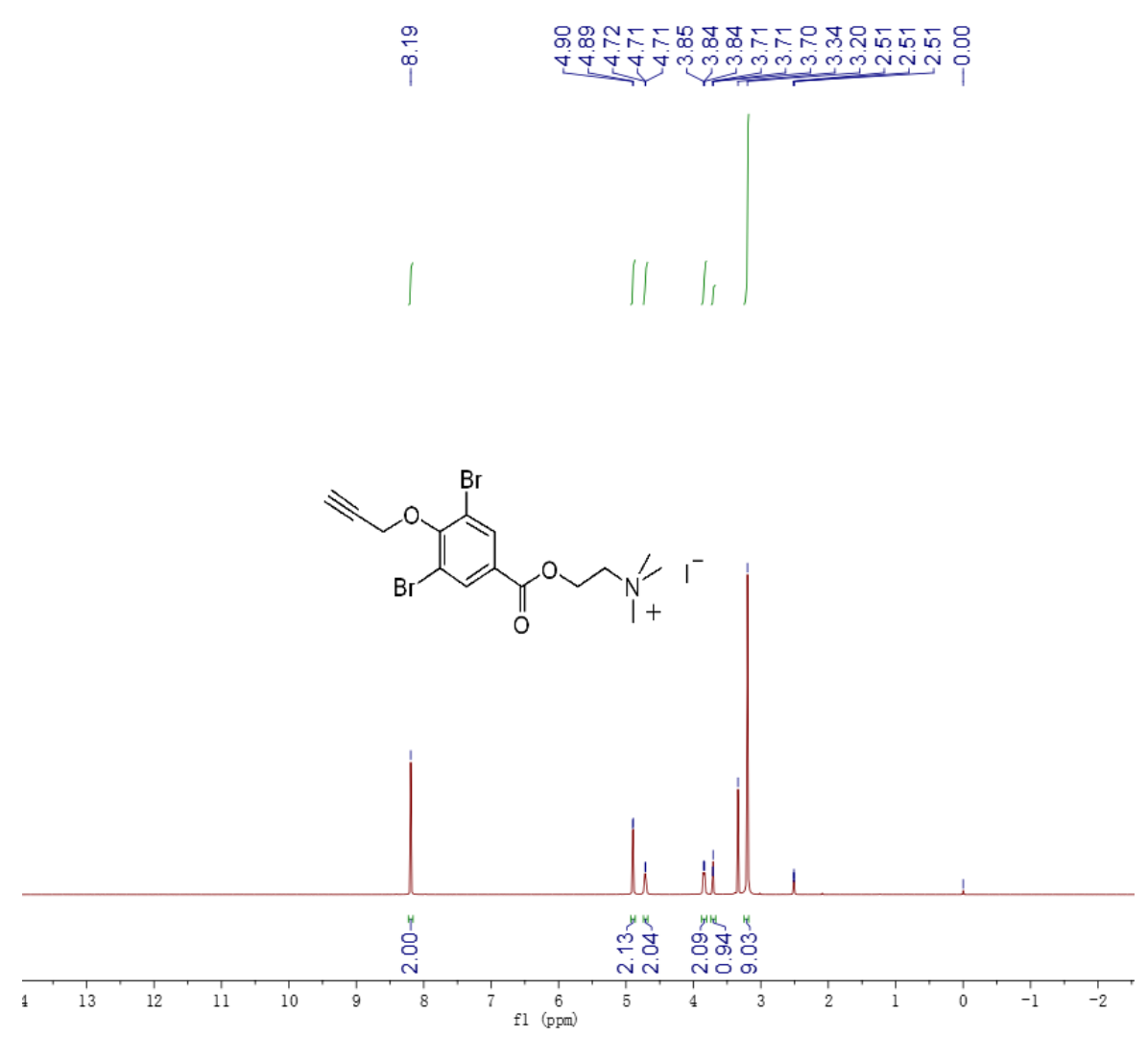

${ }^{1} \mathrm{H}$ NMR spectrum of 60
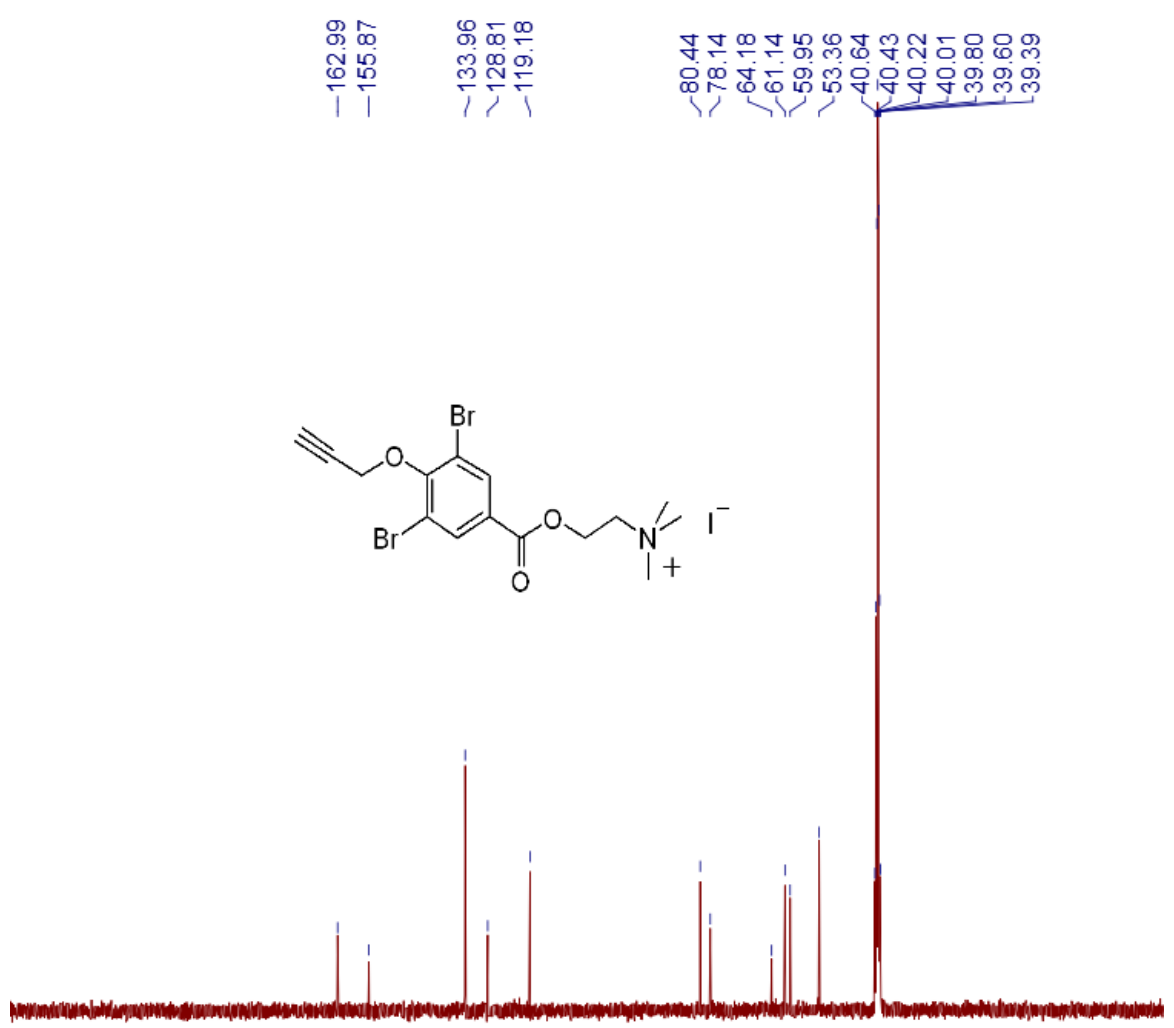

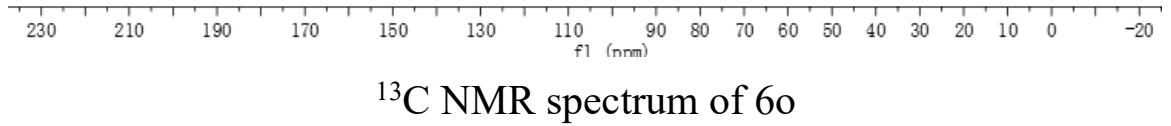




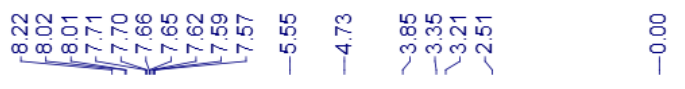

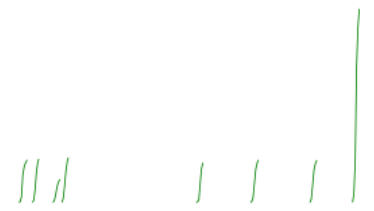

$\underbrace{1}_{0}$

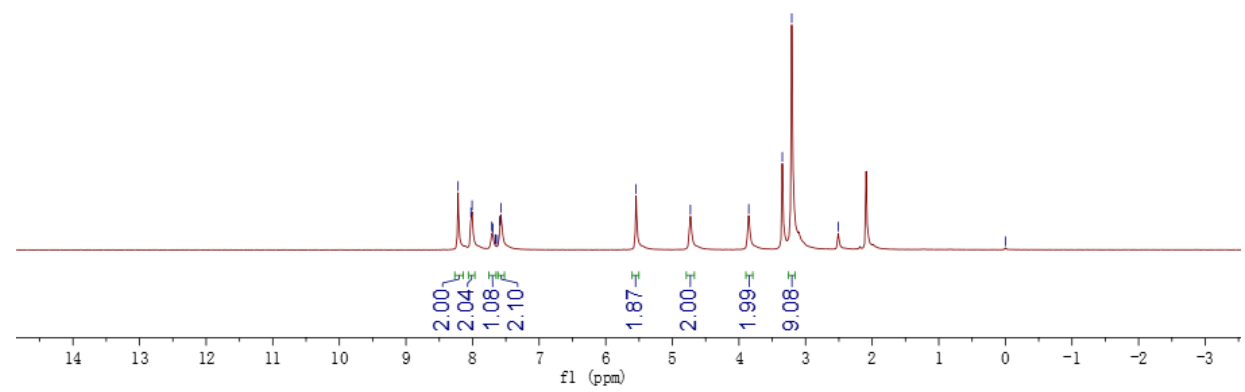

${ }^{1} \mathrm{H}$ NMR spectrum of $6 \mathrm{p}$

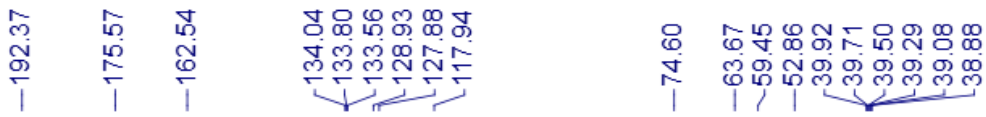<smiles>C[N+]([I-])([I-])CCOC(=O)c1cc(Br)c(OCC(=O)c2ccccc2)c(Br)c1</smiles>

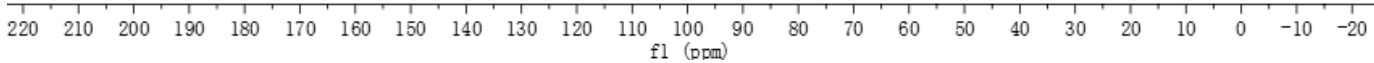

${ }^{13} \mathrm{C}$ NMR spectrum of $6 \mathrm{p}$ 


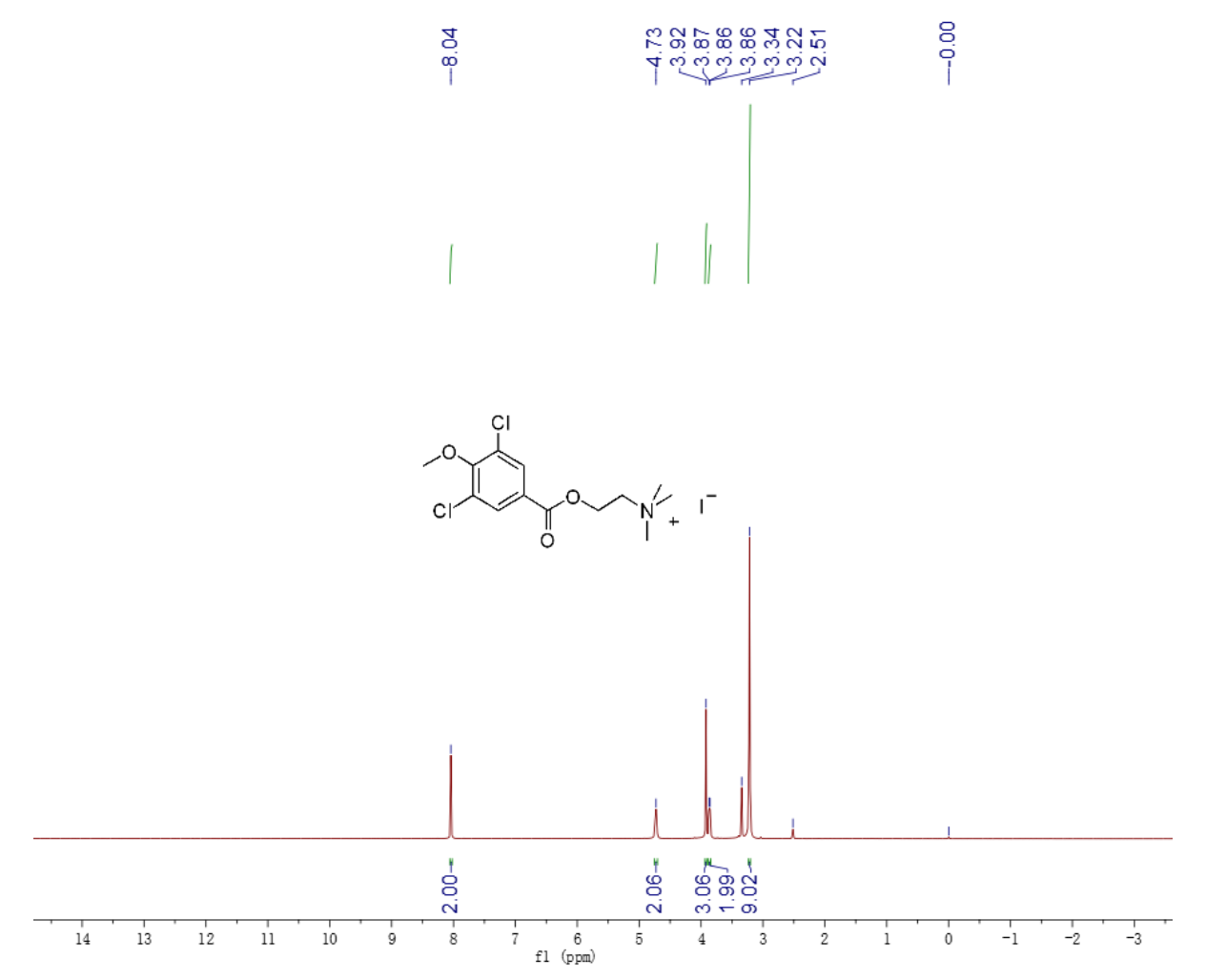

${ }^{1} \mathrm{H}$ NMR spectrum of $6 \mathrm{q}$

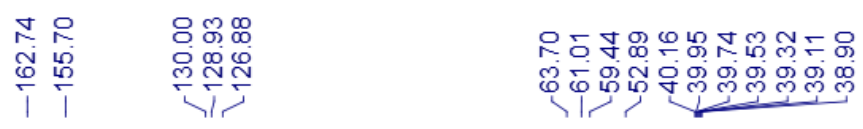<smiles>COc1c(Cl)cc(C(=O)OCC[N+](C)(C)[I-])cc1Cl</smiles>

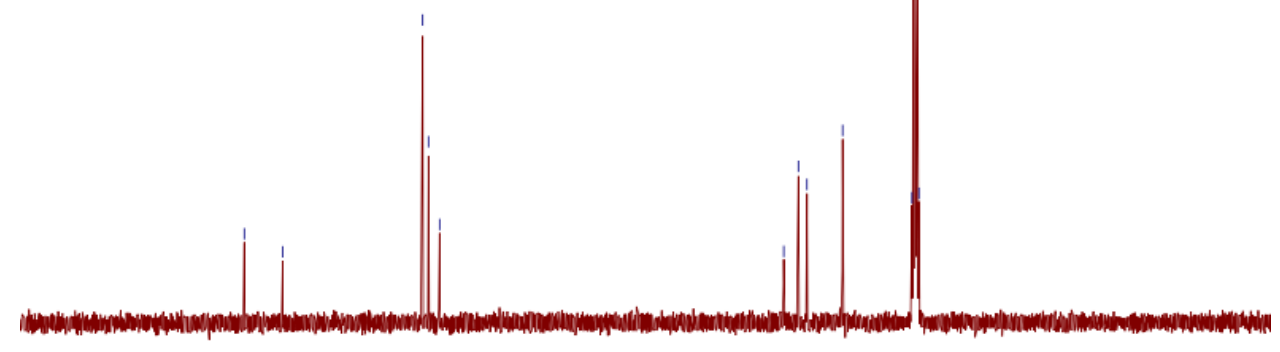

\begin{tabular}{llllllllllllllllllllllllllllllll}
\hline & 100 & 190 & 180 & 170 & 160 & 150 & 140 & 130 & 120 & 110 & 100 & 90 & 80 & 70 & 60 & 50 & 40 & 30 & 20 & 10 & 0 & -10 & -20
\end{tabular}

${ }^{13} \mathrm{C}$ NMR spectrum of $6 \mathrm{q}$ 
$\underset{m}{m}$

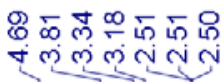

i

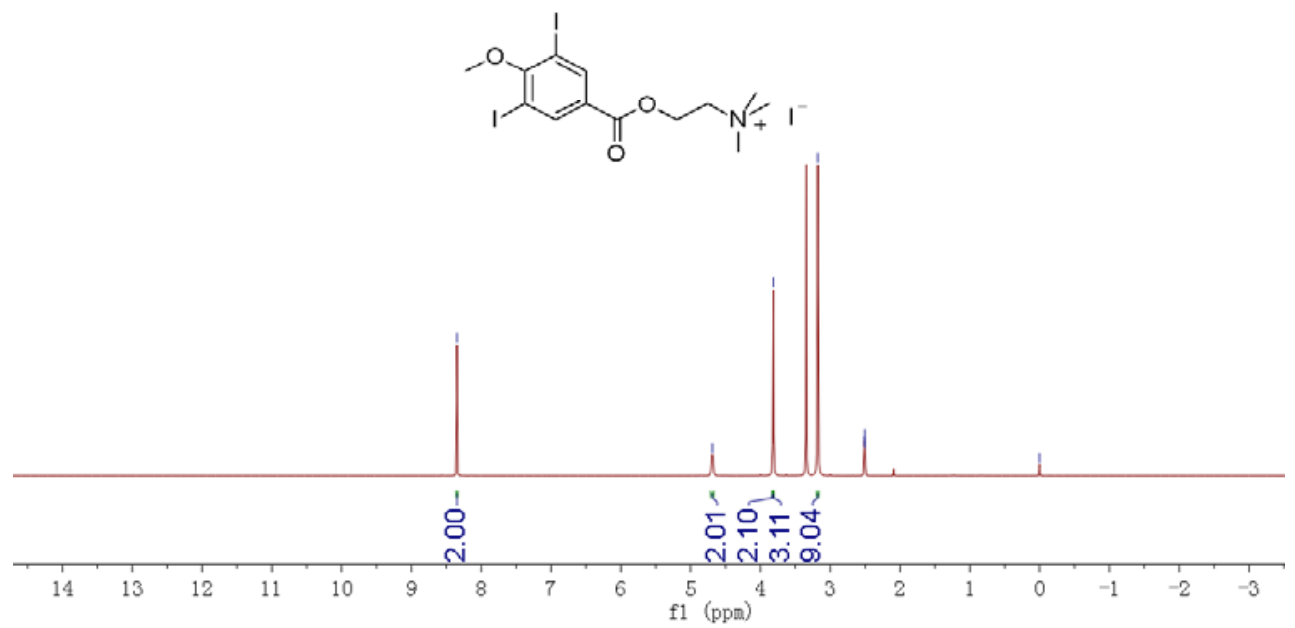

${ }^{1} \mathrm{H}$ NMR spectrum of $6 \mathrm{r}$
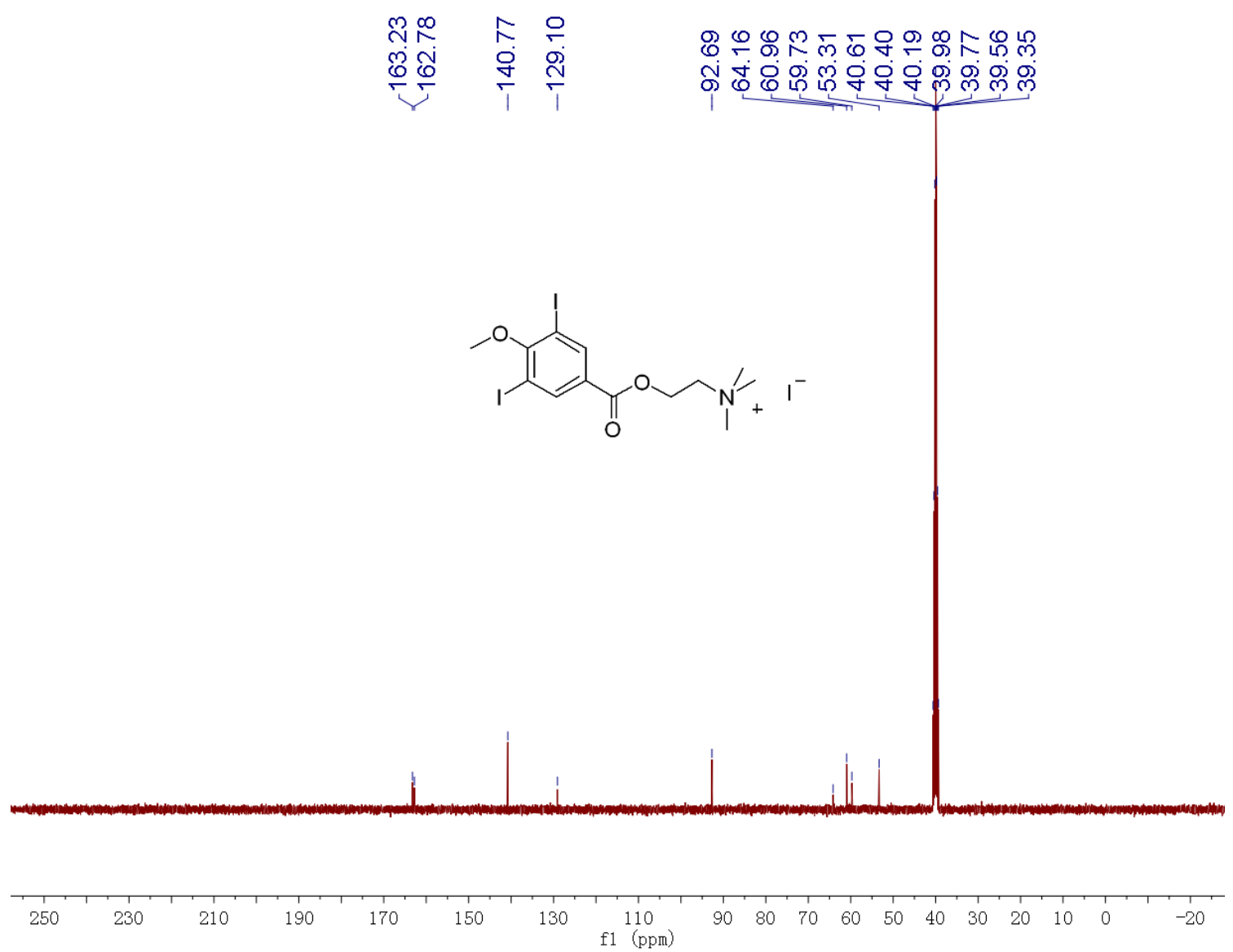

${ }^{13} \mathrm{C}$ NMR spectrum of $6 \mathrm{r}$

S65 


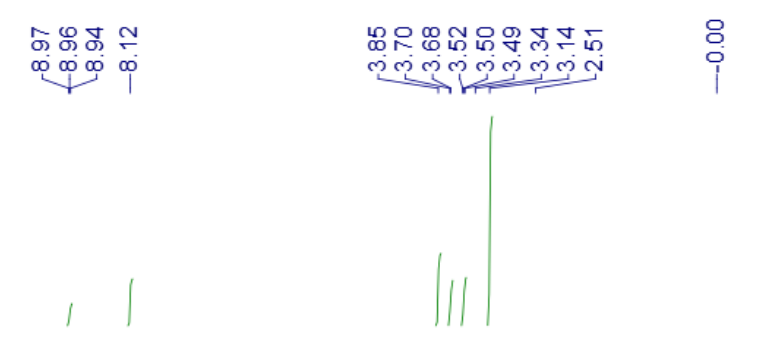<smiles></smiles>

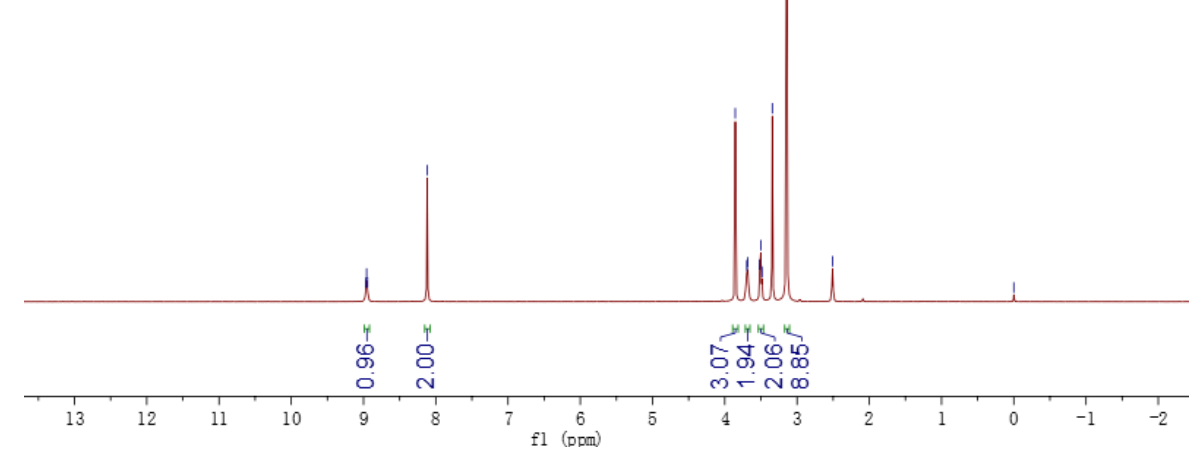

${ }^{1} \mathrm{H}$ NMR spectrum of $6 \mathrm{~s}$

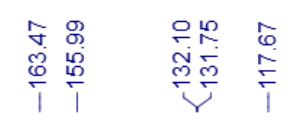<smiles>COc1c(Br)cc(C(=O)NCC[N+](C)([NH3+])[I-])cc1Br</smiles>

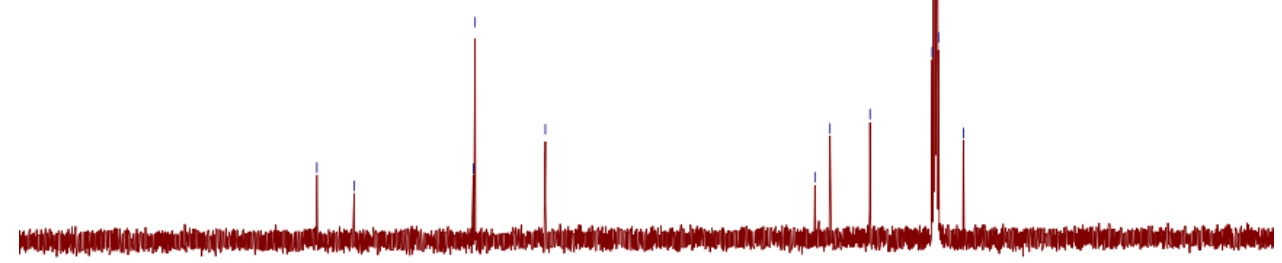

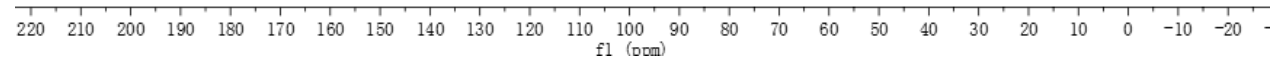

${ }^{13} \mathrm{C}$ NMR spectrum of $6 \mathrm{~s}$ 

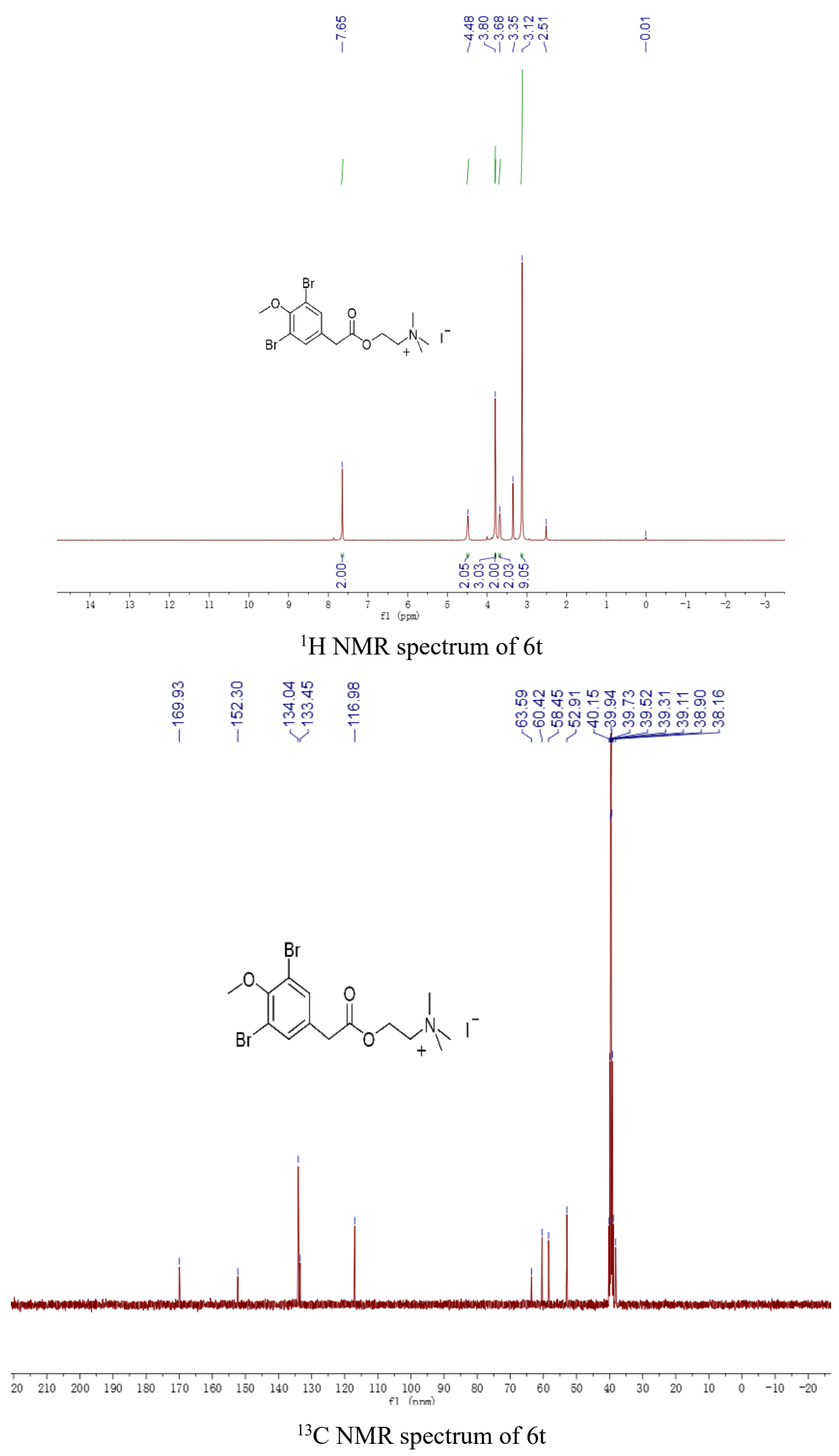


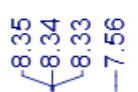

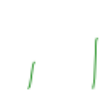

웡엤쌔음

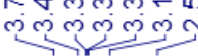

$\stackrel{8}{i}$

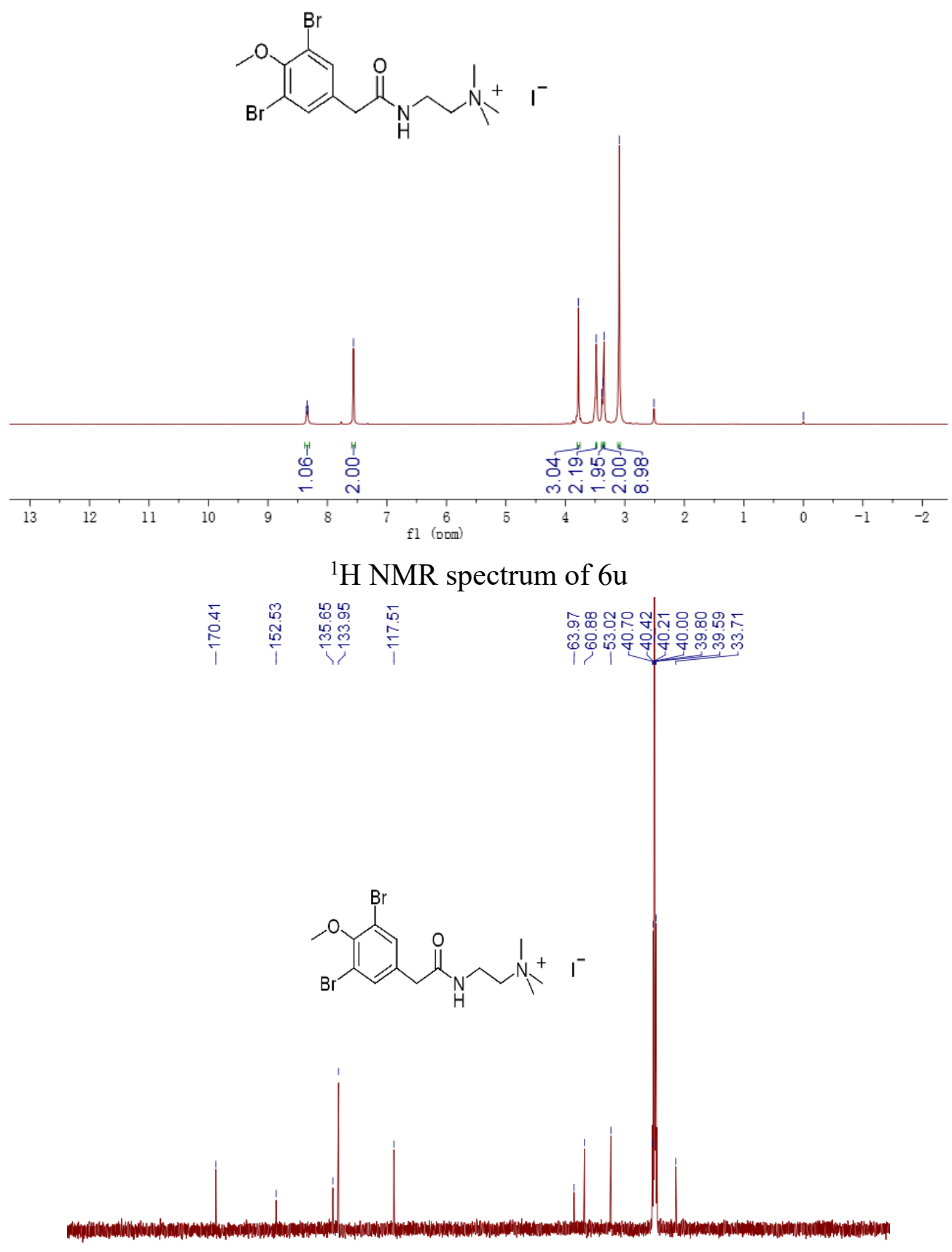

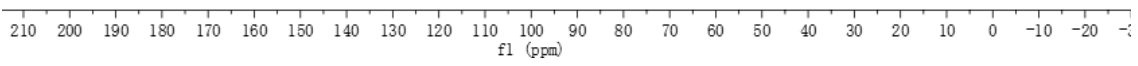

${ }^{13} \mathrm{C}$ NMR spectrum of $6 \mathrm{u}$ 


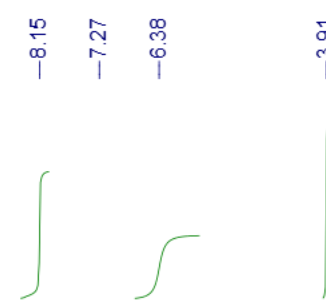

웅
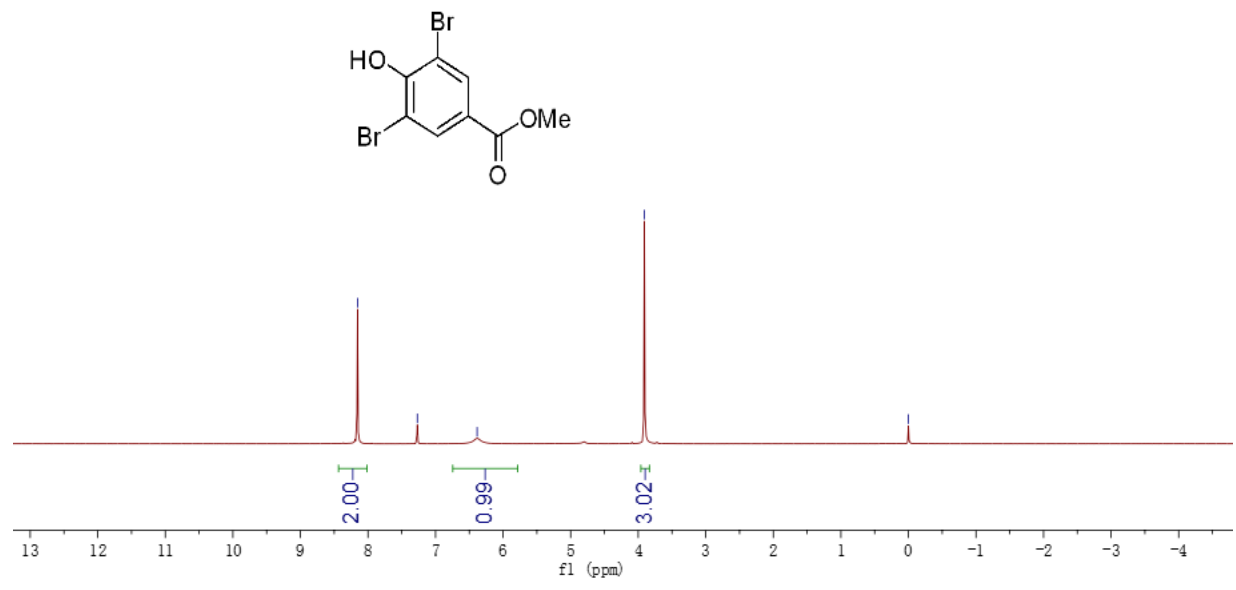

${ }^{1} \mathrm{H}$ NMR spectrum of 8

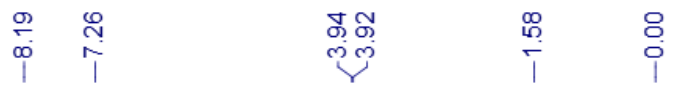

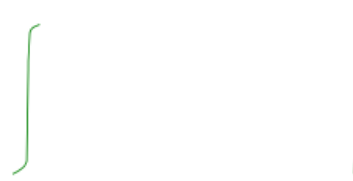

$\overbrace{0 M e}^{C}$

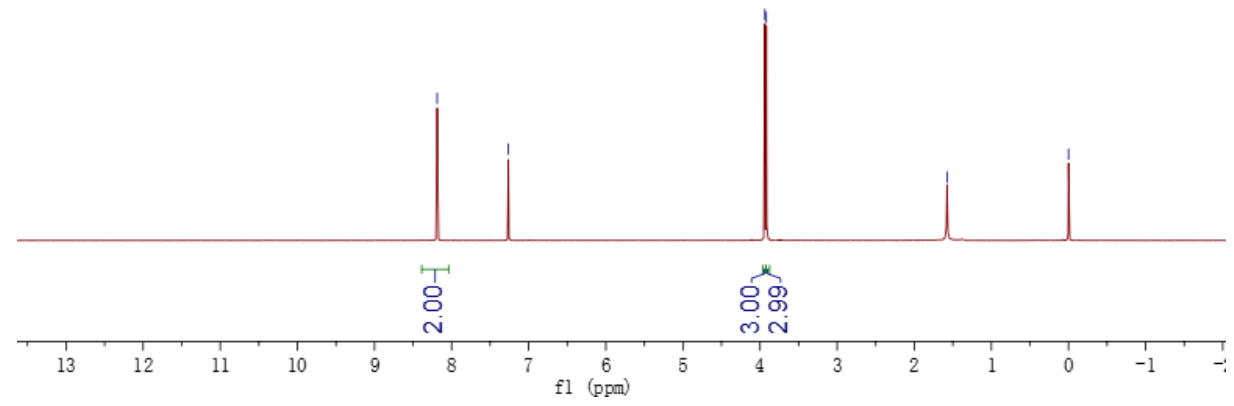

${ }^{1} \mathrm{H}$ NMR spectrum of 9 

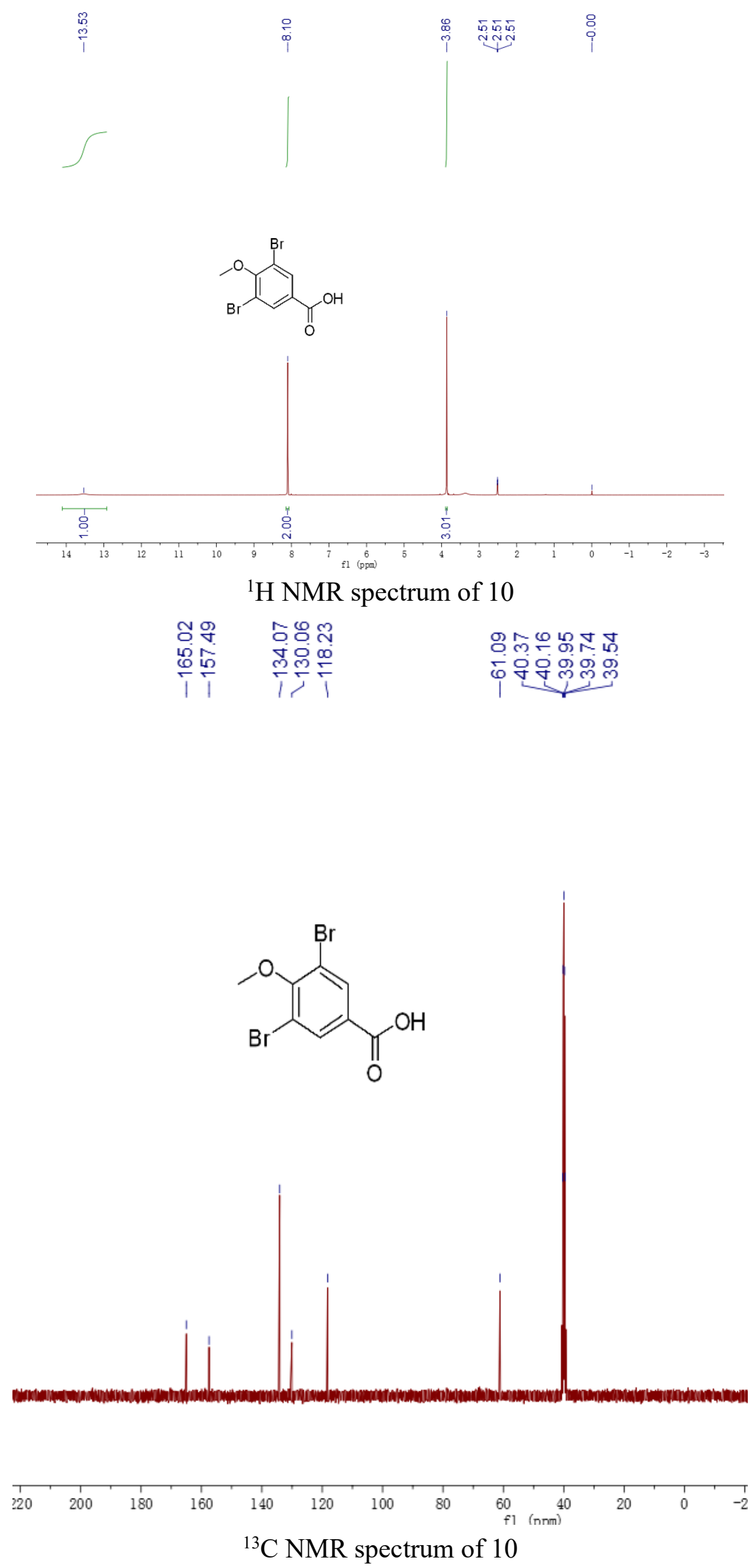

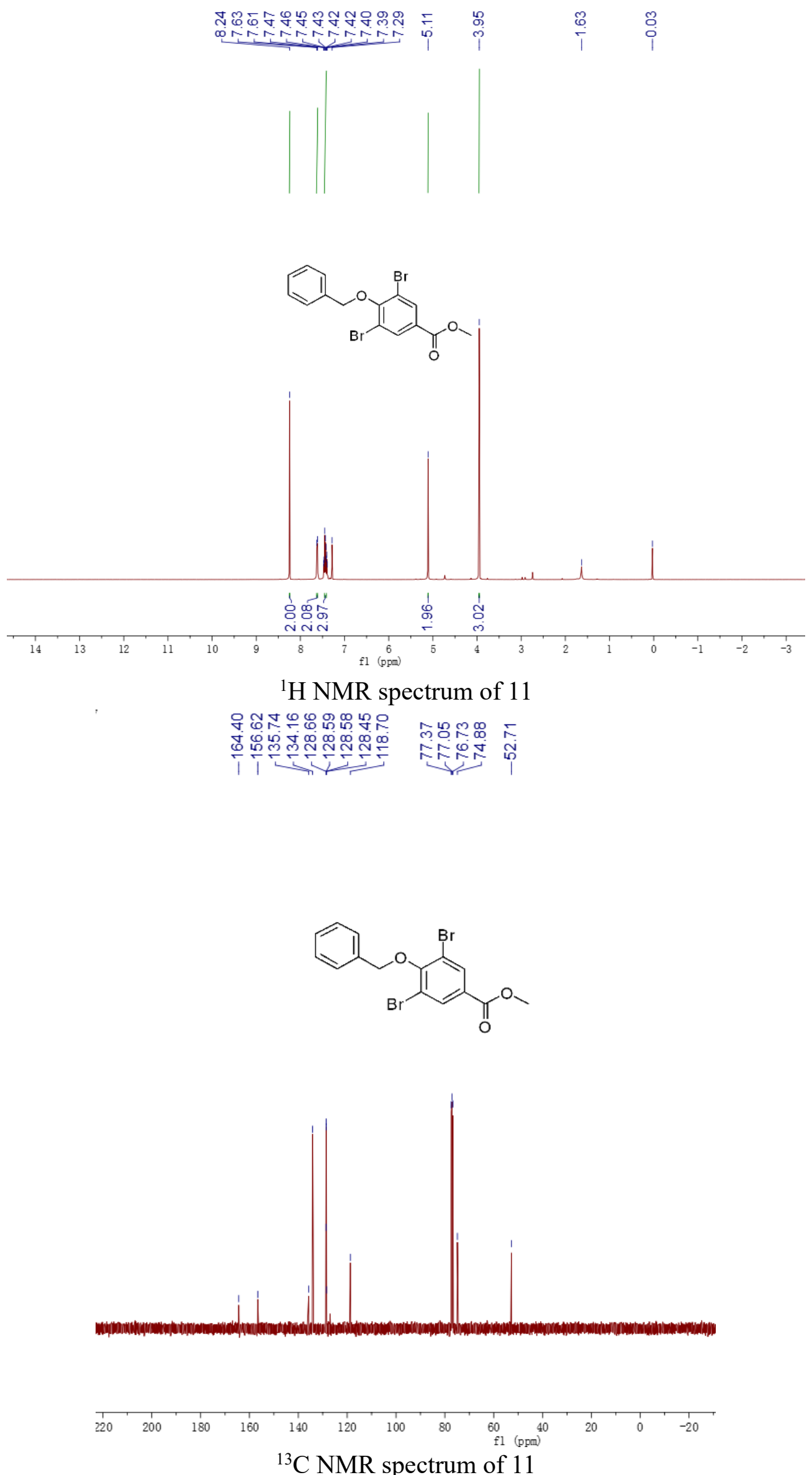

${ }^{13} \mathrm{C}$ NMR spectrum of 11 


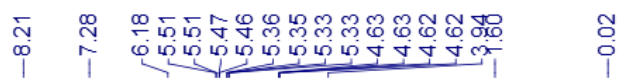
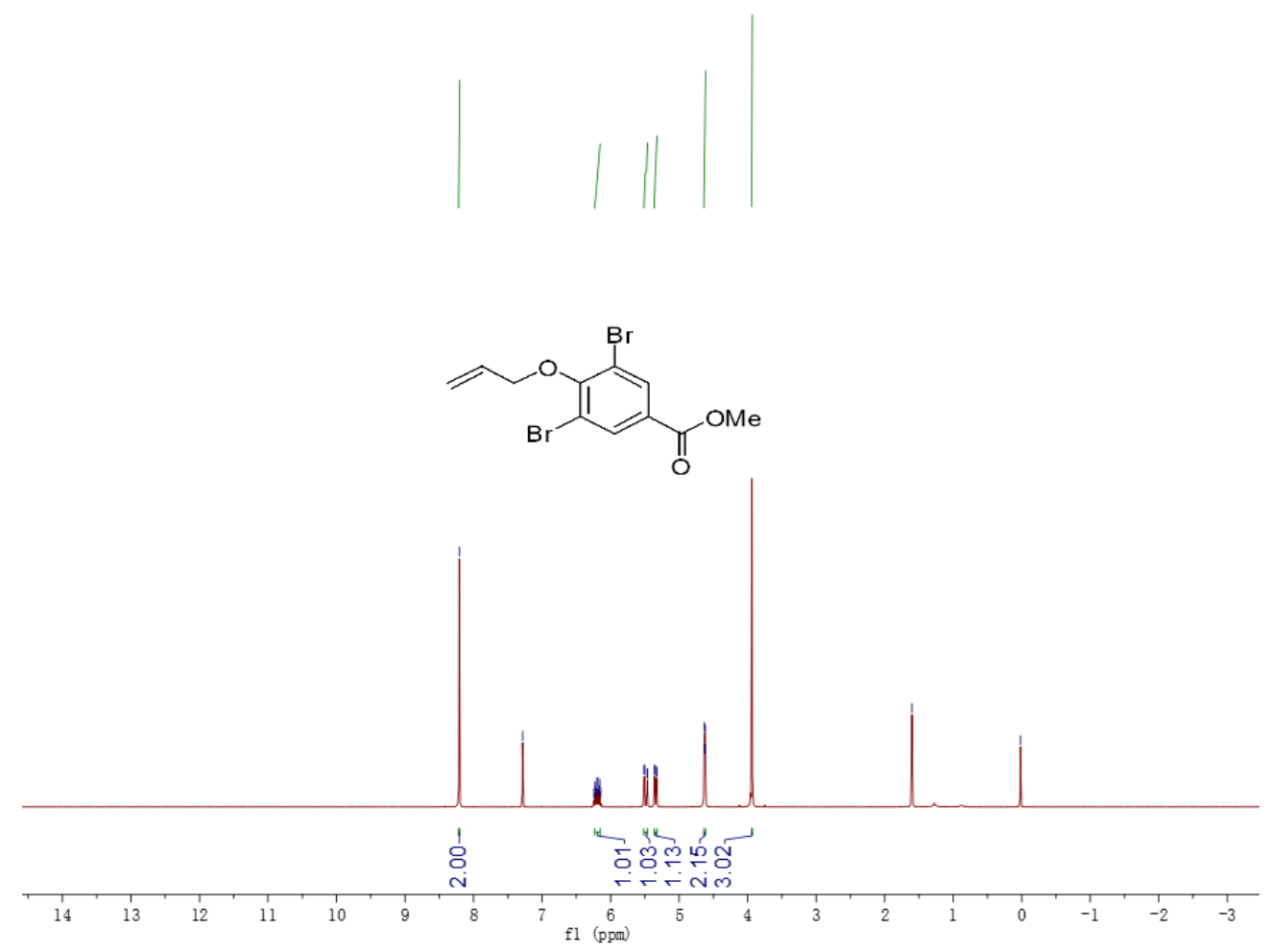

${ }^{1} \mathrm{H}$ NMR spectrum of 12

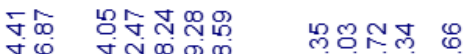

एं
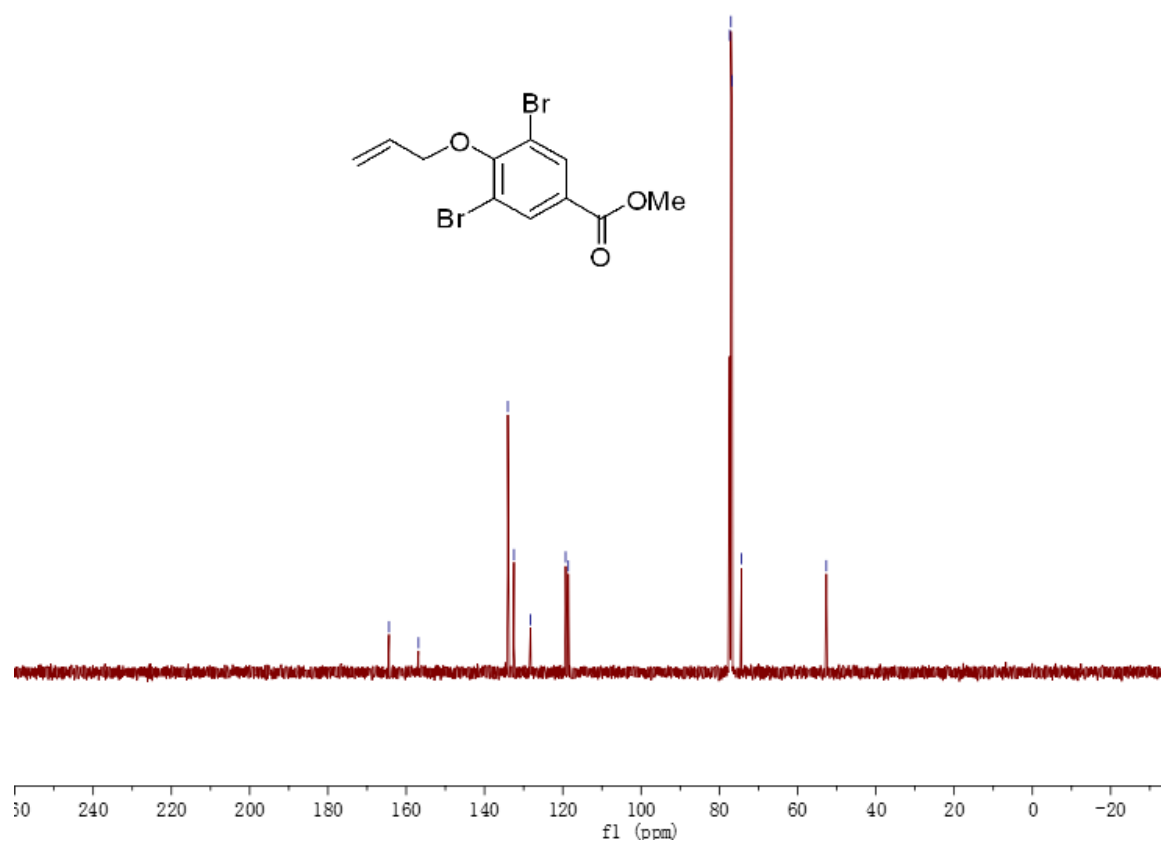

${ }^{13} \mathrm{C}$ NMR spectrum of 12 

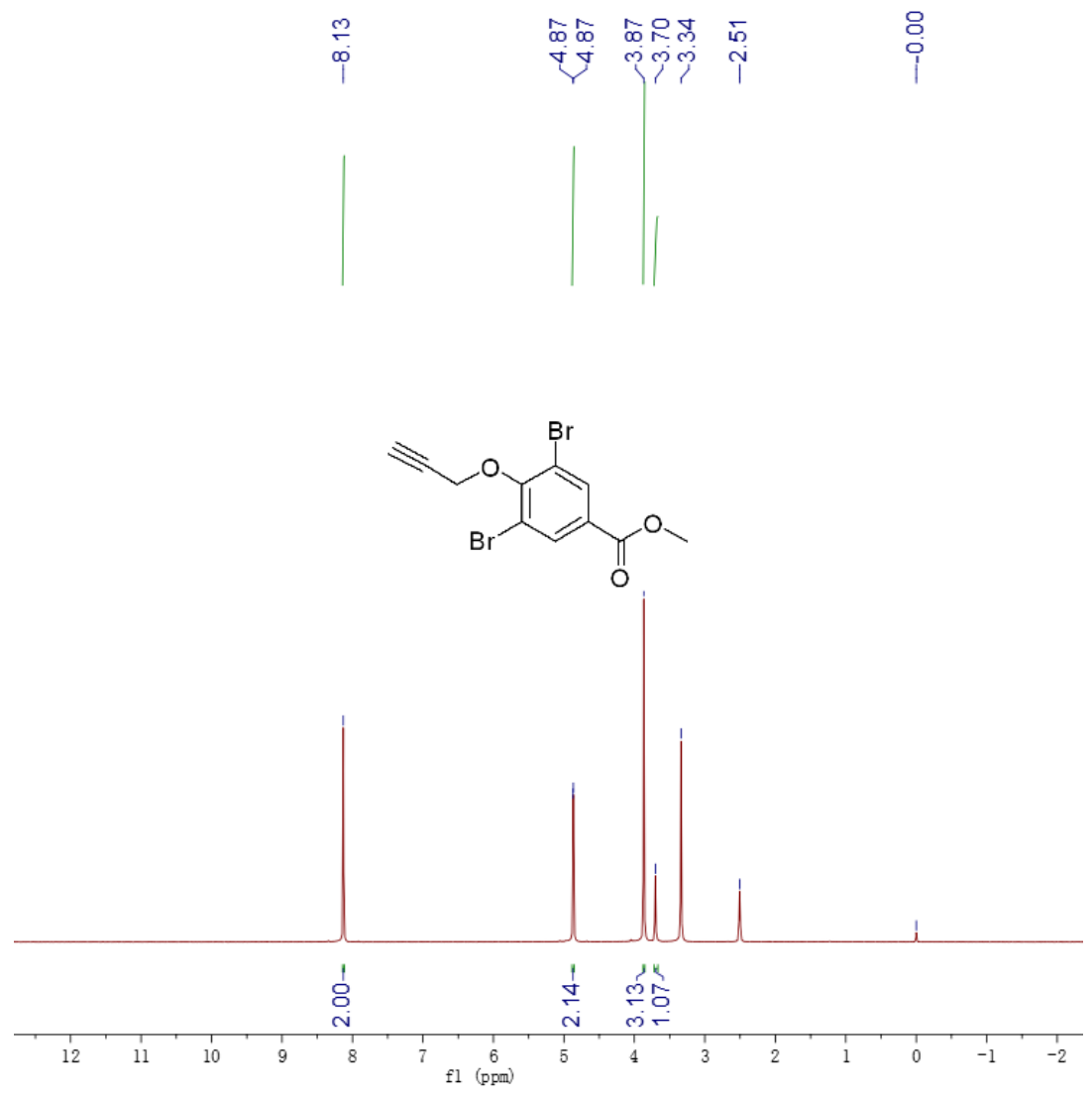

${ }^{1} \mathrm{H}$ NMR spectrum of 13

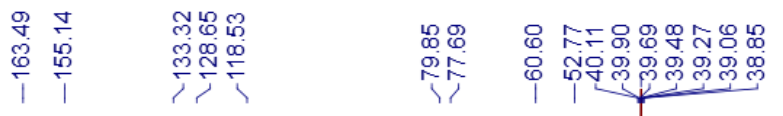<smiles>C#CCOc1c(Br)cc(C(=O)OC)cc1Br</smiles>

$\begin{array}{llllllllllllllllllllllllll}210 & 200 & 190 & 180 & 170 & 160 & 150 & 140 & 130 & 120 & 110 & 100 & 90 & 80 & 70 & 60 & 50 & 40 & 30 & 20 & 10 & 0 & -10 & -20\end{array}$

${ }^{13} \mathrm{C}$ NMR spectrum of 13 

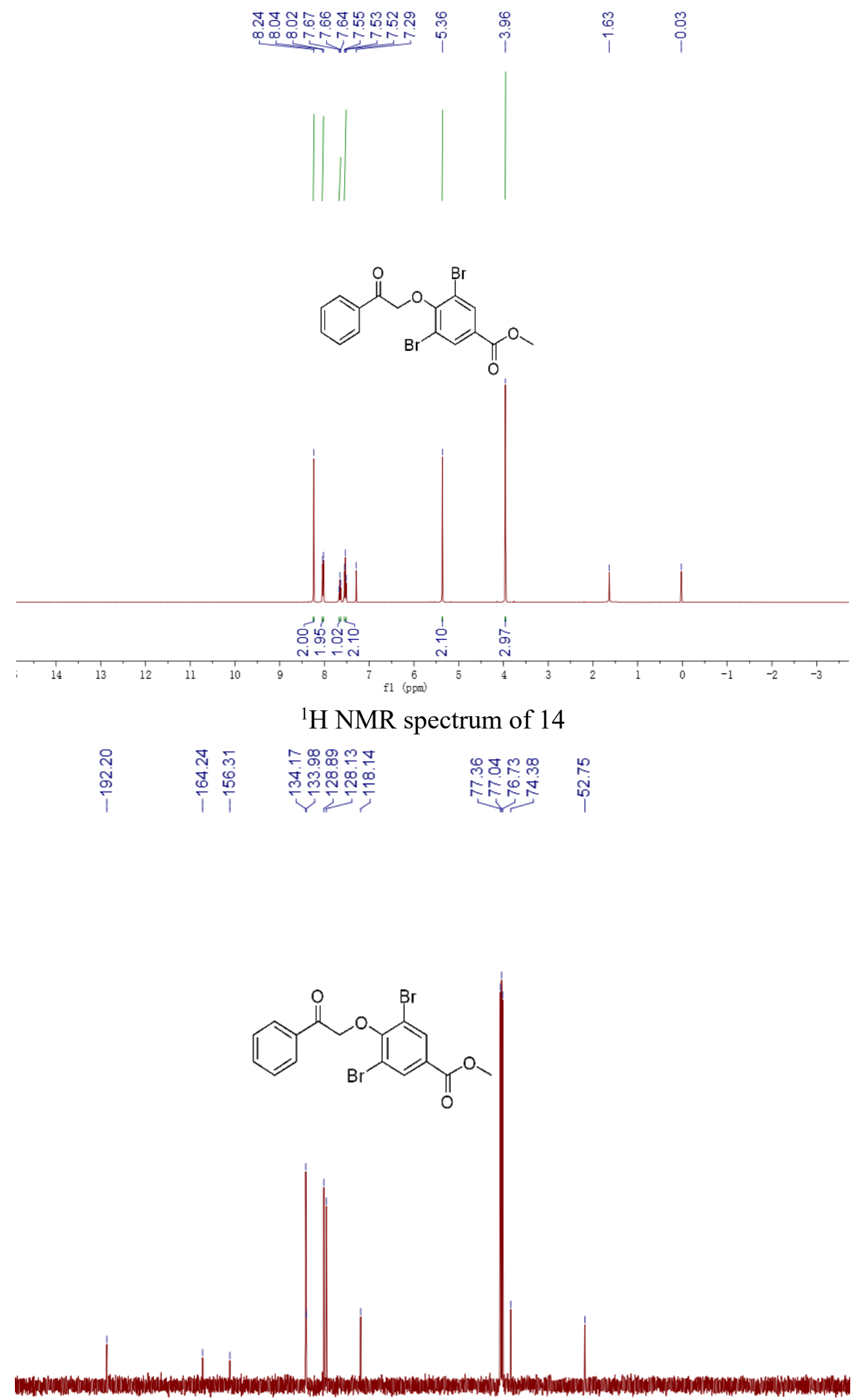

$\begin{array}{lllllllllllllllllllllllllllllll}0 & 210 & 200 & 190 & 180 & 170 & 160 & 150 & 140 & 130 & 120 & 110 & 100 & 90 & 80 & 70 & 60 & 50 & 40 & 30 & 10 & 10 & 0 & -10 & -20\end{array}$

${ }^{13} \mathrm{C}$ NMR spectrum of 14 


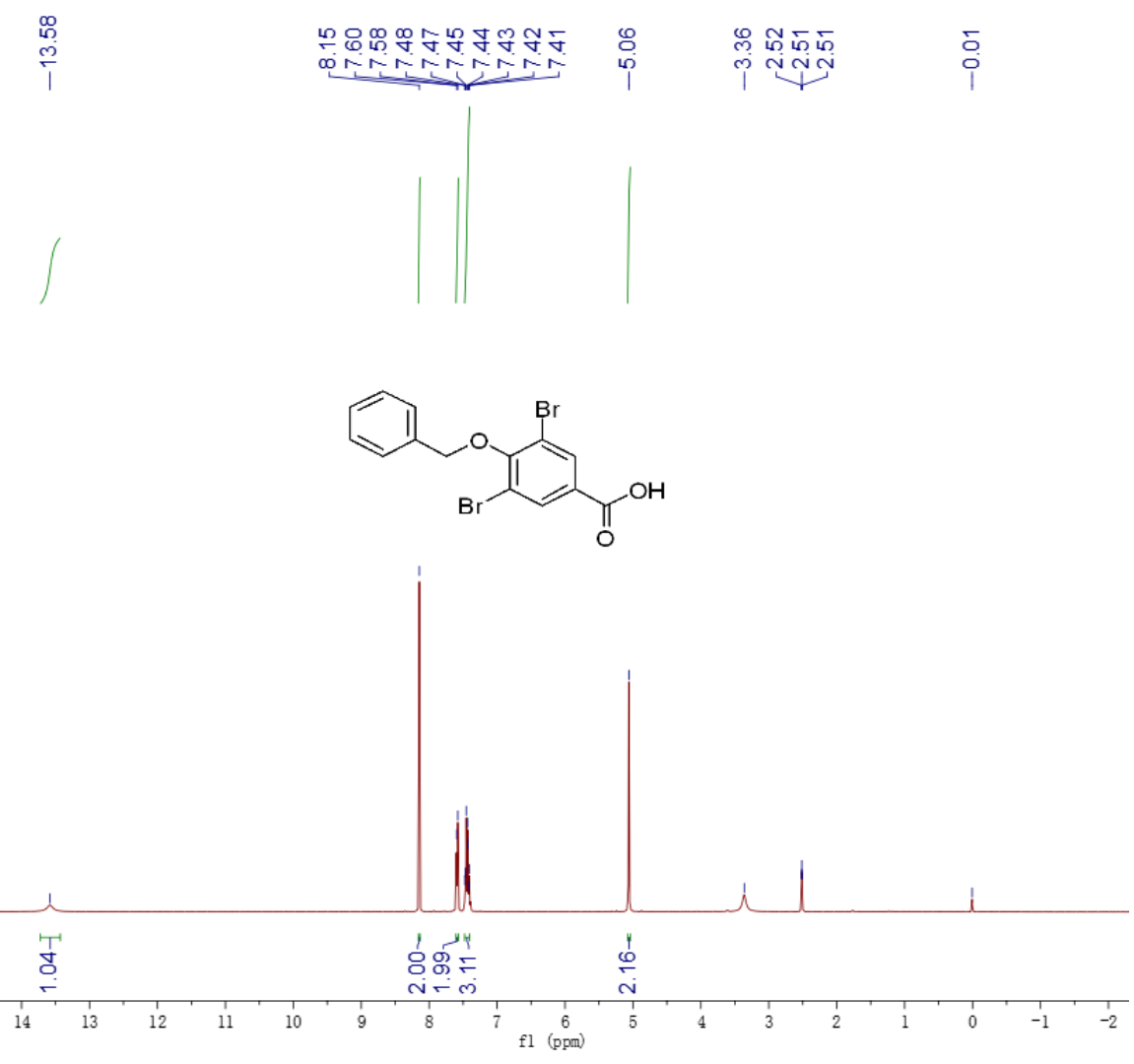

${ }^{1} \mathrm{H}$ NMR spectrum of 15

R.

产

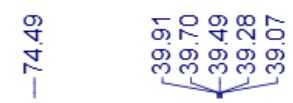

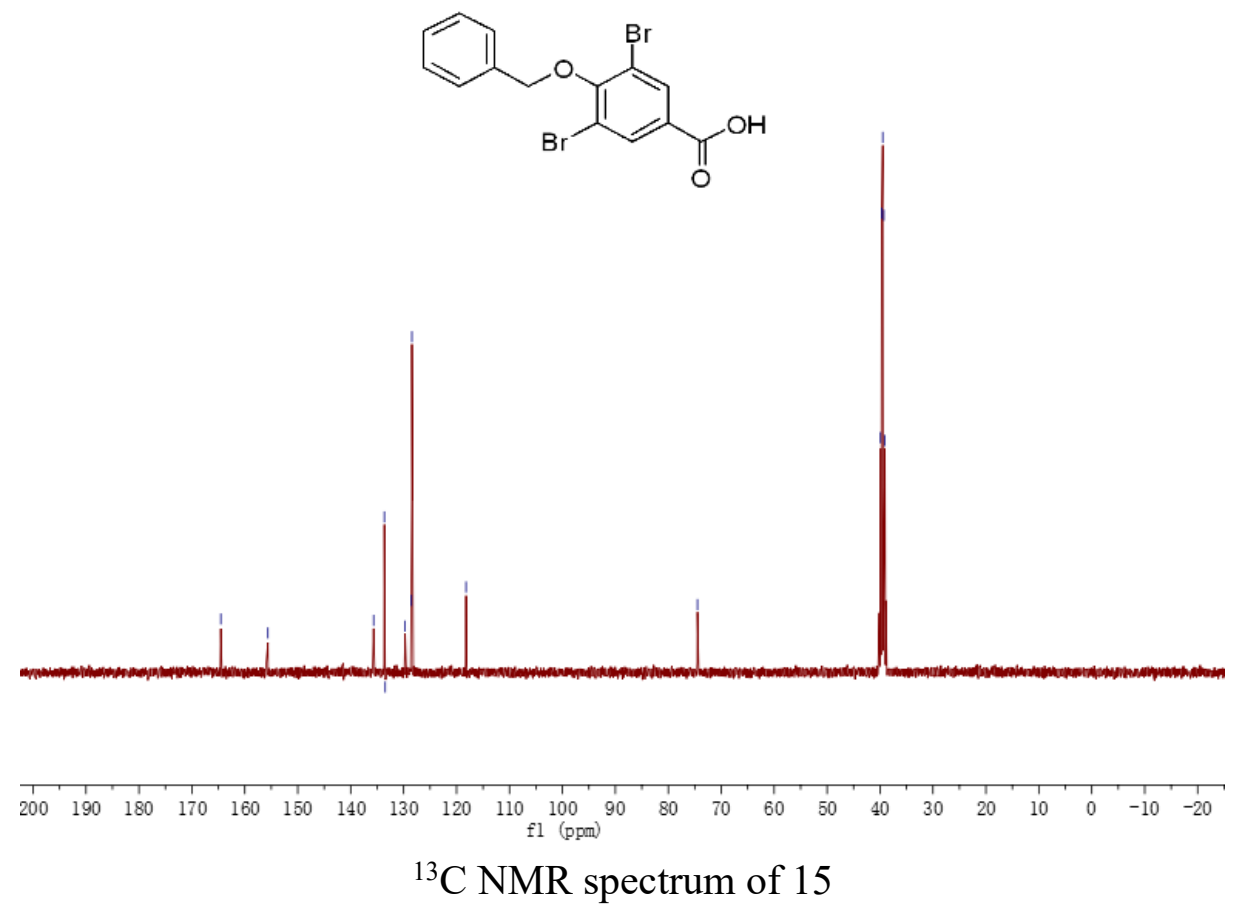




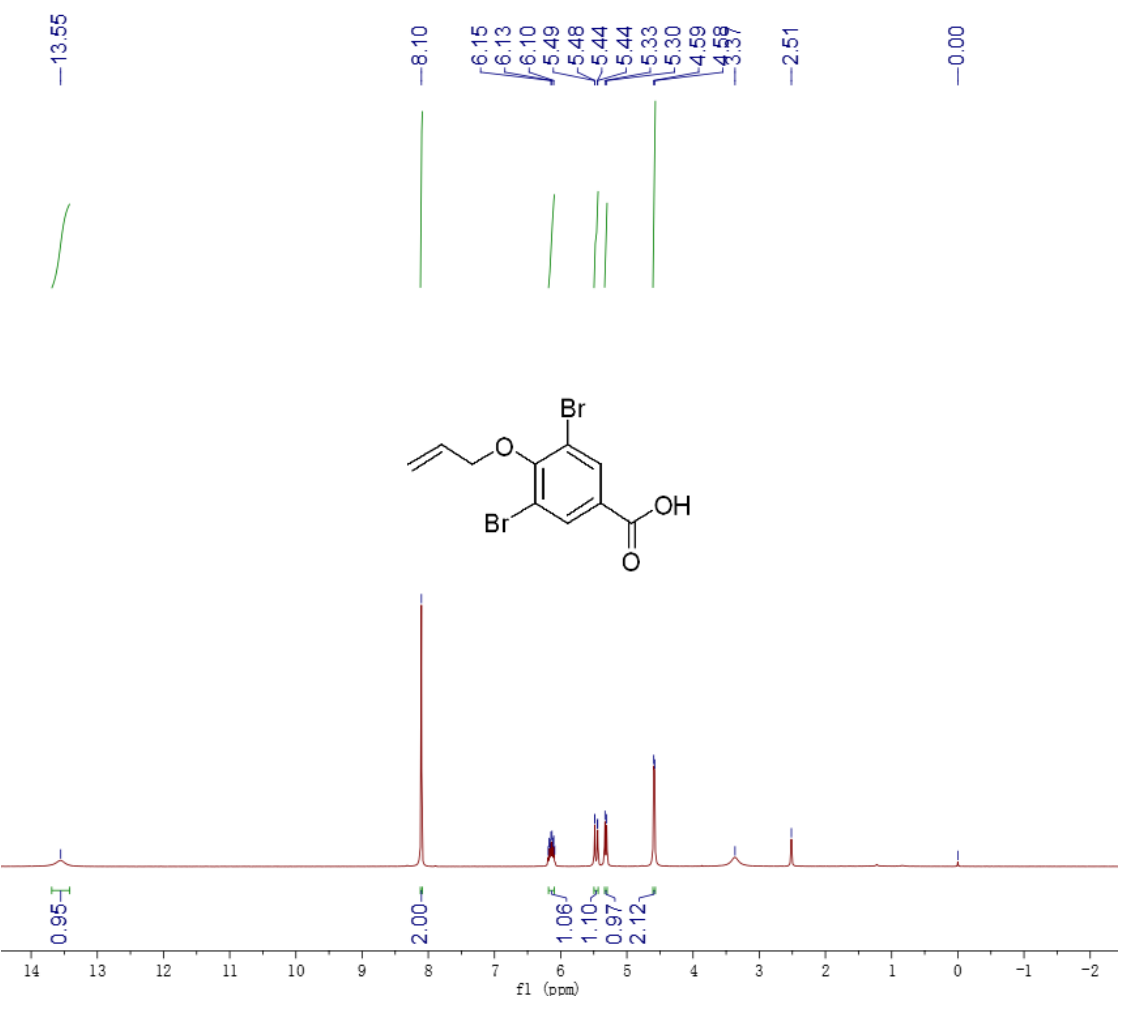

${ }^{1} \mathrm{H}$ NMR spectrum of 16

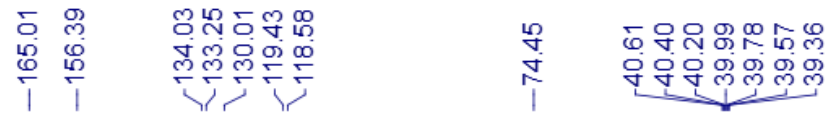

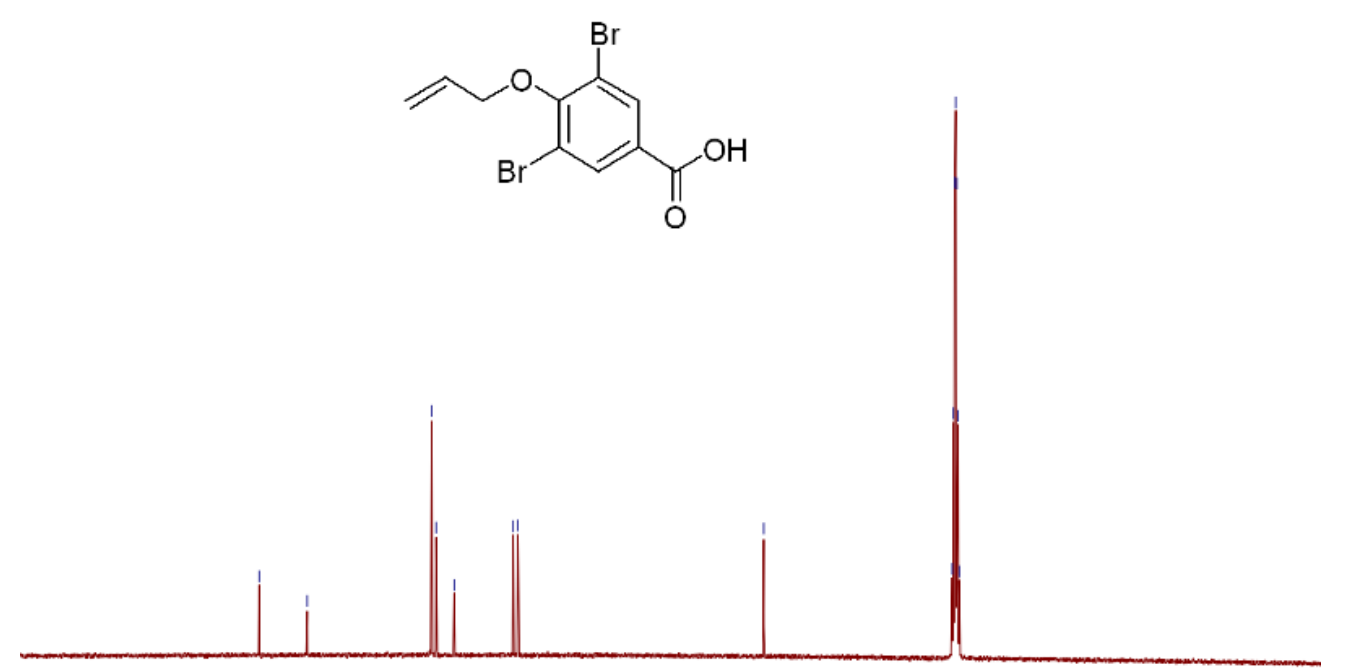

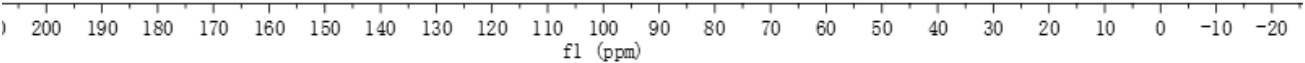

${ }^{13} \mathrm{C}$ NMR spectrum of 16 

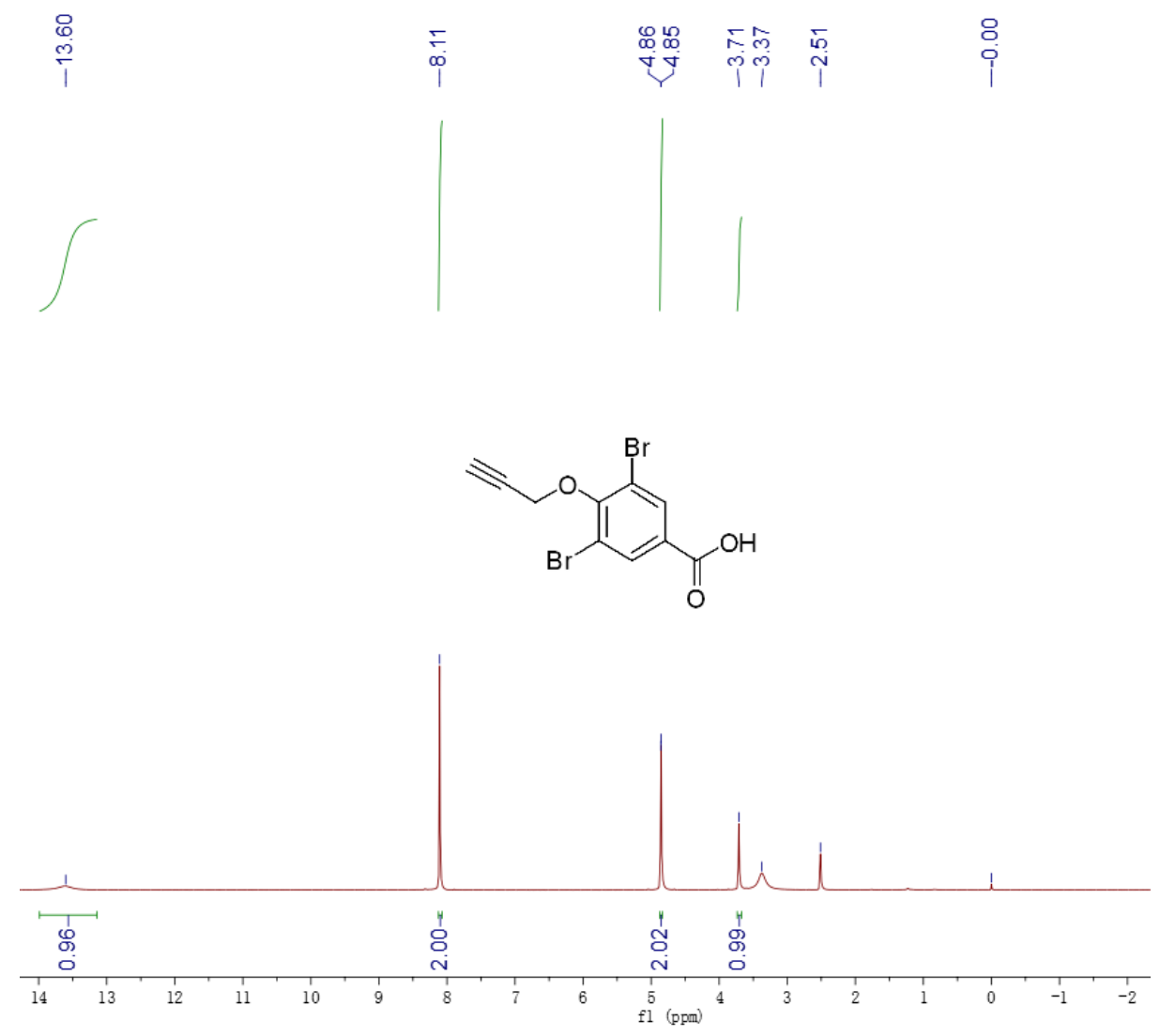

${ }^{1} \mathrm{H}$ NMR spectrum of 17

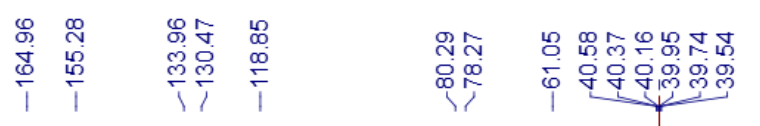<smiles>C#CCOc1c(Br)cc(C(=O)O)cc1Br</smiles>

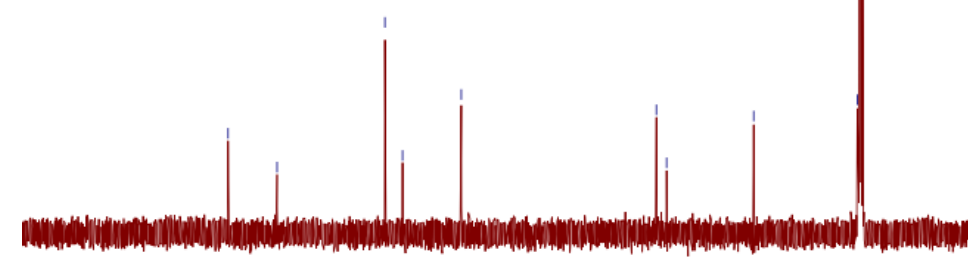

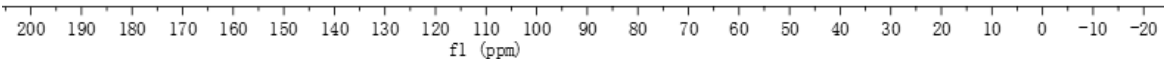

${ }^{13} \mathrm{C}$ NMR spectrum of 17 


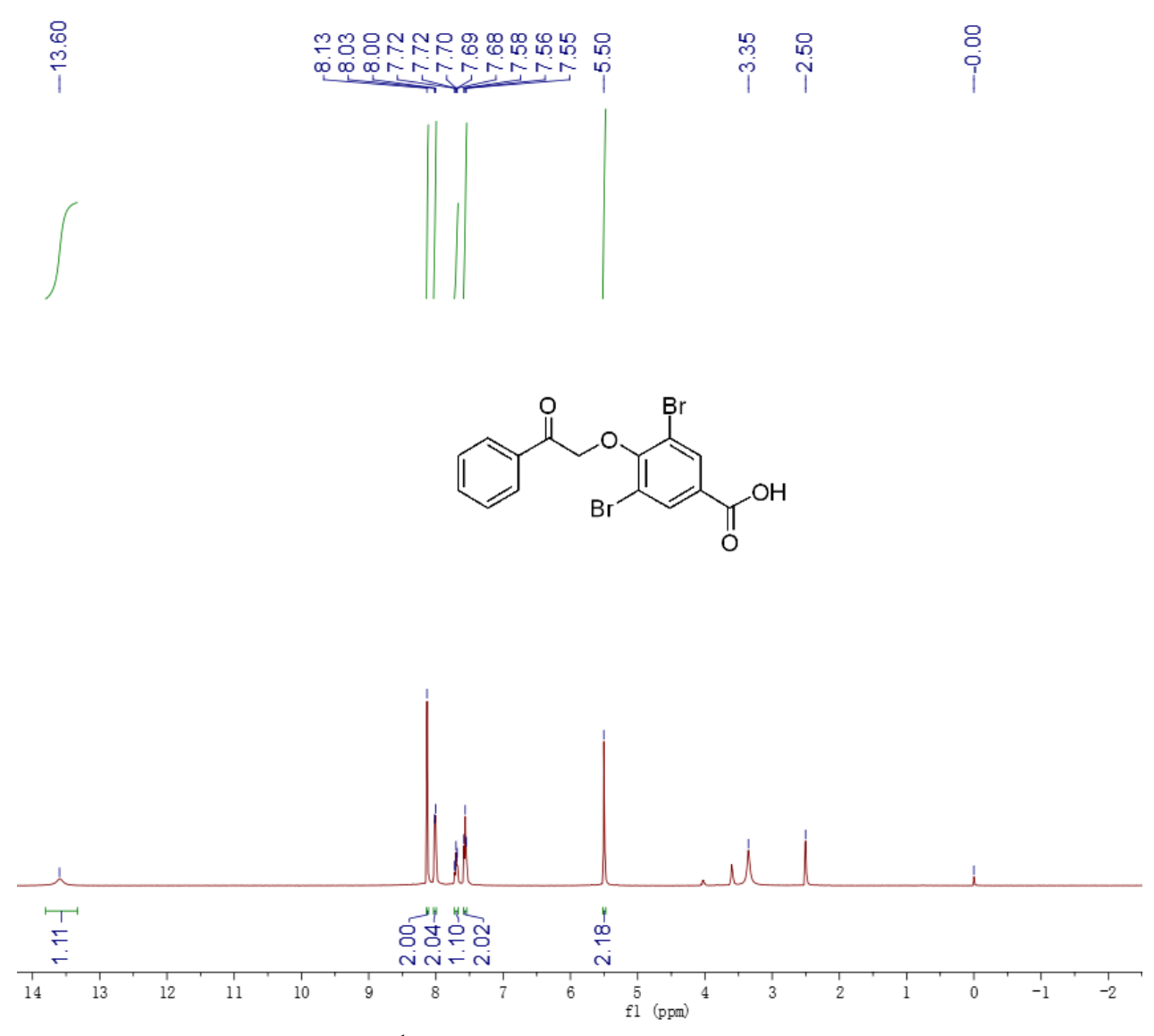

${ }^{1} \mathrm{H}$ NMR spectrum of 18
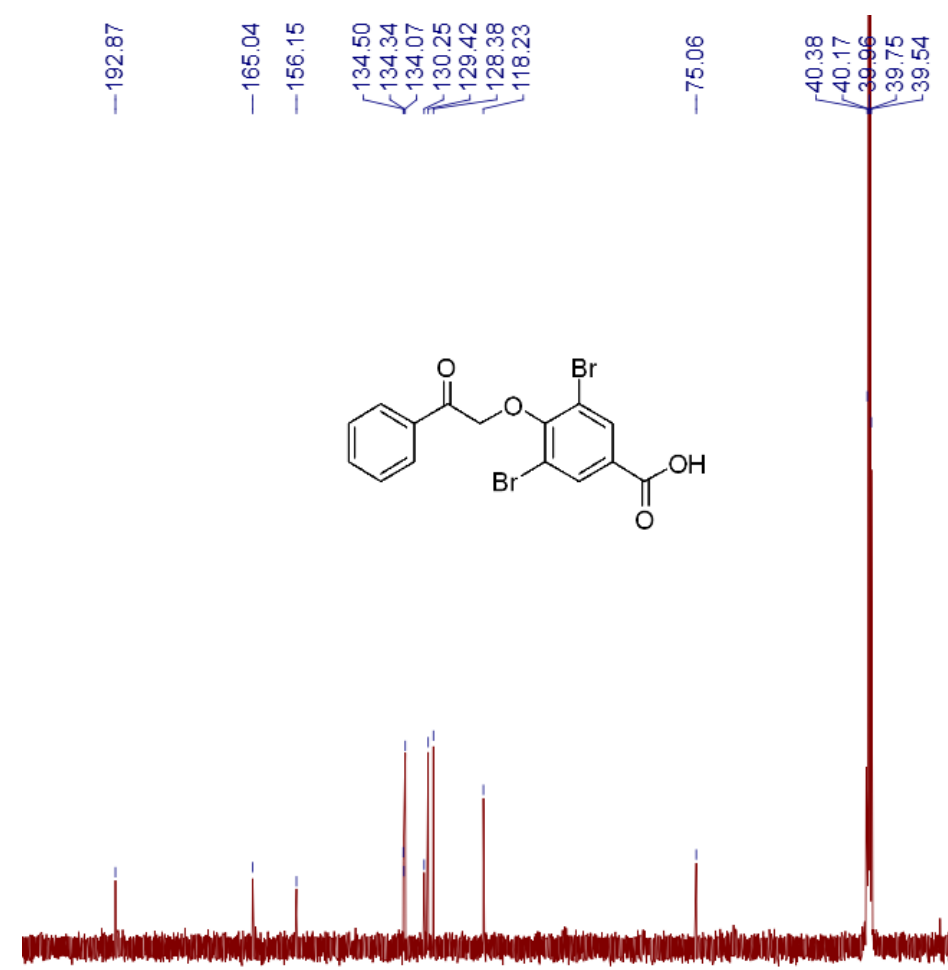

$\begin{array}{llllllllllllllllllllllllllllll}210 & 200 & 190 & 180 & 170 & 160 & 150 & 140 & 130 & 120 & 110 & 100 & 90 & 80 & 70 & 60 & 50 & 40 & 30 & 20 & 10 & 0 & -10 & -20\end{array}$

${ }^{13} \mathrm{C}$ NMR spectrum of 18 